University of Louisville

ThinkIR: The University of Louisville's Institutional Repository

Electronic Theses and Dissertations

$12-2017$

\title{
Since the time of Eve : La Leche League and communities of mothers throughout history.
}

Joanna Paxton Federico

University of Louisville

Follow this and additional works at: https://ir.library.louisville.edu/etd

Part of the Catholic Studies Commons, Cultural History Commons, History of Gender Commons, History of Religion Commons, History of Science, Technology, and Medicine Commons, Social History Commons, United States History Commons, Women's History Commons, and the Women's Studies Commons

\section{Recommended Citation}

Federico, Joanna Paxton, "Since the time of Eve : La Leche League and communities of mothers throughout history." (2017). Electronic Theses and Dissertations. Paper 2848.

https://doi.org/10.18297/etd/2848

This Master's Thesis is brought to you for free and open access by ThinkIR: The University of Louisville's Institutional Repository. It has been accepted for inclusion in Electronic Theses and Dissertations by an authorized administrator of ThinkIR: The University of Louisville's Institutional Repository. This title appears here courtesy of the author, who has retained all other copyrights. For more information, please contact thinkir@louisville.edu. 
SINCE THE TIME OF EVE:

\title{
LA LECHE LEAGUE AND COMMUNITIES OF MOTHERS THROUGHOUT HISTORY
}

\author{
By \\ Joanna Paxton Federico \\ B.A., University of Notre Dame, 2006

\begin{abstract}
A Thesis
Submitted to the Faculty of the

College of Arts and Sciences of the University of Louisville in Partial Fulfillment of the Requirements

for the Degree of
\end{abstract}

Master of Arts in History

Department of History

University of Louisville

Louisville, Kentucky

December 2017 
Copyright 2017 by Joanna Paxton Federico

All rights reserved 

SINCE THE TIME OF EVE:

\title{
LA LECHE LEAGUE AND COMMUNITIES OF MOTHERS THROUGHOUT HISTORY
}

\author{
By \\ Joanna Paxton Federico \\ B.A., University of Notre Dame, 2006
}

A Thesis Approved on

November 20, 2017

by the following Thesis Committee

Thesis Director

Lara Kelland

Katherine Massoth

Diane Pecknold 


\section{DEDICATION}

This thesis is dedicated to my mother

\section{Karen McMinn Paxton}

and to my grandmothers

Joanna Emge McMinn and Peggy Sabel Paxton

who showed me three different, wonderful ways to be a mother. 


\section{ACKNOWLEDGEMENTS}

I would like to thank my advisor, Dr. Lara Kelland, for her insight and enthusiasm. I would also like to thank the other members of my thesis committee, Dr. Diane Pecknold, who guided me through an early incarnation of this project, and Dr. Katherine Massoth, who opened my eyes to exciting new avenues for future research. My thanks also go out to Dr. Linda Pollock, my former advisor at Tulane University, who introduced me to the history of motherhood. Many thanks as well to Morgen MacIntosh Hodgetts and the staff of the Special Collections and Archives at DePaul University Library for their help in navigating the La Leche League International records. Finally, I want to thank my husband, Christopher Federico, and my sons, Salvadore and Robert Federico, for their patience and support, and my brother John Paxton for his invaluable babysitting services during my evening classes. 


\title{
ABSTRACT \\ SINCE THE TIME OF EVE: \\ LA LECHE LEAGUE AND COMMUNITIES OF MOTHERS THROUGHOUT HISTORY
}

\author{
Joanna Paxton Federico
}

November 20, 2017

La Leche League International (LLL) is the oldest and largest breastfeeding support group in the world. This thesis examines how, beginning in 1956, seven Catholic housewives from suburban Chicago built up the institutional knowledge to sustain a cohesive global network of breastfeeding mothers. It also explores how LLL managed this knowledge over time in response to developments in scholarship and changing social conditions. Based on a narrative analysis of LLL publications, this thesis argues that the League's founders drew selectively from existing bodies of knowledge and from their own cultural perspectives to establish a sense of community among breastfeeding women. They enhanced this feeling of connection by suggesting that women across time and space shared the same embodied experience of breastfeeding. This thesis adds to existing studies on La Leche League by drawing attention to how the organization developed institutional knowledge and deployed collective identity and memory. 
TABLE OF CONTENTS

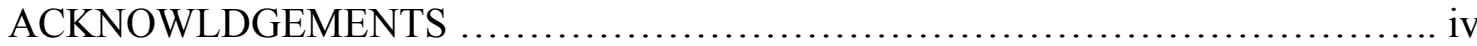

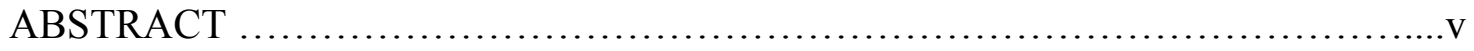

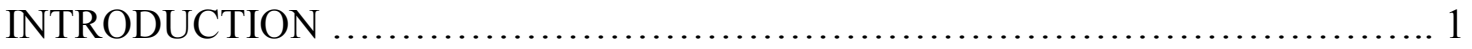

I. A BRIEF HISTORY OF LA LECHE LEAGUE $\ldots \ldots \ldots \ldots \ldots \ldots \ldots \ldots \ldots \ldots \ldots \ldots . . . \ldots$

II. LITERATURE REVIEW ............................................... 24

III. BUILDING COMMUNITIES OF MOTHERS ..............................49

IV. CREATING INSTITUTIONAL KNOWLEDGE ............................71

V. SHAPING AND RESHAPING INSTITUTIONAL KNOWLEDGE..............116

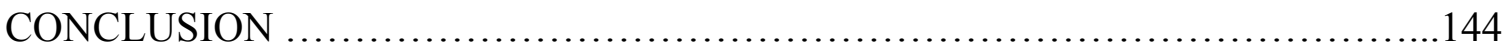

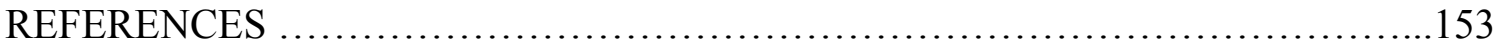

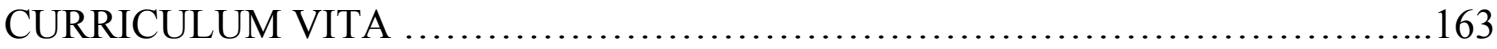




\section{INTRODUCTION}

La Leche League International (LLL) is the world's oldest and largest breastfeeding support organization. Founded in 1956 by seven housewives in suburban Chicago, the League grew at a phenomenal rate during its first three decades and was instrumental in dramatically increasing breastfeeding rates throughout the world. By the 1980s, LLL boasted over 4,000 local groups in 43 countries, and they had partnered with the World Health Organization (WHO) and the United Nations International Children's Emergency Fund (UNICEF) to draft accords protecting maternal and child health. ${ }^{1}$ The League's expansion over less than thirty years from a small group of mothers chatting in a living room about a relatively taboo subject to a global organization that authored international public health policy reflects remarkable skill in community building and an impressive accumulation of institutional knowledge.

This thesis examines how the League created a sense of collectivity among their members and allies and how they amassed and shaped the knowledge that allowed them to so effectively grow their organization in their first thirty years. It also explores how, as the League's growth slowed in the 1980s, the organization began to reconsider and

\footnotetext{
${ }^{1}$ La Leche League International, The Womanly Art of Breastfeeding, $3^{\text {rd }}$ ed. (Franklin Park, IL: La Leche League International), 1981, 339-340. For current breastfeeding statistics, see Centers for Disease Control, National Center for Chronic Disease Prevention and Health Promotion, Division of Nutrition, Physical Activity, and Obesity, "Breastfeeding Report Card, Progressing Toward National Breastfeeding Goals, United States, 2016," (Atlanta: Centers for Disease Control), 2016; For statistics from 1956, see Herman F. Meyer, "Breastfeeding in the United States: Extent and Possible Trend," Pediatrics 22, no. 1 (1958),116-121.
} 
reshape - to a limited extent — its institutional knowledge and the collective memory of its own history in ways designed to appeal to younger generations. I argue that La Leche League increased women's receptivity to a new, yet traditionalist construction of motherhood by claiming it was neither new nor traditional, but, instead, timeless. They appealed to shared experiences of frustration with mothering in the modern bottle-feeding world and contrasted these with a vague, sometimes mystical sense of connection and power among breastfeeding mothers across time and space. The League's founders bolstered their credibility by allying themselves with scientific authorities who supported the organization's vision of a natural, transhistorical model of embodied motherhood. Over time, the organization incorporated new authorities and the perspectives of new generations of mothers into their body of institutional knowledge. However, I argue, they continued to accept new information only to the extent that it reinforced their unchanging universalist construction of motherhood.

Motherhood was always at the center of everything La Leche League did as an organization. Although LLL was known as a breastfeeding support organization, infant feeding was only one component of their organizational mission. As encapsulated in their slogan, "good mothering through breastfeeding," the League's overall goal was to promote a particular model of mothering that was grounded in breastfeeding but held implications far beyond this single act. ${ }^{2}$ La Leche League's ideal was "natural

\footnotetext{
${ }^{2}$ Alternate versions of this slogan include "better mothering through breastfeeding" and simply "mothering through breastfeeding." This slogan was printed on numerous League publications including in the mastheads of the newsletters La Leche League News and Leaven. Today, the "first concept" of the League's ten-concept philosophy states, "Mothering through breastfeeding is the most natural and effective way of understanding and satisfying the needs of the baby," and one of the three points of LLL's "General Purpose" is "To encourage good mothering through breastfeeding." See "La Leche
} 
mothering," a highly intuitive set of behaviors, that extended from the profound physical and emotional ties between nursing mothers and their infants. ${ }^{3}$ The seven "Founding Mothers" believed this type of intensive, embodied motherhood had been largely lost in the twentieth century amid an impersonal modern culture and a mainstream ideal of "scientific mothering," which favored formula feeding and rigid, hands-off childcare regimens. According to the League's manual The Womanly Art of Breastfeeding, traditional, intimate female communities had once been integral in passing on the practical knowledge and skills new mothers needed to successfully act on their latent maternal instincts, but these communal practices had all but disappeared as urbanization and industrialization broke up pre-modern community structures and drew young people far from their natal homes. ${ }^{4}$ Through La Leche League, the seven Founding Mothers hoped to establish a new type of female community, one that would replicate historic communities of women and reintroduce young mothers to traditional feminine knowledge. They believed that through reviving breastfeeding, which would foster deep mother-child bonds, they could help to produce healthy and emotionally secure children, strengthen families, and ultimately counter the de-humanizing forces of a modern "sick

League Philosophy," La Leche League International, 19 February 2017, accessed November 3, 2017, http://www.llli.org/philosophy.html; "LLL Purpose," La Leche League International, November 2004, accessed November 4 2017, http://www.1lli.org/lad/tall1/philosophy.html.

${ }^{3}$ For a discussion of natural mothering see Chris Bobel, The Paradox of Natural Mothering. Christina G. Bobel, "Bounded Liberation," Gender \& Society 15, no. 1 (2001): 130-51. For a discussion of scientific mothering see Rima D. Apple, Perfect Motherhood: Science and Childrearing in America (New Brunswick, N.J.: Rutgers University Press), 2006.

${ }^{4}$ La Leche League of Franklin Park, The Womanly Art of Breastfeeding, (Franklin Park, IL: La Leche League of Franklin Park), 1957. 
society." ${ }^{5}$ Fueled by a cynical disillusionment with the present, their larger mission was to create a better tomorrow. However, they premised their vision of the future on a romanticized construction of the past.

Certainly, many elements of LLL's models of woman-to-woman support and intense physical and emotional bonding between mothers and infants were not complete innovations, but overall, the League's particular notion of natural mothering did not have the timeless historical footing that the founders claimed. The League's collective memory, or pool of shared memories and visceral impressions of what the past must have been like, informed their understanding of motherhood across time more than any concrete knowledge of historical female experiences. According to sociologist Maurice Halbwachs, collective memory is a perspective in which groups remember and reconstruct the past in light of the present. ${ }^{6}$ Given the present-centered vantage point, this process is prone to anachronism. Beyond this, though, for Halbwachs, collective memory tends toward nostalgia because the constraints of the present continue to affect people in concrete ways and are therefore felt much more strongly than those of the past. By contrast, historical constraints may have been deeply painful long ago, but they no longer pose any active threat, so they are easily forgotten. ${ }^{7}$ From La Leche League's collective memory perspective, they understood their mothering ideal as pre-modern-

\footnotetext{
${ }^{5}$ League medical advisor Herber Ratner used the term "sick society" in his forewords to both the second and third editions of the League's manual. Herbert Ratner, foreword to The Womanly Art of Breastfeeding, $2^{\text {nd }}$ ed. by La Leche League International (Franklin Park, IL: La Leche League International, 1963), v-vii; Herbert Ratner, foreword to The Womanly Art of Breastfeeding, $3^{\text {rd }}$ ed., La Leche League International (Franklin Park, IL: La Leche League International, 1981), ix-xii.

${ }^{6}$ Maurice Halbwachs, On Collective Memory, Lewis A Coser, ed. (Chicago: University of Chicago Press) 1992, 40.

${ }^{7}$ Halbwachs, On Collective Memory, 50.
} 
timeless and instinctual — but it was shaped just as much, if not more, by the founders' contemporary anti-modern sentiments.

Reacting against what they saw as the insidious effects of modern scientism and capitalism on mother-child relations, the League's founders overlooked other sources of oppression that limited mothers' autonomy, such as patriarchy, class and other social hierarchies. These forces had acted upon women in the past and continued to profoundly affect less privileged women in the present. However, the League's founders were not looking for these types of oppression in their exploration of the history of motherhood, and, therefore, they did not find them. Additionally, patriarchal values - particularly constructions of domestic gender roles - did continue to shape the mothering experiences of the League's relatively privileged white, middle-class founders and their peers in the $20^{\text {th }}$ century, but they did not necessarily acknowledge them as such. They viewed their seclusion in the home as their own choice and, somewhat contradictorily, the natural order in family life. They did not see their stay-at-home status as a historically and culturally specific social arrangement that, in many ways, limited their own access to the public sphere while facilitating their husbands'. These blind spots in the League's collective memory led the founders to idealize many elements of the premodern past, in which they did not recognize constraints on women, and to demonize certain aspects of modernity, in which they had firsthand experience with an oppressive healthcare system and a competitive, materialistic society.

The belief in a mythic golden age of motherhood in the past led LLL's founders to look for historical precedents to solve the problems they saw in modern family life, rather than developing innovative solutions that may have been more appropriate to the 
contemporary social environment. Ignoring historical sources of women's oppression blinded them to the pitfalls of a model of motherhood that made mothers entirely dependent upon husbands for financial support. The League's presentist cultural perspective also assumed that female communities had always been harmonious, failing to recognize the roles that distinctions of race, class, religion, marital status and other factors played in creating friction between women. The founders' emphasis on historical precedent eventually spilled over into the organization's institutional memory. From the late 1970s, League publications increasingly portrayed the group, and the founders in particular, as progenitors of various progressive late twentieth-century social movements including the self-help movement, the women's health movement, and the Second Wave of feminism more broadly. The League had engaged with members of these movements in a variety of ways. In particular, the League's early efforts in the 1950s and 1960s at questioning medical authority and asserting women's autonomy over their own bodies may have directly or indirectly influenced later activists. However, the actual relations between League members and members of other movements were complicated at best, and, at worst, outright antagonistic. Later League writers, nevertheless, overlooked the tensions that had existed between their organization and other feminists and extended their rosy vision of the past to their own history.

In this thesis, I consider the League's historical context from several angles, based primarily upon a narrative analysis of publications by the League's founders, members, and allies from the 1950s to the 2010s. In Chapter I, I present a brief overview of the history of La Leche League as an organization. The literature review in Chapter II describes how my research fits in with existing scholarship by exploring relevant studies 
of LLL, women's history, and collective identity and memory. In Chapter III, I explore how LLL fostered a sense of collective identity to build the network of communities that made up their organization and how they encouraged a particular collective memory consciousness to encourage breastfeeding women to see themselves as members of a larger, transhistorical community of mothers. Chapter IV evaluates how the unique cultural environment in which the League arose — white, middle-class, midcentury Catholic suburbia - influenced the beliefs of the founders and their early allies. Finally, in Chapter V, I analyze the extent to which the League and its allies have shaped and reshaped their institutional knowledge to fit with their pre-existing beliefs and in light of changing conditions over the organization's six decades of history. Overall, I conclude that the League's founders and their later heirs in the organization tended to seek out and promote only that evidence-whether from personal experiences, medicine, history, anthropology, psychology, or feminist ideologies — which supported their particular worldview. Similarly, they rejected as invalid or ignored as irrelevant any argument that did not support their perspective, regardless of its intrinsic merit. 


\section{A BRIEF HISTORY OF LA LECHE LEAGUE}

The mid-twentieth century saw some of the lowest rates of maternal breastfeeding ever recorded. In 1956, the year La Leche League was launched, only about a third of newborns were fed any breastmilk when they were released from the hospital. ${ }^{8}$ Although most health professionals and laypeople in the 1950s agreed that, in theory, breastmilk was best for babies, they were also generally convinced that modern mothers could not produce enough — or good enough — milk to satisfy their offspring. Some mothers never put a baby to breast, but many others, especially first-time mothers, attempted to breastfeed for a few days or weeks before adding cereals or switching their infants to cow's milk-based formulas. Midcentury mothers often gave up exclusive breastfeeding in response to persistent fussing, sometimes from their babies, but more often from relatives, friends, and even nurses and doctors. These influential figures undermined many a new breastfeeding mother's confidence with impertinent, and irrelevant, questions about the size and shape of her breasts, the richness of her milk, and whether

${ }^{8}$ Jessica L. Martucci, Back to the Breast: Natural Motherhood and Breastfeeding in America (Chicago: University of Chicago Press), 2015, 71; Meyer, "Breastfeeding in the United States." 
she was overtiring herself. They offered helpful commentary such as, "You can't just let the child STARVE!"” It was in this inhospitable environment that La Leche League was conceived.

One hot day in the summer of 1956, two breastfeeding mothers, Marian Tompson and Mary White, attended a picnic put on by a Catholic church group at Wilder Park in the Chicago suburb of Elmhurst. Tompson and White chatted under a tree, periodically nursing their babies. From their shady vantage point they watched other mothers struggling to keep their babies' bottles at the right temperature - first cold to prevent the cow's milk from spoiling in the heat, then warm enough to appeal to the baby. Many of these women approached the two nursing mothers, confessing that they had wanted or tried to nurse their babies but had stopped for one reason or another. Tompson and White could empathize. They had each faced their own struggles with breastfeeding and had used bottles and formulas when their older children were infants. Both had ultimately succeeded in breastfeeding with the help of White's husband, Gregory White, a family physician who promoted "natural" practices such as unmedicated childbirth and breastfeeding. ${ }^{10}$ Tompson and White had previously discussed the differences they perceived between bottle feeding and breastfeeding, and how much they wished that

\footnotetext{
${ }^{9}$ La Leche League of Franklin Park, The Womanly Art of Breastfeeding, 18.

${ }^{10}$ Gregory White had been away with the Army when the Whites' first son was born shortly after the end of World War II. Without her husband's support, Mary White had weaned young Joseph soon after leaving the hospital. The White's second child was born after Gregory White was demobilized, and his support helped Mary White to breastfeed this and all of their subsequent nine children without using supplements. Marian Tompson had seen a different doctor with each of her first three children. Her fourth was delivered by White, at the Tompson's home, and with his and Mary White's support, Tompson was finally able to successfully breastfeed her fourth children and the three more who followed without supplements. See Kaye Lowman, LLLove Story (Franklin Park, IL: La Leche League International), 1978.
} 
other mothers could experience the pride and the unique sense of closeness they felt while nursing their babies. Now, hearing the litany of breastfeeding failures from the mothers at the picnic, Tompson came to two realizations: first, that, like herself and White, many women resorted to bottle feeding as a second choice, and second, that most of their difficulties could have been overcome with a little information and a lot of encouragement. The two women wondered together what they could do to help other mothers succeed in breastfeeding, and Tompson hit upon the idea of a support group. After the picnic, the two called friends who also felt strongly about breastfeeding, and within a few weeks five more breastfeeding mothers—-Mary Ann Cahill, Edwina Froehlich, Mary Ann Kerwin, Viola Lennon and Betty Wagner-joined Tompson and White to pool their knowledge and plan what would become La Leche League.

This picnic itself has become part of the League's institutional memory. It serves as a sort of foundation myth for the organization and has been recounted frequently in League literature over the years. ${ }^{11}$ The League has held reunions in Wilder Park over the years, and the original picnic was even depicted in a line drawing in the second edition of The Womanly Art of Breastfeeding. The League's numerous accounts of the 1956 picnic do not vary much overall; they generally contain the basic details of White and Tompson nursing their babies while other mothers struggled with bottles in the heat and lamented their breastfeeding failures. However, the accounts do differ in their description of who

\footnotetext{
${ }^{11}$ The most detailed descriptions appear in the following: Mary Ann Cahill, Seven Voices One Dream, (Schaumburg, IL: La Leche League), 2001, 23-25; La Leche League International, The Womanly Art of Breastfeeding $2^{\text {nd }}$ ed. (Franklin Park, IL: La Leche League International), 1963, 152; Marian Tompson, "La Leche League: The Story of Our life or 'The First Eighteen Months Are the Hardest," La Leche League Newsletter 1, no. 1 (1957), 1; Lowman, LLLove Story, 11; Kaye Lowman, The Revolutionaries Wore Pearls, (Schaumburg, IL: La Leche League), 2007, 13.
} 
had arranged the picnic. The picnic was hosted by a local Christian Family Movement (CFM) group, a Catholic organization that encouraged families to work for social change. In some accounts the League describes the picnic as a church picnic or a family picnic, but only rarely do they explicitly mention CFM. This is likely because mentioning CFM would require describing the organization, which would be mostly irrelevant to the broader story the League was attempting to tell about its founding. Yet the founders' involvement in CFM was in many ways profoundly influential on the way they envisioned their mutual-support network. Further, that the women at a CFM picnic had wanted to breastfeed does not necessarily create the same impression of a general, widespread desire among American women in the 1950s to breastfeed. Members of CFM were a self-selected group of middle-class white Catholic women who were already concerned with living in accord with a particular shared understanding of God's, and Nature's, plan for families.

After the picnic, over the summer of 1956, the seven women met to discuss how their group could best help mothers who wanted to breastfeed. They searched for as much published information as they could find - which was not much. They consulted Gregory White, and reached out to his professional and philosophical mentor, Herbert Ratner, a clinical professor at Northwestern and Public Health Minister of the suburb of Oak Park, who was an even more outspoken advocate of natural practices in medicine than White. After several planning sessions and discussions with their medical advisors, the first official meeting of the League was held one evening in October of 1956 with the founders hosting five of their pregnant friends at the Whites' home in Franklin Park. 
The founders tried a handful of different formats for their group meetings in the early months, but fairly quickly hit upon a successful format that has endured for six decades. At the first few meetings Marian Tompson, who had been elected the League's president by her fellow "Founding Mothers," read articles about breastfeeding to the assembled women. Soon, though, the founders decided that mothers of young children would really appreciate an opportunity to have adult conversation and feel like part of a community of peers. They shifted the meetings to more of a facilitated group discussion format that actually better fit Tompson's original goal of providing information and encouragement. Soon the founders settled upon a consistent meeting structure, which has changed little over the past six decades. A small group of women met for a series of four discussion-based meetings in a member's home, each loosely focused on a particular theme and presided over by a single, experienced breastfeeding mother called a Leader. ${ }^{12}$ League founders outlined four topics for these "Series Meetings": the advantages of breastfeeding, adjusting to life with a new baby, breastfeeding difficulties, and nutrition and weaning. In the League's early years, a separate meeting for fathers was also held periodically, with Ratner speaking to the fathers about how and why to support their wives' breastfeeding efforts. Although the original plan was that women would come for one series while pregnant to prepare for breastfeeding, the founders soon discovered that many women continued to participate in the League for months or years after they "graduated" from their first series, to maintain the sense of community they had found in

\footnotetext{
${ }^{12}$ In recent years, meetings tend to be held in public meeting rooms at churches, hospitals or maternity stores rather than in homes.
} 
the group and so that they could continue to give and receive support. ${ }^{13}$ The founders had not expected this, nor had they anticipated the extraordinary growth their little group of friends and neighbors would quickly see.

The founders were all members of a variety of religious, charitable and civic organizations and had originally envisioned La Leche League as yet another small, local group to add to their calendars. Much to their surprise, after a few meetings, the original group expanded beyond the capacity of the Whites' living room, so some of the women split off to meet at Edwina Froehlich's house. The group had not yet advertised, but news of the League was beginning to spread by word of mouth. Within a year, new La Leche League groups had begun popping up throughout the Chicago area and women from across the country were calling and writing for support and information. In 1957, to reach women who lived too far away to attend series meetings — and to avoid writing the same sort of letters over and over - the founders set to work writing their manual, The Womanly Art of Breastfeeding, and in the meantime launched a newsletter, La Leche League News. ${ }^{14}$ The original manual was simply an unbound collection of thirty-nine pieces of three-hole punched loose-leaf paper, hand-assembled and mailed by the founders and their children, but it sold 17,000 copies in just over six years. ${ }^{15}$ As the

\footnotetext{
${ }^{13}$ La Leche League of Franklin Park, The Womanly Art of Breastfeeding, 1; Elizabeth Bryant Merrill, "Learning How to Mother: An Ethnographic Investigation of an Urban Breastfeeding Group," Anthropology \& Education Quarterly 18, no. 3 (1987), 222-40.

${ }^{14}$ La Leche League of Franklin Park, The Womanly Art of Breastfeeding.

${ }^{15}$ Many references to the first edition say that it was thirty pages. The copy in the archives at DePaul University has thirty-one numbered pages of text (printed on one side). It also includes a cover and seven additional, unnumbered pages which list titles and contents for various subsections. See The Womanly Art of Breastfeeding Loose Leaf Booklet Copy With Notes 1958, Box 10 Folder 2, La Leche League International Records, DePaul University Special Collections and Archives, DePaul University. For
} 
League connected with more women through their newsletter and manual, new groups continued to form across the country. The organization officially incorporated as nonprofit in 1958 under the name La Leche League of Franklin Park (the suburb where most of the founders lived), and in 1962, the League had enough subsidiary groups that they organized into administrative units called chapters, each consisting of roughly five groups, in order to streamline their management. The following year, the organization rented its first office so that the founders could move their ever-expanding masses of papers and files off their dining room tables and out of spare bedrooms. They also hired their first employee, a part-time stenographer to help keep up with the ever-increasing paperwork the rapidly expanding organization generated. 1963 also saw the publication of the second, expanded, hardcover edition of The Womanly Art of Breastfeeding, which eventually went through 29 printings and sold 1,172,000 copies. ${ }^{16}$ By 1964 the League had spread to Canada, Mexico, and New Zealand, and the organization officially changed its name to La Leche League International and held its first international convention. A year later, they launched another periodical, Leaven, which was aimed at Leaders rather than the general membership of the League.

The early 1970 s were a somewhat stormy period for the League's administration as conflicts arose over whether the organization should officially oppose abortion (they did not) and whether the League should discontinue the use of religious language in their publications (they did). During the later 1970s and early 1980s the League worked to

sales information see subsequent editions of the manual including La Leche League International, The Womanly Art of Breastfeeding, $2^{\text {nd }}$ ed.

${ }^{16}$ La Leche League International, The Womanly Art of Breastfeeding, $2^{\text {nd }}$ ed. For sales information see subsequent editions including La Leche League International, The Womanly Art of Breastfeeding, $3^{\text {rd }}$ ed. 
curb unethical formula marketing practices in the Global South. They had first learned in the 1960s about the dangers of artificial feeding in poor and impoverished communities, especially in tropical climates. In areas that lacked access to clean water, refrigeration, and facilities in which to sterilize bottles and nipples, feeding infants cow's milk based formulas could lead to deadly diarrheal infections. Further, because formulas were so expensive and required the extra cost of bottles, nipples, sterilization equipment and fuel for heating, many poor parents diluted the formulas. Although formula manufacturers were aware of this, they aggressively marketed their products, often willfully misleading poor, illiterate mothers about the comparative risks of breastfeeding and formula feeding, and even giving these mothers just enough free samples of formula to interfere with their breastmilk production. The League did not directly participate in the widespread Nestle boycotts of the late 1970s and early 1980s, but they contributed to the drafting of the World Health Organization's 1981 International Code of Marketing of Breastmilk Substitutes. ${ }^{17}$

The height of the League's expansion took place in the 1960s, but the League continued to add groups and grow in numbers into the early 1980s. By 1981, when the

\footnotetext{
${ }^{17}$ The first boycott of Nestle began in 1977. The British charity War on Want had published a booklet called The Baby Killer which drew attention to the dangers of formula feeding in the developing world. The booklet mentioned Nestle, among other formula manufacturers, and Nestle sued the publishers for libel. This suit drew publicity, which in turn sparked the boycott. The boycott has continued off and on since the 1970s, but received the most publicity in the 1970s and early 1980s. See Mike Muller, The Baby Killer: A War on Want Investigation into the Promotion and Sale of Powdered Baby Milks in the Third World (London: War on Want), 1974. For information on the history and continuing relevance of the Nestle boycotts from the perspective of the author The Baby Killer, see Mike Muller, "Nestlé Baby Milk Scandal Has Grown Up But Not Gone Away," The Guardian, 13 February 2013, accessed November 6, 2017, https://www.theguardian.com/sustainable-business/nestle-baby-milk-scandal-foodindustry-standards.
} 
League published the third edition of their manual, they claimed over 4,000 groups and 18,000 Leaders (Leaders took turns leading groups) in 43 countries. The organization also employed more than 50 staff members, although many worked part-time because the League was committed to a mother-friendly workplace and kept all staff and volunteer positions mother-sized. ${ }^{18}$

Over the course of the 1980s, however, the League's growth slowed for a number of reasons. The organization had, in a sense, saturated the market, as numerous groups already existed in each state, most major cities, and many small communities in the US, as well as many locations across the globe. Manual sales also slowed, with the 1981 third edition selling 536,000 copies, just over half of total sales of the previous edition. With over a million and a half copies in circulation, many new breastfeeding mothers already owned a copy or could borrow one from a friend. The drop in sales hurt the League financially, as they had come to depend on manual sales for a large portion of their funding and had not anticipated the decline. Another change that negatively impacted the League's growth was even more unexpected. In 1981, the League reorganized its administrative structure, and eliminated the position of president, which founder (and picnic-goer) Marian Tompson had held for 25 years. Back when the group's mission had been to help a few friends and neighbors, each of the seven founders had been granted an administrative role, and this structure was proving increasingly unwieldy. The founders,

\footnotetext{
${ }^{18}$ La Leche League International, The Womanly Art of Breastfeeding $3^{\text {rd }}$ ed., 339-340. Although the League has not necessarily explicitly defined the term mother-sized, it appears across a variety of League literature in describing administrative and leadership roles in the organization. The shared meaning is basically part-time, but in terms more specific to the highly involved mothers that made up the League's participants it meant able to be accomplished without interfering with mothering duties.
} 
other than Tompson, felt that eliminating the position of president would go a long way toward making the now global organization less top-heavy and more efficient. As president, Tompson had not had much of a managerial function, but she had served as an official spokesperson for the League in the media. In this capacity, she had been a guest on the nationally syndicated Phil Donahue Show six times, as well as at national and international gatherings of governmental and non-governmental organizations concerning breastfeeding and maternal and infant welfare. Without Tompson, the League lost a consistent, recognizable representative, and their public relations suffered.

A final, key factor that contributed to the plateau in the League's growth after 25 years of expansion was that the League's particular construction of mothering through breastfeeding, which had arisen in the 1950s, had begun to seem outdated, and even regressive to mothers living in the very different economic and cultural climate of the 1980s. ${ }^{19}$ The League did not have an official philosophy for the first fifteen years of its existence. The founders had considered the manual to be representative of their shared beliefs about breastfeeding and motherhood and did not feel that it was necessary to write a more succinct summary of their views. Founder Mary White joked, "The seven of us had such a marvelous unanimity of thought... I think we were all kind of surprised that other people weren't able to read our minds or absorb our philosophy by osmosis.."20 Eventually, as the founders recognized that some of their Leaders and some of the groups that called themselves part of La Leche League had different views, they began to codify their ideology. A small committee worked to distill the League's core beliefs from the

\footnotetext{
${ }^{19}$ See Martucci, Back to the Breast.

${ }^{20}$ Lowman, LLLove Story, 40.
} 
then-current second edition of The Womanly Art of Breastfeeding, and in the fall of 1972 they published the first official La Leche League Philosophy. It consisted of eight "concepts," or recurring themes. A ninth concept was added in 1973 and a tenth in 1975. The third concept was revised slightly in 1979 and the tenth in 1981, but subsequently the Philosophy has not changed. ${ }^{21}$ Since 1981 , the following ten concepts have comprised the LLL Philosophy:

1) Mothering through breastfeeding is the most natural and effective way of understanding and satisfying the needs of the baby.

2) Mother and baby need to be together early and often to establish a satisfying relationship and an adequate milk supply.

3) In the early years the baby has an intense need to be with his mother which is as basic as his need for food.

4) Human milk is the natural food for babies, uniquely meeting their changing needs.

5) For the healthy, full-term baby, breast milk is the only food necessary until the baby shows signs of needing solids, about the middle of the first year after birth.

6) Ideally the breastfeeding relationship will continue until the baby outgrows the need.

7) Alert and active participation by the mother in childbirth is a help in getting breastfeeding off to a good start.

8) Breastfeeding is enhanced and the nursing couple sustained by the loving support, help, and companionship of the baby's father. A father's unique relationship with his baby is an important element in the child's development from early infancy.

9) Good nutrition means eating a well-balanced and varied diet of foods in as close to their natural state as possible.

10) From infancy on, children need loving guidance which reflects acceptance of their capabilities and sensitivity to their feelings. ${ }^{22}$

Over the years, both before and after the publication of their official Philosophy, the League's notion of "good mothering" has met with a mixed reception, encompassing

\footnotetext{
${ }^{21}$ Lowman, LLLove Story, 37; Fiona Reynoldson, Eileen Harrison and Monique Kitts, "The History of LLL Philosophy," Leaven 39, no. 5 (2003), 102-103.

22 "La Leche League Philosophy."
} 
enthusiasm, censure and ambivalence. ${ }^{23}$ As evidenced by the organization's precipitous growth, many women embraced La Leche League's construction of motherhood and its valorization of nature, emotions, family life, and women's bodies. The League promoted breastfeeding as a transformative and maturing experience, and many members found participation in the League similarly life-altering. According to Mary Jane Brizzolara, who joined the League in 1957 and quickly rose in the ranks of its administration, finding La Leche "was like coming home to mother." She elaborated on this experience in 1978:

Being part of the League was a major turning point in the lives of nearly all of us who were involved in the early years. It tremendously influenced our characters and our personality development. Through League we found and adopted certain principles, and we lived our lives by them. I'm still living by those principles today. La Leche League changed the course of my life. ${ }^{24}$

Other women, including representatives of feminist organizations such as the National Organization for Women and the Boston Women's Health Book Collective, have found the League's construction of intensive, selfless, biologically based motherhood to be problematic, if not outright destructive to women. ${ }^{25}$ Members of NOW picketed a local LLL meeting in protest of their advocacy of traditional gender roles, and Our Bodies, Ourselves declared that The Womanly Art of Breastfeeding was a

\footnotetext{
${ }^{23}$ See, for example, Boston Women's Health Book Collective, Our Bodies Ourselves (New York: Simon and Schuster), 1973. For further discussion of negative responses to the League and groups with similar mothering philosophies see Elisabeth Badinter, The conflict: How modern motherhood undermines the status of women (New York: Metropolitan Books/Henry Holt and Co) and 2011; Bernice L. Hausman, Mother's Milk: Breastfeeding Controversies in American Culture (Hoboken: Taylor and Francis), 2014. ${ }^{24}$ Cited in Lowman, LLLove Story, 38. Emphasis added.

${ }^{25}$ The League's periodical literature is filled with testimonials about the League's ability to empower and validate women. A collection of articles that speak to this are found in Virginia Sutton Halonen, Nancy Mohrbacher, and La Leche League International, Learning a Loving Way of Life, (Franklin Park, Ill.: La Leche League International), 1987.
} 
useful resource for breastfeeding information, "if you can get past the sickening stuff about a woman's role is to bear and raise children."${ }^{, 26}$

The most controversial point of the League's ideology in the 1980s was the "third concept" listed above, which is often referred to as the "mother-baby togetherness" or "mother-baby separation" concept. In and of itself, the concept may not seem offensive, but it is based upon, and used to support, a foundational belief that mothers are the only acceptable primary caregivers of young children (except in very rare cases where a single, permanent mother substitute could stand in). A corollary to this belief is that mothers of young children should not work away from home. This concept, along with the rest of the philosophy, also constructed bottle-feeding, even with expressed breastmilk, as a distant second choice that placed children and mothers at risk of physical and emotional disturbance. In 1950s white suburban America, a mother staying at home full time was not much of rarity nor was it considered much of a sacrifice among most of the League's early members. Since the mid-1960s, however, primarily white feminist organizations, such as those cited above, had painted domesticity as a culturally constructed concept that placed women at the service of individual men, and of patriarchy at large, and left them physically and emotionally drained, as well as psychologically unfulfilled. ${ }^{27}$ By the 1980s, the effects of such anti-domesticity feminist ideologies had shaped cultural constructions of women and motherhood. Additionally, women were having fewer children and marrying later, and mothers of young children formed the

\footnotetext{
${ }^{26}$ Boston Women's Health Book Collective, Our Bodies, Ourselves, 227.

${ }^{27}$ Feminists of color have viewed domesticity differently. See the literature review below for brief descriptions of Patricia Hill Collins' and Dorothy Roberts' discussions of black motherhood.
} 
fastest growing sector of the paid workforce. This contrasted sharply with the landscape of the League's early years when many mothers had withdrawn from the workforce following World War II, and the end of that war and the start of the Cold War had triggered an unusually low age of marriage and a baby boom. ${ }^{28}$ It is worth noting that only one of the League's founders was married after age 30 or had fewer than six children. All these changes had rendered the League's view of selfless maternal devotion acutely suspect for a new generation of mothers influenced by recent feminist thought.

From the 1980 s to the 2000 s, the League expanded their work with poor and minority mothers domestically and internationally. The majority of the League's administration and membership had always been white, middle-class, married women, but, especially as news of the formula marketing scandal spread, some League members expressed a desire to reach out to women outside the organization's relatively privileged core demographic. With this in mind, in 1982, a League Leader worked with the United Nations International Children's Emergency Fund (UNICEF) to establish a program in Brazil to train low-income mothers to serve as breastfeeding counselors and establish peer support groups in their own communities. Later, in 1988, the United States Agency for International Development (USAID) awarded the League a Child Survival Grant to undertake similar projects in Guatemala and Honduras. Meanwhile, in 1987, the League had inaugurated its US-based peer counselor program, training a pilot group of inner-city Chicago mothers. Peer counselors worked in their own communities, taking paid jobs in clinics and with the United States' Department of Agriculture's Special Supplemental

\footnotetext{
${ }^{28}$ Elaine Tyler May, Homeward Bound: American Families in the Cold War Era. Fully Rev. and Updated 20th Anniversary ed. (New York, NY: Basic Books), 2008.
} 
Nutrition Program for Women, Infants and Children (WIC). A few years later, in the early 1990s, League representatives contributed to the drafting of WHO/UNICEF's Innocenti Declaration and Baby Friendly Hospital Initiative. Later that decade and into the early 2000s, the League participated in the ten-year, multi-agency, multi-site LINKAGES project which was coordinated by USAID and included groups such as Catholic Relief Services and World Vision. The project targeted women affected by HIV/AIDS and sought to "(e)nsure the availability of culturally appropriate and easily understood educational materials" ${ }^{29}$ These efforts, along with the International Code of Marketing of Breastmilk Substitutes helped to increase breastfeeding rates and to curtail many abuses by formula manufacturers globally, and in so doing have saved the lives of countless children. However, the US has never adopted the Code and only $22 \%$ of births in the US occur in designated Baby-Friendly hospitals. ${ }^{30}$

In writing about their history, the League has increasingly emphasized the radical and avant-gard elements of their early philosophy and actions. As early as 1978, in the book LLLove Story, which traced the history of the League, writer Kaye Lowman included an anecdote in which Marian Tompson refers to the 1950s as "those unliberated days." ${ }^{31}$ In the fourth edition of $W A B F$ the authors claimed that the League was "the precursor of the Feminist Movement" and "the beginning of self-help groups and

\footnotetext{
${ }^{29}$ LINKAGES Project, "Facts for Feeding: Recommended Practices to Improve Infant Nutrition during the First Six Months" (Washington, DC: LINKAGES, Academy for Educational Development), 1999.

30 "Find Facilities," Baby Friendly USA November 2, 2017, accessed 6 November 2017, https://www.babyfriendlyusa.org/.

${ }^{31}$ Lowman, LLLove Story, 21.
} 
women's control over health-care issues." 32 By 2003, the reconceptualization of the early League had come so far that Lowman's new, updated League history was entitled The Revolutionaries Wore Pearls. As this title suggests, Lowman and the founders acknowledge that the League's earliest participants were in many ways traditional, conservative 1950s housewives, but they also highlight that they were empowered and enlightened women who were aggressive champions of the rights of mothers and children. By the 1990s, many League participants had embraced the most conservativeseeming element of League philosophy_-women remaining in the home — as a radical political and feminist choice to reject the predominantly male values of the marketplace and embrace the predominantly female values of the home. The contemporary liberationist assessment of the League's early history and philosophy is not entirely inaccurate, but it is highly colored by events that have taken place in the interim and by a desire to appeal to an audience whose values do not entirely align with those the founders held in the 1950 s.

${ }^{32}$ La Leche League International, The Womanly Art of Breastfeeding $4^{\text {th }}$ ed., (Franklin Park, IL: La Leche League International), 1990, cited in Lynn Weiner to La Leche League, 5 May 1992 La Leche League International Records, DePaul University Special Collections and Archives, DePaul University, emphasis in Weiner's letter. 


\section{LITERATURE REVIEW}

Although feminists have developed more nuanced views of women, patriarchy and motherhood since the 1960s, feminist scholars continue to lead the charge in critiques of LLL's conservative engagements with most women's issues. "Bounded Liberation," the title of a 2001 study of the contemporary League by women's and gender studies scholar Chris Bobel, aptly encapsulates the academic feminist view of the League as empowering to women as mothers, but only within a limited, domestic sphere. ${ }^{33}$ Scholars from a range of disciplines from theology to public health have explored LLL's simultaneous empowerment and constraint of mothers, highlighting the influence of varied maternalist, religious, and scientific ideologies on the League's construction of motherhood. ${ }^{34}$ Interestingly, scholars studying the contemporary League and those analyzing the League's early history tend to come to similar conclusions about the ideology of the organization and its members. A number of these feminist academics have hit upon the term "paradox" to describe the relationship between broader

\footnotetext{
${ }^{33}$ Christina G. Bobel, "Bounded Liberation."

${ }^{34}$ Merrill, "Learning How to Mother;" Lynn Y. Weiner, "Reconstructing Motherhood: The La Leche League in Postwar America," The Journal of American History 80, no. 4 (1994): 1357-381; Jessica L. Martucci, "Why Breastfeeding?: Natural Motherhood in Post-War America," Journal of Women's History 27, no. 2 (2015), 110-33; Bobel, The Paradox of Natural Mothering; Bobel, "Bounded Liberation;" Linda M. Blum and Elizabeth A. Vandewater, "Mother to Mother": A Maternalist Organization in Late Capitalist America," Social Problems 40, no. 3 (1993): 285-300. Jule DeJager Ward, La Leche League: At the Crossroads of Medicine, Feminism, and Religion (Chapel Hill: University of North Carolina Press), 2000.
} 
feminism(s) and La Leche League and its peer organizations. Another point worth remarking is that many of the scholars who have written about the League, including Bobel, have been current or former participants in the League who responded to the organization with a profound ambivalence - a paradoxical emotion in itself. These scholars have personally reacted to the League as supportive and empowering of embodied womanhood and motherhood, yet they have generally found the League's ideology constricting, a feeling likely heightened because, as academics, none of them could live up to the model of the full-time, at home mother, even if they wished to. In seeking to valorize the mothering labor of women, League ideology has diminished the contributions that women, such as the academics who have studied the League, might make to society through their paid labor. This study suggests that the League's utter rejection of consumerist values has led them to overlook that mothers might work for reasons other than poverty or unbridled acquisitiveness. The League has often downplayed the positive social contributions of any work that is paid. This is particularly evident in the emphasis many League founders and participants have placed on the fact that their work was done on a volunteer basis and primarily conducted from home, even when such work often required long hours and occasionally included travel. ${ }^{35}$

The League's rejection of the capitalist values of the marketplace and their emphasis on unpaid care work reflects a particular response to the divergent constructions of motherhood Sharon Hays outlines in in her aptly titled book, The Cultural

\footnotetext{
${ }^{35}$ For more on the League's attitude to mothers' employment see Martucci, Back to the Breast.
} 
Contradictions of Motherhood. ${ }^{36}$ Hays sees motherhood as the site where anxieties about the incompatibility of opposing realms of contemporary life-morality vs capitalism, private vs public, family vs work, childhood vs adulthood - play out. The home, family and childhood are ruled by love and selflessness, while work, the public sphere and adulthood are ruled by competition and selfishness. Mothers, particularly working mothers, must navigate between these mutually exclusive realms in their own daily lives as they spend time in the home with children and in the wider world of the market. Perhaps more problematically, mothers must also protect their children from contamination by capitalist, adult values and yet somehow prepare them to function productively under these values once they reach maturity. ${ }^{37}$ Many feminists have responded to these contradictions by urging a restructuring of the male-centered values of contemporary capitalism and workplace environments so that workers can succeed professionally regardless of gender and domestic obligations. ${ }^{38}$ La Leche League members, by contrast, reject the masculine values of capitalism outright, seeing them as corrupt and thus undesirable for either men or women. They seek to live by the antimaterialist mantra, "people before things. ${ }^{39}$ While League members recognize that most

\footnotetext{
${ }^{36}$ Sharon Hays, The Cultural Contradictions of Motherhood (New Haven: Yale University Press), 1996.

${ }^{37}$ Hays, The Cultural Contradictions of Motherhood.

${ }^{38}$ For feminist critiques of contemporary capitalism, especially in the world of paid employment, see Christine L. Williams, Still a Man's World: Men Who Do "Women's Work," (Berkeley: University of California Press), 1995; Joan Acker, "Hierarchies, Jobs, Bodies: A Theory of Gendered Organizations," in Judith Lorber and Susan A. Farrell, eds. The Social Construction of Gender (Newbury Park, Calif.: Sage Publications), 1991. ${ }^{39}$ This saying appears frequently in League writings and is a common refrain at League meetings. For example, see Niles Newton, foreword to The Womanly Art of Breastfeeding, $3^{\text {rd }}$ ed. by La Leche League International (Franklin Park, IL: La Leche League International, 1981), xiii-xiv.
} 
men and some poor women may have to compromise with the existing capitalist structure to support their families, they feel that mothers, especially of infants, have a stronger moral obligation, by virtue of their physical and emotional bond with their children, to refuse to concede to misguided capitalist ethics.

Based on the League's moralistic construction of motherhood as a duty and an activity that can positively shape a society's future, many scholars have classified LLL as a "maternalist" organization. ${ }^{40}$ According to historian Lynn Weiner, maternalism “implies a kind of empowered motherhood or public expression of those domestic values associated in some way with motherhood." ${ }^{41}$ However, as a philosophy, maternalism "embodies some contradictions" and has been variously described as "feminist, antifeminist, conservative, progressive, radical, or some combination thereof." 42 Although maternalist ideologies are typically deployed by women's organizations on behalf of women and children, some scholars suggest they can also be invoked by men. Kathleen S. Uno provides one example of men's use of maternalism in the Japanese men of the late nineteenth and early twentieth centuries who promoted Western constructions of motherhood to further their nationalist agenda. ${ }^{43}$ By contrast, Molly Ladd-Taylor prefers a narrower definition of maternalism. In her view, while a number of women's

${ }^{40}$ For a discussion of LLL as a maternalist organization and explorations of the concept of maternalism see the articles in Lynn Weiner, ed., "Maternalism as a Paradigm," Journal of Women's History 5, no. 2 (1993): 95-130 and Andrea O'Reilly, ed., Maternal Theory : Essential Readings (Toronto: Demeter Press), 2007.

${ }^{41}$ Lynn Weiner, "Maternalism as a Paradigm: Defining the Issues" Journal of Women's History 5, no. 2 (1993): 96.

${ }^{42}$ Ibid.

${ }^{43}$ Kathleen S. Uno, “Maternalism in Modern Japan,” Journal of Women's History 5, no. 2 (1993): 126-130. 
organizations have invoked notions of motherhood, truly maternalist organizations share four beliefs:

1. that there was a uniquely feminine value system based on care and nurturance,

2. that mothers performed a service to the state by raising citizen-workers,

3. that women were united across class, race, and nation by their common capacity for motherhood and therefore shared a responsibility for all the world's children, and

4. that ideally men should earn a family wage to support their 'dependent' wives and children at home. ${ }^{44}$

The political implications of maternalism thus depend upon who is invoking motherhood, to what end, and what is meant by "motherhood" in a given context.

Maternalism can also be understood as not just an ideology associated with certain strains of feminist organizing, but a shared way of thinking among mothers. Feminist philosopher Sara Ruddick has described such a perspective as "maternal thinking," expanding on Sandra Bartky’s description of "feminist consciousness.."45 Collective consciousness, according to Bartky, arises when the possibility of liberation becomes real, and the oppressed group recognizes the contradiction between what is and what could be. ${ }^{46}$ Liberal and radical feminists in the mid-twentieth century recognized the contradictions between the domestic and public ideologies by which they were judged as women and as workers. Broadly speaking, liberal feminists envisioned women liberated by laws protecting their equal economic and political rights while radical feminists saw liberation in the form of more fundamental changes in social values and

\footnotetext{
${ }^{44}$ Molly Ladd-Taylor, "Toward Defining Maternalism in U.S. History," Journal of Women's History 5, no. 2 (1993): 110.

${ }^{45}$ Sara Ruddick, Maternal Thinking : Toward a Politics of Peace (Boston, Massachusetts: Beacon Press), 1995; Sandra L Bartky,"Toward a Phenomenology of Feminist Consciousness," Social Theory and Practice 3, no. 4 (1975), 425-39.

${ }^{46}$ Bartky, "Toward a Phenomenology of Feminist Consciousness."
} 
constructions of gender. Expanding on Bartky, Ruddick maintains that motherhood can lead to its own form of feminist consciousness. For Ruddick, mothering triggers certain changes in perspective about the nature of human life and relations. Significantly, this consciousness is not intrinsic to women or broader female experiences, but arises from the act of mothering, which involves the intense physical and emotional care of helpless beings and the moral training of the next generation. ${ }^{47}$

In La Leche League's particular maternalist construction, some elements of maternal thinking were common to women, but others were the result of the specific mothering experience of breastfeeding on demand and the attendant physical and emotional connections between mother and child. For La Leche League, breastfeeding, not just mothering, was transformative. As founder Viola Lennon phrased it, "breastfeeding, in and of itself, gives you some vision of what a human person is. To me, breastfeeding your baby leads to self-discovery., ${ }^{48}$ The League emphasized that mothers were responsible for teaching their children well so that they could make the world a better place in the future, but they also held that breastfeeding, and participation in the League, made mothers better people in the present. However, League publications, especially those written by advisor Herbert Ratner, also frequently suggested, confusingly, that breastfeeding does not necessarily make women better people, but that it is women who are already better people who choose to breastfeed. For instance,

\footnotetext{
${ }^{47}$ Ruddick, Maternal Thinking. Ruddick still suggests that most mothers develop "maternal thinking" and although she does include non-mothers who practice mothering in her paradigm, her underlying constructions of mothers and children have been critiqued as excessively universalizing. See Ruddick's reflection on these critiques and her original , Sara Ruddick, "On Maternal Thinking," Wsq: Women's Studies Quarterly 37, no. 2 (2010), 305-08.

${ }^{48}$ Cited in Cahill, Seven Voices One Dream, 52.
} 
Ratner claimed that " $(\mathrm{t})$ he willingness of a mother to be 'tied to her baby' by nursing becomes the first sign that she is ready to accept the obligations of motherhood." ${ }^{49}$

Although maternalism is tied strongly to belief in biologically determined gender roles and has thus had an uneasy relationship with other branches of feminism that sought to eradicate such dichotomies, LLL shared kinship with mainstream mid-twentieth century feminism on another level. The League's small group meeting arrangement was similar to the Consciousness-Raising (CR) strategy later employed by proponents of women's liberation, beginning in the late 1960s. CR involved women meeting in small groups to reflect in a structured manner on their experiences of gender oppression in contemporary patriarchal society. Drawing out common themes across the stories of group members led many women to the realization that "the personal is political." That is, that experiences each woman had felt were the result of her particular life circumstances were actually shaped by patriarchal structures that acted upon all women and therefore far from unique. ${ }^{50}$ Weiner has pointed out the similarities between $\mathrm{CR}$ and the League's organizing strategy (which predated CR by over a decade), saying that both "made common the problems of individual women and nurtured their sense of belonging to a special subculture." ${ }^{51}$ However, early feminists attributed women's oppression to patriarchy and sought equal access to the public sphere by the acquisition of political and economic rights for women. By contrast, the League did not seek access to the public sphere, which they viewed as corrupt. Instead they sought to increase societal regard for

\footnotetext{
${ }^{49}$ Cited in Mary White, "Mary White Reviews," La Leche League News 1, no.3, n.p. ${ }^{50}$ Kathie Sarachild, "A Program for Feminist 'Consciousness Raising,"” in Notes from the Second Year: Major Writings of the Radical Feminists, (New York: Radical Feminism), 1970.

${ }^{51}$ Weiner, "Reconstructing Motherhood," 1362.
} 
"womanly" values and women's historical, natural, domestic roles. Weiner sums up the complexities of LLL's relationship with feminism, saying that LLL "reconstructed mothering in a way that was both liberating and constricting and so ironically offered both prologue and counterpoint to the emerging movement for women's liberation." 52 I argue that the League's particular emphasis on the oppressive power of novel contemporary medical and capitalist institutions, which did not exist in the past or the undeveloped world, as opposed to patriarchy, class or other structures of inequality, which have existed in various forms throughout time and space, led them to assume that women in the past and in traditional communities did not experience much oppression at all, at least within their maternal roles.

The League's founders were all part of a particular midcentury, Midwestern Catholic subculture. In the Chicago suburbs where they lived the founders were able to interact primarily with other Catholics who shared similar religious and social values. Feminist theologian Jule DeJager Ward has shown that the League's organizing strategy was modeled, consciously or unconsciously, on midcentury Catholic social movements, especially the Christian Family Movement mentioned above. CFM was a radical movement among the Catholic laity, an offshoot of the Young Christian Workers (YCW), which was based on the teachings of the Belgian priest Joseph Cardijn. ${ }^{53}$ All seven of the League's Founders as well as advisors Gregory White and Herbert Ratner, participated in

\footnotetext{
${ }^{52}$ Weiner, "Reconstructing Motherhood," 1381.

${ }^{53}$ Two-Edwina Froehlich and Viola Lennon — had also previously been active in the related organization, Young Christian Workers, on the national and international level, as single women addressing issues faced by working women as well as the role of the laity within the Catholic Church. See Margery Frisbie, An Alley in Chicago : The Ministry of a City Priest (Kansas City, MO: Sheed \& Ward), 1991.
} 
CFM. Additionally, both Edwina Froehlich and Viola Lennon had been highly involved in YCW at the national level, with Froehlich having served as its first national president. According to Ward, CFM "focused on the relationship between society and the family," bringing families together in a linked network of small groups to discuss and engage in social justice both locally and globally, following the process "observe, judge, act." ${ }^{\text {,54 }}$ Beyond organizing strategy, the League also shared with CFM and YCW a particular view of "nature." Reflecting on her decision to become involved in the League, Viola Lennon said that YCW had been one of the most potent influences in her life up to that point, encouraging her to "cooperate with nature" because doing so was "one of the major tenets" of YCW. Lennon felt that "(m)arrying and having children just seemed to fit in with that philosophy of 'doing things naturally." "55 Ward suggests that this view of nature was linked to midcentury American Catholic views which, in turn, were based on Enlightenment views of natural philosophy. This link is most often merely subtext that comes through in the League's assertions about "Nature's plan," but at times it is explicit, particularly in Ratner's writings as he cites Rousseau and G.K. Chesterton. ${ }^{56}$

Ward has also evaluated how LLL's maternalist feminism intersected with medical science and Roman Catholic theology, particularly in the League's early years as the founders were establishing its philosophy. Ward suggests that the League was not always aware of the contradictions between these influences or even that they were referencing them. According to Ward, this lack of awareness led to two main problems.

\footnotetext{
${ }^{54}$ Ward, La Leche League, 144.

${ }^{55}$ Cahill, Seven Voices One Dream, 18; See also Frisbie, An Alley in Chicago.

${ }^{56}$ Ratner, Foreword to The Womanly Art of Breastfeeding, $2^{\text {nd }}$ ed., 3; Ward, La Leche League, 129.
} 
First, the League's efforts to appear scientifically objective impeded both their scientific and religious arguments. Relying on medical studies to support their recommendations has left the League's advice "vulnerable to scientific counterclaims." ${ }^{, 57}$ At the same time, the League alluded to a morality intrinsic to mothering through breastfeeding — putting the needs of the most vulnerable first—which "may actually stand on firm moral ground which the League neglects to claim," either for fear of alienating people of different beliefs or because this argument cannot be substantiated by scientific research. ${ }^{58}$ Second, the Catholic heritage of the League's founders and many of its early members and advisors profoundly, if subconsciously, shapes their construction of gender roles. Their "adherence to unacknowledged religious metaphors for family life" leads them to embrace "traditional Christian beliefs about essential differences between men and women" which were always incompatible with contemporary society but became increasingly alien over the decades. ${ }^{59}$ Ward argues further that the midcentury Catholic notion of gender complementarity is of debatable theological soundness, anyway. Ultimately, Ward says, the League's embrace of biological and religious constructions of gender roles leads to a "central paradox" in League philosophy: "The women of the League fully acknowledge that breast feeding is a learned art. Despite this recognition, they also wish to claim for mothers a certain instinctual knowledge, something that gives them an edge over expert advice, something particularly womanly." ${ }^{60}$ Overall, the League's combination of maternalist feminism, science and theology combines in a

\footnotetext{
${ }_{58}^{57}$ Ward, La Leche League, 5.

${ }^{58}$ Ibid.

${ }^{59}$ Ibid.

${ }^{60}$ Ward, La Leche League, 161.
} 
"quasi-religious narrative" where "distinctions between what is literal and what is metaphorical blur" and "verifiable scientific realities are sometimes unconsciously linked to the metaphors and symbols of Christianity." ${ }^{, 61}$ Thus, for Ward, in early League writings, evolution, a personified "Nature," and God traded off responsibility for creating the world, but all three had a "plan" for humanity. I add to Ward's argument that the League was able to smoothly elide mythical stories of the dawn of man and scientific theories of human origins because both types of accounts are largely ahistorical acts of memory that use contemporary evidence to metaphorically explain or hypothesize about the distant past.

Other scholars have similarly noted a tension in the convergence of some of LLL's seemingly incongruous intellectual and cultural influences. Chris Bobel's analysis of the League and of similar strands of "natural motherhood" in the late twentieth century points to a mix of ideologies similar to those listed by Ward. Despite the passage of time, the only major difference in Bobel's analysis is that a philosophy of nature has largely taken the place of Catholic faith among the women she studied. According to Bobel, "(i)t might be an overstatement to claim that the natural mothers have replaced God or Man as the authority that dictates a life course with nature as represented by the body, but perhaps not." ${ }^{\prime 62}$ Like Weiner and Ward, Bobel suggests that La Leche League responded to the contemporary contradictions of motherhood (as elucidated by Hays), not by forcing mothers to walk a tightrope between private and public values, but by pushing them to reject the public in favor of the private. For natural families, the compromise continued to

\footnotetext{
${ }^{61}$ Ward, La Leche League, 1-5.

${ }^{62}$ Bobel, The Paradox of Natural Mothering, 99.
} 
be that mothers, based on their deeper natural connection to their children, remain in the home, while fathers take jobs outside the home, perhaps even working extra hours to support their growing families. This compromise engendered its own paradox, wherein mothers are expected to change the public sphere while existing entirely outside of it. In an unusual perversion of the above-cited feminist mantra that "the personal is political," instead of recognizing how political structures influence even the intimate details of their personal lives, these women viewed their personal decisions as having far-reaching political implications. Yet, how household decisions can truly impact society on the macro scale is not elucidated in these women's ideology. Further, they failed to acknowledge the ways in which their actions served the interests of existing power structures:

The authority women 'enjoy' in the home operates as an illusion of power and self-determination or, in Foucauldian terms, a form of the 'invisible' internalized power of the state. Because women 'buy into' this logic, enforcement (by men, institutions, or both) is rendered virtually unnecessary; women police themselves as good mothers and good wives who protect the socially constructed boundary between women and men. ${ }^{63}$

Bobel has suggested that while League and other natural mothers claim to be actively choosing the domestic values Hays describes (which they construct as "natural") their actions do not reflect those of autonomous agents, but rather those of "an individual dutifully following a script." This script is derived from "biologically determinist and historically gendered ideas about women, mothers, and families." ${ }^{.64}$ Per Bobel, "The choice to embrace the ideology of 'nature is best' was, in a sense, the last choice they

${ }^{63}$ Bobel, The Paradox of Natural Mothering, 46

${ }^{64}$ Bobel, The Paradox of Natural Mothering, 99. 
made. ${ }^{.65}$ For these women, the natural was so obviously superior to its opposite- - the cultural — that choosing to embrace nature was the only rational choice.

Although since the beginning the League's founders and members acknowledged that social pressures can make breastfeeding unpopular and difficult, they still tended to construct breastfeeding as a choice made by individual women. This notion of choice originally provided women who did breastfeed with a sense of validation and accomplishment for overcoming various obstacles to breastfeeding. However, as breastfeeding became more and more the recommended and socially valued method of infant feeding from the 1980s to the present, the construction of choice can leave mothers feeling intensely guilty for choosing not to breastfeed. The League has failed to recognize that their breastfeeding advocacy may have become just as coercive as the antibreastfeeding climate of the mid-twentieth century. Philosopher Rebecca Kukla argues that turn-of-the-millennium breastfeeding advocacy messages often created an exaggerated opposition between the interests of a mother and those of her child. This rhetoric constructed breastfeeding as nearly always in the infant's best interest while artificial feeding nearly always served the mother's interests. Moreover, the infant's desire to breastfeed was purely unselfish instinct, and meeting this need promoted not just the health and cognitive and emotional development of individual infants, but those of whole populations. By contrast, reasons a mother might not breastfeed were construed as, if not outright selfish, at least morally suspect due to association with market and social interests. ${ }^{66}$ Trying to convince mothers to breastfeed based on these contrasting

\footnotetext{
${ }^{65}$ Bobel, The Paradox of Natural Mothering, 98.

${ }^{66}$ The original manual suggests that bottle-feeding spread because it was "new" and "talked about," La Leche League of Franklin Park, The Womanly Art of Breastfeeding, 1.
} 
interests, says Kukla, would "either fail to increase breastfeeding rates, or, if it does talk some women into breastfeeding, it may do so at the cost of their emotional, physical, social, or economic security." ${ }^{97}$ According to Kukla, acting in the mother's interests ultimately serves the child because what is detrimental to the mother is detrimental to her child. For instance, if a mother is excessively stressed by trying to balance breastfeeding with her other obligations or if she must cut back her paid working hours to successfully breastfeed, the child will eventually feel negative effects. Kukla suggests that "we need to correct the extent we try to protect infant health—not to mention the health of the nation — by trying to fix mothers' characters, at the level of their personality and their choices, rather than working to change the socially embedded status of maternal practices so as to make healthy choices more workable. ${ }^{, 68}$

La Leche League has advocated on behalf of women who have faced discrimination as a result of breastfeeding, one notable early example being Iowa firefighter Linda Eaton. In 1978 Eaton was sent home without pay for nursing her son in the women's locker room at the firehouse. As the incident gained national attention, $\mathrm{La}$ Leche League, along with the National Organization for Women, rose to defend Eaton and accuse her employer of sex discrimination. However, while they have stood behind women who have struggled against constraints on their ability to balance work and breastfeeding, the League has continued to promote individualized solutions, rather than

Herbert Ratner wrote that infant feeding shifted in response to the "vagaries of women, the styles of the time, and cultural pressures," Herbert Ratner, Foreword to La Leche League of Franklin Park, The Womanly Art of Breastfeeding, $2^{\text {nd }}$ ed., v-vi.

${ }^{67}$ Rebecca Kukla, "Ethics and Ideology in Breastfeeding Advocacy Campaigns," Hypatia 21, no. 1 (2006), 177.

${ }^{68}$ Ibid. Emphasis in original. 
advocating for more mother-friendly workplaces. As the world's largest breastfeeding advocacy group, the League would form a significant lobby in favor of legislation or corporate policies supporting more mother- and breastfeeding-friendly employment practices (paid maternity leaves, pumping or nursing facilities, break time for pumping or nursing, on-site child care, flex time, etc.) Yet, according to sociologist Linda Blum, the League has not capitalized on this potential and is rendered "remarkably disabled by its unwillingness to enter the political arena. ${ }^{.69}$ Blum suggests that the League refused to engage actively in politics for fear of stoking internal conflicts. After nearly breaking up over "the abortion issue," in the 1970s Blum says, the League refused to take a stand on any potentially divisive issue, "even on maternalist grounds." ${ }^{, 70}$ Advocating breastfeeding-friendly workplaces, particularly workplaces with pumping facilities, might help working mothers to successfully provide breastmilk to their babies, but actively promoting such arrangements could create the impression that the League supports (rather than merely tolerates) mother-baby separation, flying in the face of the League's "third concept."

Since at least the 1980s, feminists, particularly feminists of color, have highlighted the effects of the overlapping identity categories which Kimberlé Crenshaw has termed "intersectional identities." 71 In engaging with the effects of intersectional positions on women's experiences, feminists have destabilized the universal category of woman. Patricia Hill Collins and Dorothy Roberts have more specifically questioned

${ }^{69}$ Linda M. Blum, "Mothers, Babies, and Breastfeeding in Late Capitalist America: The Shifting Contexts of Feminist Theory," Feminist Studies 19, no. 2 (1993), 291-311. ${ }^{70}$ Ibid.

${ }^{71}$ Kimberle Crenshaw, "Mapping the Margins: Intersectionality, Identity Politics, and Violence against Women of Color," Stanford Law Review 43, no. 6 (1991), 1241-299. 
universal assumptions about the meaning of the category mother. Collins has pointed out that feminism's focus on "the concerns of white, middle class women" inaccurately assumes both "a relative degree of economic security exists for mothers and their children" and that "all women enjoy the racial privilege that allows them to see themselves primarily as individuals in search of personal autonomy, instead of members of racial ethnic groups struggling for power."72 Roberts has illuminated the "rhetoric and policies that degrade Black women's reproductive decisions" and that enable politicians and conservative polemicists to blame African American mothers for any number of insidious social ills including, rather ironically, racial inequality. ${ }^{73}$

Over the decades and informed by these changes in feminist scholarship and activism, La Leche League has increasingly acknowledged differences between populations of women. They partnered with governmental and non-governmental organizations such as WIC and UNICEF to train poor and minority women in the US and across the globe as peer counselors to serve within their own communities. However, these efforts remain largely outreach, separate from the mainstream of the League's organizational structure. The League also still sees the major sources of oppression for these women as science and consumerist capitalism, albeit exaggerated by poverty and minority status, rather than patriarchy or other class ideologies. Further, despite increased engagement with mothers of diverse backgrounds, as described above, LLL has

\footnotetext{
${ }^{72}$ Patricia Hill Collins, "Shifting the Center: Race, Class and Feminist Theorizing About Motherhood," in Maternal Theory: Essential Readings, ed. Andrea O'Reilly (Toronto: Demeter Press, 2007), 313.

${ }^{73}$ Dorothy Roberts, Killing the Black Body: Race, Reproduction, and the Meaning of Liberty, (New York: Pantheon Books), 1997, 3.
} 
not revised its written philosophy since 1981, and their ideology continues to be rooted in a universalist construction of motherhood and breastfeeding.

Integral to this universalist construction is the belief that most women in the past lived according the League's mothering and breastfeeding ideals. Bobel explains that the natural mothers she studied understood themselves as not just promoting natural values and family structures, but as recovering values and structures that existed at some time in the past. These late twentieth-century mothers believed they were living a "lifestyle that harks back to older, more rigidly defined gender roles, a time when women provided unpaid labor to family and home while men worked for pay in the public sphere."74 This construction of history, according to Bobel "is bounded by class and race and is, moreover, in many ways illusory." ${ }^{, 75}$ Nevertheless, Bobel's natural mothers believed that this history existed and therefore viewed their efforts to change society as simultaneously revolution and renaissance. The League's founders had similarly envisioned their organization as an intentionally created community that could replace some of the key functions of historical female kin and village networks, while disrupting contemporary constraints on breastfeeding. As the founders had put it forty years before Bobel's studies, “(b)reastfeeding is part of a womanly heritage, and it would naturally follow, in fact it seems almost inevitable that mothers should initiate the revival in breastfeeding.,"76

The notion of revival was central to a 1987 study by anthropologist Elizabeth Bryant Merrill that analyzed the structure and function of a local LLL group. According to Merrill, the League's mothering culture was transmitted through "intragenerational

\footnotetext{
${ }^{74}$ Bobel, The Paradox of Natural Mothering, 101.

75 Ibid.

${ }^{76}$ La Leche League International, The Womanly Art of Breastfeeding, 2.
} 
modeling" or "cofiguration," a process wherein peers actively seek to learn from one another's mothering experiences. ${ }^{77}$ This stands in contrast to the intergenerational modes of transmission the founders believed to have dominated in the past, in which women learned about mothering relatively passively, by being mothered as infants and then by observing and practicing mothering behaviors as children and young adults. Although the League had existed when most of Merrill's ethnography subjects were young, most of the women she studied had not been breastfed as infants and therefore had not had the opportunity to passively absorb "mothering through breastfeeding." Thus, peers, rather than elders, were the most readily available role models for these women. ${ }^{78}$

In addition to describing the transmission of League culture, Merrill characterized the League as a "nativistic movement." According to Ralph Linton, a nativistic movement is "any conscious, organized attempt on the part of a society's members to revive or perpetuate selected aspects of its culture." More specifically, the League was a "perpetual-rational nativistic movement." ${ }^{, 79}$ The main purpose of this sort of movement is "the maintenance of social solidarity. The elements selected for perpetuation become symbols of the society's existence as a unique entity. They provide the society's members with a fund of common knowledge and experiences which is exclusively their own...." According to Linton, nativistic movements are typically associated with indigenous cultures seeking to counter colonial influences, but "dominant as well as dominated groups" can initiate such movements. ${ }^{80}$ The founders of La Leche League and

\footnotetext{
${ }^{77}$ Merrill, "Learning How to Mother," 223.

${ }^{78}$ Cited in Merrill, "Learning How to Mother," 222-223.

${ }^{79}$ Merrill, "Learning How to Mother," 223.

${ }^{80}$ Ibid.
} 
the majority of the women who have formed their core membership in subsequent decades can be considered both dominated and dominant. They were dominated by an authoritarian healthcare system and a capitalist economy which devalued women's reproductive and caregiving capacities. Yet they were dominant in their status as white, educated, heterosexual, married, and middle-class. The "culture" the founders and their heirs over the decades wished to revive was that of "mothering through breastfeeding." Women's domination by scientific healthcare and consumer capitalist systems had created a rupture in this imagined historic, female culture. Despite this, once their movement had begun, the founders' and League members' dominant class and race status helped to facilitate its spread. The League's founders and most of its participants have possessed the social and cultural capital to successfully resist their domination and to make alliances with influential figures within the dominant systems, such as Ratner and Gregory White and the other scientists and physicians who have served on the League's Professional Advisory Board. Their racial and class identities have also profoundly shaped their vision of what mothering entails, particularly their assumption that mothering occurs within an egalitarian, heterosexual marriage in which the husband works outside the home to support the wife's mothering activities in the home. Even as the League increasingly engaged with women of different backgrounds, they continued to try to fit these women's mothering experiences into a model based on a midcentury, American, white, middle-class, heterosexual, married, Catholic perspective.

${ }^{81}$ Paige Hall Smith, "Is It Just so My Right?" Women Repossessing Breastfeeding," International Breastfeeding Journal 3, no. 1 (2008), n.p. 
More recently, public health scholar Paige Hall Smith has characterized La Leche League similarly to Merrill, though using a slightly different framework. For Smith, the La Leche League of the early 2000s employed a strategy of repossession, which is "commonly used by women and other groups who have experienced oppression as a way of reconnecting to previously alienated parts of their bodies, experiences and lives." ${ }^{, 82}$ Repossession entails three steps: reconnecting, redefining and normalizing. ${ }^{83}$ Like Merrill's assessment, Smith's entails a central conviction that women are recovering a practice and community that have historical roots. I add to this a focus on the acts of creation necessary to integrating supposedly traditional practices and communities with actual contemporary social situations and the cognitive leaps necessary to see continuity in the face of obvious disruption.

Like other mutual support groups, much of La Leche League's communication with its membership has taken the form of small group meetings where individuals relate first person testimonials. Merrill had previously described how, although mothers moved in and out of a LLL group depending on their interest and the age of their children, a core body of mothers generally attended meetings on a regular basis. A Leader became familiar with the stories of the core mothers and could appeal to them when she wanted to illustrate a particular theme to new mothers. The core mothers learned the routine, and shared stories that fit the theme when prompted or when they saw an appropriate opening. Smith saw the same process twenty years later, describing it with slightly

\footnotetext{
${ }^{82}$ Ibid.

${ }^{83} \mathrm{Ibid}$. Smith draws the three-step repossession framework from C. Matria and Patricia Mullen, "Reclaiming Menstruation." Women \& Health 3, no. 3 (1978), 23-30.
} 
different language, pointing to a relative stability in the League's communicative strategies across time.

The stories shared at League meetings form a large portion of the organization's institutional knowledge. Merrill described these stories as a "body of oral tradition that is transmitted and modeled with some predictability for new people, while giving support to group members." ${ }^{84}$ This institutional knowledge allowed the group to reproduce itself as new mothers learned and added to the repertoire. However, while, as Merrill pointed out, Leaders actively strove to shape new members' engagement with the League's collective memory, this body of knowledge inevitably evolved and was reinterpreted to a certain extent as new generations of women moved through the organization. ${ }^{85}$

More broadly, the League's communication styles and strategies have reflected efforts to create a cohesive communal identity, following trajectories similar to those of early nationalists, as described by Benedict Anderson. For Anderson, to build a nation requires building a national consciousness based largely on shared bodies of knowledge, ways of communicating, and experiences of externally imposed constrictions. ${ }^{86}$ Since 1956, LLL participants have described and spread a sort of breastfeeding consciousness or League consciousness in group meetings and through their publications. At League meetings, Leaders provided specific breastfeeding information and advice in response to questions, but the bulk of the exchange typically consisted of one mother sharing a joyful

\footnotetext{
${ }^{84}$ Merrill, "Learning How to Mother," 236. ${ }^{85}$ Ibid.

${ }^{86}$ Benedict Richard O'Gorman Anderson, Imagined Communities : Reflections on the Origin and Spread of Nationalism, Rev. ed. (London: Verso), 2006. In Anderson's model, for early anti-colonial nationalists, printed works in Latin and vernaculars made up the shared bodies of knowledge and communication, while colonial boundaries and bureaucracy represented a major shared constraint.
} 
or frustrating mothering experience, followed by a chorus of others affirming her feelings and recounting similar experiences. This breastfeeding information and the communal pool of shared experiences represent collective bodies of knowledge. In analyzing the recurring themes of their stories, mothers have been able to name the externally imposed constraints on their mothering: healthcare systems, capitalist values, and workplace structures, all of which paid lip service to women's breastfeeding and mothering, but in practice engendered doubt in women's maternal capacities and placed higher value on their productive and sexual roles.

In the burgeoning suburban environment of the 1950s in which the League arose, many middle-class mothers were transplants with little or no family or community support in their new neighborhoods. To unite these women, who often began by feeling isolated from one another and from society at large, into a meaningful community, the League needed to emphasize their shared qualities. For Anderson, highlighting unifying characteristics and goals, and thereby creating a shared identity, is essential to creating a functional collective. For early second wave feminists, the shared identity was "woman," a construction based on biological difference from and social subordination to men. For La Leche League, the more narrow shared identity was "breastfeeding mother," a construction which encompassed traits—-naturalness, sensitivity, caring — and practicesnurturing, cleaning, feeding — assumed to be intrinsic to breastfeeding and motherhood. Biological difference from men was also central to the identity of breastfeeding mother, as was subordination to male medical experts, but broader patriarchal and class-based subordination was not part of LLL's collective identity. 
In emphasizing shared traits, groups also minimize differences, both past and present. Anderson cites nineteenth century theorist Ernest Renan, who said that "the essence of a nation is that all of its individual members have a great deal in common and also that they have forgotten many things. ${ }^{, 87}$ That is, a nation has forgotten the divisions that previously kept it from unity and the violence that has brought it together.

References to a shared past are potent in developing unity as not only do they foster a sense of common heritage and fate, but they also allow present sources of inequality and difference to be glossed over: even if class or other distinctions matter now, travelling far enough into the past can render them moot. Halbwachs suggests that "one can escape from society only by opposing to it another society." $" 88$ That is, even if the present is oppressive, the past can always be viewed as less so. It does not really matter if the past was actually less oppressive because from the perspective of the present it always is: the past no longer exists and thus no longer holds the power to actively oppress anyone. ${ }^{89}$ For La Leche League, the past was a time before the rise of interventionist maledominated medical systems and consumerist values. Without analyzing the past in its own right, the absence of these particular oppressions gives the illusion of a past without any oppression.

In Halbwach's explanation of collective memory, the past is mythologized as it is conflated with nature, childhood and innocence. Further, he says, memory seeks continuity, as opposed to history which seeks change and upheaval, and memory looks to

${ }^{87}$ Cited in Anderson, Imagined Communities 204.

${ }^{88}$ Halbwachs, On Collective Memory, 49.

${ }^{89}$ Ibid. Of course, the past does continue to affect many institutions and ideologies, but through the passage of time these have become present institutions and ideologies. 
the past for a glimpse of an earlier self rather than to see the past in and of $i t s e l f .^{90}$ Michael Kammen similarly highlights that memory is focused not on the past but on the relationship between the past and the present. For Kammen, the usefulness of a memory or tradition often trumps accuracy as "(w)e arouse and arrange our memories to suit our psychic needs. ${ }^{91}$ La Leche League's collective memory of motherhood as uniform and universal throughout all of pre-modern history, filled psychic needs for purpose and status: women exist to be mothers, and mothers perform a noble, necessary function.

Halbwachs describes the human tendency to nostalgia, in which people "adopt in regard to times past the attitude of the Greek philosophers who put the golden age not at the end of the world but at its beginning." ${ }^{.92}$ In a large qualitative survey, Roy Rosenzweig and David Thelen found this perspective to be particularly marked in white Americans, who view history, at least recent history, as a story of decline. African Americans, by contrast, highlight progress and achievements, chiefly citing the Civil Rights movement. ${ }^{93}$ Although most League participants over the decades have been white, the League has exemplified both of these tendencies at different times. In the early years, the League's founders viewed the early- to mid-twentieth century as a period of social decline. Even in the twenty-first century League members still sees the present as inferior to the pre-modern past in many ways: hospitals and doctors still unnecessarily impede breastfeeding, cultural taboos against breastfeeding in public continue, and

\footnotetext{
90 Ibid.

${ }^{91}$ Michael Kammen, Mystic Chords of Memory, The Transformation of Tradition in American Culture (New York: Vintage Books), 1993, 9.

92 Halbwachs, On Collective Memory, 48.

${ }^{93}$ Roy Rosenzweig and David P. Thelen, The Presence of the Past : Popular Uses of History in American Life, (New York: Columbia University Press), 1998, 116.
} 
consumerism continues to flower. However, as the League has grown in size and impact, its members have been quick to remark on the contributions they have made to shaping more sensitive and scientifically informed maternal and infant care, to improving maternal and infant mortality rates in the developing world, and to increasing public acceptance of breastfeeding (even if they still have a long way to go).

In summary, although in recent decades the League has claimed that they have brought about radical developments in women's experience of empowered motherhood, their guiding philosophy has remained unchanged and therefore largely uninfluenced by the organization's engagement with feminism or multiculturalism. The League's institutional memory has imposed a presentist slant on the organization's history, reading into it varieties of feminist and multi-cultural engagement that are not borne out by the tangible historical evidence of their own writings and those of their contemporaries. The League continues to construct any motherhood that falls short of their ideal as a compromise, and while they may sometimes see such a compromise as understandable or even unavoidable, they always see it as unfortunate. The League's uncompromising philosophy has remained firmly rooted in their original universalizing, positivist conviction that there is one mothering ideal whose embodiment can be found somewhere, or even everywhere, in the premodern past. 


\section{BUILDING COMMUNITIES OF MOTHERS}

\section{Introduction}

At that picnic in the summer of 1956, Marian Tompson and Mary White had experienced a shared revelation. Tompson recalled that prior to that day she had thought "the women who were bottle-feeding simply preferred to feed their babies that way." Hearing from so many women, one after another, about how they had wanted to nurse but failed destroyed Tompson's illusion: “That's when it really hit us that the problems we had had in trying to nurse our babies were common to a lot of other mothers. It wasn't just Mary’s particular rare problem or my particular rare problem."94 Tompson and White felt they had to do something to help these women.

Interestingly, although the two women had finally succeeded in breastfeeding thanks to the advice and encouragement of White's doctor husband, Gregory White, they saw the solution for other women's breastfeeding struggles along a somewhat different path. Instead of the help of a doctor, Tompson and White felt that these women needed support and information from other mothers. They believed this "mother-to-mother" model would be best for two main reasons. First, unlike Gregory White, most American physicians of the day were ill-informed on breastfeeding physiology and practice. Most doctors considered breastmilk to be superior to cow's milk formulas, but the advantage

\footnotetext{
${ }^{94}$ Cited in Cahill, Seven Voices, One Dream, 23; Cited in Lowman, LLLove Story, 11.
} 
was mostly theoretical because breastfeeding was very tricky for mothers to do correctly. These doctors would be of little help in counseling a breastfeeding mother, even if they did not pressure her to stop breastfeeding altogether. Second, White and Tompsons saw male obstetricians and pediatricians as newcomers to the field of breastfeeding management whose input was only necessary in unusual cases. White and Tompson and their fellow League founders believed that breastfeeding was "strictly a woman's art, to be passed on from mother to daughter." 95

The League's founders believed that breastfeeding strategies, such as how to latch the baby properly to the breast and how long to nurse on each side, had historically been learned largely through passive observation of female kin and neighbors, with any difficulties best managed under the advice of this traditional female community. In her 2011 memoir, Marian Tompson emphasized the perceived ancient heritage of this type of female network, saying “(m)other-to-mother support was not a new idea-women have been supporting other women for millennia." The primary difference was that La Leche League would be "an organized effort to take advantage of the natural way women have of helping each other."96 This view reflects an imagined continuity between the women of the League and women throughout the past. However, the primary aim of Tompson's statement was to bolster a sense of shared heritage and identity within the community she had helped to create, La Leche League, rather than to demonstrate a verifiable link with any particular historical community or practice. Further, by emphasizing that women have behaved this way for “millennia," Tompson's statement downplays the intentionally

\footnotetext{
${ }^{95}$ La Leche League of Franklin Park, The Womanly Art of Breastfeeding, 2.

${ }^{96}$ Marian Leonard Tompson, Passionate Journey: My Unexpected Life (Amarillo, TX: Hale Pub), 2011, 62.
} 
constructed nature of the League, which critics might construe as artificial or a product of a specific cultural milieu (as I contend) by suggesting that the League mimics more organic, enduring female collectivities from more natural times. Tompson and the other League founders felt that these matrilineal kin groups, along with the natural mothering practices they fostered, had been eroded in large part by male doctors and the highly interventionist healthcare system they had created. Also to blame was the consumer capitalist economy that valued the new and scientific - like male doctors-over the traditional and natural—like female knowledge and kin networks. This chapter traces LLL's efforts to build communities of women starting in the late 1950s and to promote the notion that these new communities formed part of a timeless tradition of female social support and shared, embodied maternal experiences.

\section{Collective Identity in Contemporary Communities of Mothers}

As a mutual support group, a central part of La Leche League's communication strategy was to share individual, personal stories of breastfeeding and motherhood in a communal setting. As Merrill described, League Leaders continually assembled, interpreted and repeated (or encouraged others to repeat) participants' stories to highlight themes that reinforced the League's underlying philosophy. ${ }^{97}$ These stories thus served simultaneously as one of the sources of LLL's growing body of institutional knowledge and as a means for communicating the League's existing institutional knowledge. These narratives of personal experience also embodied the collective memory of the League. The stories were shaped initially by the way in which the mothers telling them viewed

${ }^{97}$ Merrill, "Learning How to Mother." 
their place in the arc of history, as part of a continuous tradition, pioneers of a new frontier of motherhood, or somewhere in between.

Since they were a single-issue organization focused on breastfeeding, La Leche League attracted many women who already shared similar values regarding motherhood and family life. But, when women did not share these values, Leaders strove to “"(bring) the mothers around' to the correct way of mothering" through discussion and role modeling. ${ }^{98}$ Thus League meetings, and the organization at large, served as a kind of echo chamber, where mothering values were shared, repeated and amplified. The League constructed mothering and breastfeeding as transformative, and they viewed participating in the League as similarly important in shaping women's views. Through the League, participants, including the founders themselves, learned to put words to the new insights and feelings they were experiencing. Edwina Froelich recalled the powerful impact that the first meetings with the other founders in the planning stages of the League had had upon her.

The meetings did so much for me.... They confirmed everything for me, put everything into words. I had a lot of inner feelings about babies and breastfeeding, and I hadn't had another mother to share them with. None of us who founded the League had ever before really shared with each other the depth of our feelings about breastfeeding and mothering until we got together at that first meeting....The meetings were reinforcing, removing the last vestiges of doubt, broadening my thinking....It is so important to find someone who shares an important feeling with you. When something is really important to you, you want to share it with someone else who thinks it's important, too. That's what made the League work. ${ }^{99}$

Developing these relationships based on shared values was one of the keys to the League's enormous success.

\footnotetext{
${ }^{98}$ Merrill, "Learning How to Mother," 235.

${ }^{99}$ Cited in Lowman, LLLove Story, 16.
} 
The founders had originally envisioned the League as a small group to help their friends and neighbors who wanted to breastfeed, but the women who participated were so pleased with the League that not only did they tell their friends about it, but they also kept coming back to meetings even after they had technically "graduated" from the four Series Meetings. ${ }^{100}$ In describing how the League crystalized its mission of "mothering through breastfeeding," rather than simply breastfeeding, Mary Ann Cahill said that "talk" was what kept women coming back to the League: "For between and around and after the words on know-how and statistics at the meetings is the talk of the mothers about their nursing experiences...Talk that has a constantly recurring theme....A them first sensed, gradually understood and absorbed, finally realized by a mother as she nurses her own baby." "101 The second edition of The Womanly Art of Breastfeeding likewise emphasized that the organization was based on personal relationships and conversations, "the League is by no means an impersonal, highly organized association. Rather we are most informal, trying to keep everything on the basis of friendly conversations between mothers. You can think of La Leche League, if you like, as a woman with a baby in her arms and a smile on her face...."102 The founders had personally experienced a sense of camaraderie and validation when they had first come together to plan the League and discuss their views about motherhood. They strove to recreate that warm, personal

\footnotetext{
${ }^{100}$ La Leche League of Franklin Park, The Womanly Art of Breastfeeding, 1. The original manual makes clear that women were originally intended to participate in one series, graduate, and move on.

${ }^{101}$ Cahill, "A Backward Glance and Forward Look," 1. Emphasis in original. The League settled upon this mission in a conversation among the founders and early League board members, Gregory White and Herbert Ratner, with Ratner serving as moderator. A transcript of this conversation is available in "A La Leche League Dialogue: An Historic Document," Child and Family 13, no. 3 (1974).

${ }^{102}$ La Leche League International, The Womanly Art of Breastfeeding, $2^{\text {nd }}$ ed., 154.
} 
experience for other women whether they came to a meeting or read the League's manual.

The League made a point of teaching its Leaders communications skills and maintaining open lines of communication with the organization. The first issue of Leaven, the League's publication directed at Leaders and active members, stated that "communication is a two-way street, so we welcome suggestions from YOU as to how (Leaven) can better serve this purpose. We'll have a column called 'Listen, Please!' Here we will print what you write in to us. Criticism and compliments will be welcome. This will be YOUR say-so, and all the rest of us will 'listen."'103 Leaven encouraged Leaders to turn to one another for information and support: "In our ten years of working together, LLLI Board Members have learned the tremendous value of talking things over with each other, thereby increasing our knowledge and understanding." ${ }^{104}$ It also emphasized that women uninterested in breastfeeding should not be solicited by Leaders to attend Meetings, but rather that initial curiosity about breastfeeding is best spread organically, through "the motherly grapevine" in a "one-mother-tells-another plan" that "works over coffee, over the back fence, in the supermarket, laundromat, doctor's office, maternity floor, etc." 105 The Leader's Handbook likewise underscored the primacy of communication in forming relationships, stating that “(a) Leader's first goal when helping a mother is to establish rapport; her second goal is to share information."106

\footnotetext{
${ }^{103}$ Leaven 1, no. 1 (1965): 1.

104 “Advice When Speaking to Doctors," Leaven 1, no.2 (1965), n.p.

${ }^{105}$ Leaven 1, no.3 (1966), n.p.

${ }^{106}$ Dor Sachetti, ed., La Leche League International Leader's Handbook, $3^{\text {rd }}$ ed. (Schaumburg, IL: La Leche League International), 1998, 11.
} 
The League's communication skills earned them recognition from other organizations. In a 1985 letter to President Ronald Reagan nominating the seven League founders for the Presidential Citizens Medal, a UNICEF representative explained that, in their efforts to promote breastfeeding, UNICEF field offices worked with LLL groups from the local to the national level and used LLL materials to "advocate and teach breastfeeding techniques to doctors, nurses, para-professionals and mothers." Moreover, the letter goes on to describe how, beyond breastfeeding information, the League holds particular skill in creating successful peer support groups. It is worth quoting the letter at length to demonstrate this point:

The emphasis of LLL activities is on enhancing the self-reliance of mothers and communities, i.e., helping people help themselves. LLL leaders have been the guiding force of mother-to-mother support movements in a large number of developing countries. Many more established agencies have been unable to replicate the effective, grassroots projects of La Leche League. UNICEF itself has learned much from its success in gaining the trust and confidence of mothers from all over the world. ${ }^{107}$

This is high praise from an international NGO and speaks to the level of organizing and communication skills the League had developed during their first thirty years of existence.

Over twenty years after the League was founded, Gregory White reflected on the reasons for its success. He said it was in part serendipity but it was also the result of the strong bond between the founders and their willingness to work together without concern for their egos. He surmised that the League had succeeded "because there were a number

\footnotetext{
${ }^{107}$ UNICEF, Letter to Ronald Reagan, June 24, 1985, Box 4, Folder 10, La Leche League International Records, DePaul University Special Collections and Archives, DePaul University. This copy of the letter has no signature, but it is written on UNICEF letterhead.
} 
of women interested in helping other nursing mothers who happened to live close together and who worked harmoniously together." More than this, they were able to stay focused on their singular mission because "all of them felt that the cause was more important than personalities." 108 This is an interesting assessment because the League's founders did forego individual credit much of the time, such as in the authorship of the manual and frequently referring to themselves collectively as "the Founders" or "the Founding Mothers," but they also made sure that their members and readers knew who they were, individually. In the second edition of the manual, they refer to themselves as "seven mothers, seven personalities." ${ }^{109}$ In many ways, this perspective reflects the overall tension in League ideology between breastfeeding as a learned skill developed in community versus an innate, individual ability. Sometimes the League suppressed individuality in favor of a sense of shared motherhood; other times they embraced it as part of what makes each mother, her breastfeeding experience, and her relationship with her child unique. Through this focus on personality and situational differences among the founders, the League created the impression that their type of motherhood was accessible to a wide range of women. However, most of the distinctions League publications highlighted were relatively superficial and idiosyncratic, and did not come close to addressing structural inequalities that limited less privileged women's ability to mother this way or their desire to do so.

In their writings, the founders often spoke as a unified group, directly addressing their readers as individuals. The use of the first person plural and the second person

${ }^{108}$ Gregory White, cited in Lowman, LLLove Story, 49.

${ }^{109}$ La Leche League International, The Womanly Art of Breastfeeding, $2^{\text {nd }}$ ed., 149. 
singular was pervasive and intentional in League writings, mimicking the personal relationships established in LLL groups and the conversations at series meetings. The second edition of The Womanly Art of Breastfeeding made this positionality explicit:

We have written this book especially for you.

'You' are someone who wants to breastfeed her baby, a mother who wants to give her child the very best possible start in life.

Naturally, you will want to know who 'we' are. Although all of us are mothers who enjoy nursing our babies and who want to encourage you and give you the benefit of our know-how, we have each had different experiences in gaining confidence in ourselves as nursing mothers.

So we would like to introduce ourselves individually to you, telling you a little about ourselves and our families. ${ }^{110}$

This was followed by biographical sketches of each of the Founders which include each Founder's name, her husband's name and profession, her bottle- and breastfeeding experiences, and a physical and/or character description. The prominence of the founder's husbands and children in these accounts speaks to the importance the women placed on their roles as wives and mothers. It is also worth noting that while the founders sometimes selected administrative tasks within the League based on their own employment and educational backgrounds, they also took on tasks within the League based on their husbands' professions. For example, Edwina Froelich became secretary because she had worked for many years as a secretary, and Betty Wagner chose to serve as treasurer since she had training in accounting. Meanwhile, Mary White served as a liaison with the medical community because her husband was a physician and she therefore had a preexisting relationship with a number of physicians of his acquaintance

${ }^{110}$ La Leche League International, The Womanly Art of Breastfeeding, $2^{\text {nd }}$ ed., 147. 
as well as access to his personal medical library. Additionally, Viola Lennon worked with her husband, an attorney, to draft various legal documents for the growing organization. This is not to say that White and Lennon did not have genuine interest in or knowledge about medicine or the law, it seems fairly evident that they did, but their access to resources and credibility was channeled through their husbands' professional networks.

League publications continued to share details, descriptions and anecdotes about the founders collectively and individually through the early 1980s. During this period, although other women contributed to the League's administration, the seven founders served as the most recognizable authors and editors, as well as the "main characters," of the League's various publications. Readers of League materials became familiar not only with the founders' personalities, but with their faces. Small portrait photographs appeared alongside the founders' columns in the News. The second edition of the manual contained a line drawing depicting the famous picnic that Mary White and Marian Tompson had attended in 1956, and the third edition of the manual, the first to contain photographs, featured a snapshot of each founder. Histories of the League likewise include numerous pictures of the founders and their families and extensive details about their home lives, their husbands, and their children.

The founders had always consciously cultivated a friendly and intimate tone in their writings, encouraging mothers to feel a personal connection with them as fellow mothers. The first edition of the manual assured mothers that, "La Leche League is a neighbor with something in her hand and heart to share with you." ${ }^{, 11}$ In the beginning, the League sent a handwritten note along with each copy of the original manual. This

${ }^{111}$ La Leche League of Franklin Park, The Womanly Art of Breastfeeding, 1. 
was meant to humanize the League for women who could not interact with them in person. Moreover, it provided women with a personal contact should breastfeeding problems arise. The writer of the note was often a Founder, but if it was not, the Founders emphasized their personal approval of the letter writer: "you can be sure that we know her well and consider her eminently qualified as an experienced nursing mother." 112 Many women wrote that even though they did not know the founders personally they felt as if they had a relationship with them through their publications or correspondence, a feeling that deepened the sense of community amid an ever-expanding organization. $^{113}$

\section{Collective Memory in Imagined Transhistorical Communities}

The League encouraged women to identify not just with them, but with breastfeeding mothers throughout the world and throughout history. Edwina Froehlich held strong views about natural childbirth and breastfeeding before she ever became pregnant. However, she vividly recalled the moment that her understanding of her role as a mother was crystallized, and it was not until she already had two children. Her account of this defining moment mixed religious metaphor, uniquely modern experiences, innate mothering instinct, and a sense of mystical connection to mothers throughout history. "Strangely enough," she began, "it all came together for me in a single moment, kind of like the story of St. Paul in the Bible, being hit by the bolt of lightning and falling off his

${ }^{112}$ La Leche League International, The Womanly Art of Breastfeeding, $2^{\text {nd }}$ ed., 154. ${ }^{113}$ For example, see the letters many League members wrote to President Reagan nominating the founders for the Presidential Citizens' Medal: Box 4, Folder 11, La Leche League International Records, DePaul University Special Collections and Archives, DePaul University. 
horse." 114 Froehlich was crossing the street with her two young sons when the traffic light changed and cars began to approach. Froehlich "instinctively" held up her hand toward the approaching cars. Seeing the cars stop in response to her simple gesture, she thought, "Wow! They realize that I am a mother, that I am responsible for these young lives." ${ }^{\prime 15}$ In the wake of this distinctively modern confrontation between (wo)man and machine, Froehlich began to understand her own experience in the context of motherhood throughout history:

I was just totally taken with my role as a mother, both the power and the responsibility of being a mother. I suddenly found myself thinking of the contribution that mothers make all over the world in caring for the next generation, not just in my time, but since the beginning of time. It was really what today we would probably call an 'epiphany' - a moment of enlightenment or special understanding. ${ }^{116}$

Froehlich had desired this sort of connection with mothers of the past since before her first son was born. Froehlich herself had been born at home, so she wanted to give birth at home as well. In 1950, however, this was medical and social anathema. When friends and family heard of her plans, they decried this dangerously old-fashioned notion, saying, "Edwina, that man is right out of the dark ages! He's a horse and buggy man!"117

Ultimately, Froehlich did give birth at home to a healthy son and felt that in doing so, she was both a relic and a pioneer:

So I did get a chance to live my fantasy of giving birth the way the vast majority of women had given birth down through the centuries. I felt good about that because I felt that, in delivering my babies at home, I gave a boost to the home birth movement. Later on, most of the Founders followed suit and also had many

${ }^{114}$ Cited in Cahill, Seven Voices One Dream, 67.

${ }^{115}$ Ibid.

${ }^{116}$ Ibid.

${ }^{117}$ Cited in Lowman, LLLove Story, 12. 
of their later babies at home. But I was the first, and I will always be proud of that. ${ }^{118}$

Froehlich's understanding of herself as a point on a continuum between mothers of the past and the future reveals LLL's emerging collective memory consciousness and one individual's interactions with it.

Many mothers shared with the League similar awakenings of collective memory consciousness - a sudden reflection on their place in the long arc of history - sparked by the act of breastfeeding. A mother named Meredith Arnold wrote to the News to share how much The Womanly Art of Breastfeeding had meant to her. Not only did it make her feel connected to other contemporary women who shared her values regarding mothering and breastfeeding, but it also illuminated to her a link between herself and women throughout history. On days when she had lingering doubts, Arnold said, she would reread her favorite passages and "imagine that I am a woman of the Ice Age, huddling in a cave long before the days of 'glass and rubber.' Then I just do what she must have done!"119 Another mother viewed contemporary life in the light of imagined prehistoric life, saying, that she did not believe "the modern menace, "nerves" was a legitimate impediment to nursing. She came to this conclusion by reflecting on the women throughout history who had successfully nursed in what must have been nerve-wracking environments, "I couldn't help but think of that cave woman whose success is so readily taken for granted. Perhaps her life wasn't as hurried, but there was always the possibility of the wild beast in the doorway. And who could say that a snarling, saber-toothed tiger

\footnotetext{
${ }^{118}$ Cited in Cahill, Seven Voices One Dream 68.

${ }^{119}$ Meredith Arnold, "Dear Mothers of La Leche League," La Leche League News 2, vol. 4 (1959), 1.
} 
didn't shake up even the hardiest cave mother?" ${ }^{120}$ Imagining a connection with prehistoric women helped mothers to ignore current social and technological influences on mothering because these would of course have been absent thousands of years ago.

The imagined relationship with these prehistoric mothers was not based on any concrete idea of what their lives were like, but an assumption that they must have breastfed and therefore shared some transcendent kinship as a result of this shared bodily experience. Women often experience pleasure while breastfeeding. As a woman's breast releases milk, her body is flooded with hormones and her uterus contracts rhythmically. This process and the resulting sensations are physiologically linked to sexual pleasure. Breastfeeding women in the mid- to late twentieth century often felt that they could not share these feelings with their bottle-feeding peers because they would not understand, might resent the suggestion that they were missing out, or even accuse breastfeeding mothers of being selfish or indulging in perverse sexual pleasure from their children. ${ }^{121}$ Imagining that women in the past would have understood helped women to feel like part of a trans-historical community rather than an outcast in their own time. In 1975, a mother named M.J. McNulty expanded on this mystical imagined community in the Illinois insert to the News:

Relaxed in my rocker, my mind drifts far, far back into time. I think about how Eve and other women felt nursing their babies. I believe we share feelings that smack of the mystical. We share with peasants and aristocrats, the godless and God-fearing, learned and the unlearned, the primitive and the civilized. These feelings we share seem to be innate .. not conditioned.

120 “The Modern Nursing Mother,"La Leche League News 4, no. 4, 1962.

${ }^{121}$ For an example of the negative repercussions of admitting a sexual response to breastfeeding see Lauri Umanski, "Breastfeeding in the 1990s: The Karen Carter Case and the Politics of Maternal Sexuality," in Molly Ladd-Taylor and Lauri Umansky, eds. "bad" Mothers : The Politics of Blame in Twentieth-Century America (New York: New York University Press), 1998. 
The willingness to protect one's own offspring at all costs .. pride in being able to nourish one's own body .. delighting in kissing, cuddling, nuzzling, and rocking for hours. ${ }^{122}$

Here McNulty imagines that other women shared not just the same physical sensations, but the same emotions about breastfeeding and about their children. While this may be a comforting, empowering, or awe-inspiring thought and is certainly helpful in building a community, it is highly presumptuous to assume that all people who engage in a behavior feel the same way about it. McNulty overlooked the difficult choices the "peasants" may have had to make regarding continued nursing or increased productive work and the feelings of the "aristocrats" about the propriety of maternal nursing. She did not recognize how the views of the "God-fearing" might have been shaped by their religious understanding of parental duty and Original Sin or the differences between the feelings of a mother nursing a wanted baby and one whose child was illegitimate, disabled, not the desired sex, or an economic burden. She did not begin to address the feelings of wet nurses toward their charges, or the myriad other situational differences that would significantly affect women's emotional response to breastfeeding. ${ }^{123}$

Of course, it is unrealistic to expect mothers like McNulty, the League founders, and the other women cited above to have initially known much about the variety of women's experiences of breastfeeding and infant care throughout history. When La

\footnotetext{
${ }^{122}$ M.J. McNulty, La Leche League News, Illinois Sparks and Prisms (1975), 1.

${ }^{123}$ For more on varied patterns of infant feeding and emotional responses to breastfeeding and motherhood, see Valerie Fildes, Breasts, Bottles, and Babies : A History of Infant Feeding (Edinburgh: Edinburgh University Press), 1986; Linda Pollock, Forgotten Children: Parent-Child Relations from 1500 to 1900 (Cambridge: Cambridge University Press), 1983; Vanessa Maher, The Anthropology of Breast-Feeding : Natural Law or Social Construct, (Oxford: Berg), 1992.
} 
Leche League emerged in the 1950s, the historical and cross-cultural experiences of women and children were rarely considered valid topics of scholarly research, and women's studies was only in its infancy when McNulty wrote her mystical reflection on breastfeeding mothers through the ages. However, in subsequent decades a number of researchers from a range of disciplines explored these subjects in depth. ${ }^{124}$ Historians, anthropologists, gender theorists and various scientists have demonstrated that the League was correct in their assumption that breastfeeding is generally healthier for infants than any other feeding method, that birth has typically taken place at home attended by women, that most women throughout history have breastfed their own children and that most infants have typically spent more time with their mothers than with any other individual. However, most of these scholars have also demonstrated that birth and childcare arrangements have varied greatly across time and space, and that the course and duration of maternal breastfeeding have been far from uniform. ${ }^{125}$ Although modern technological and medical innovations did shape motherhood particularly rapidly and on an unprecedented global scale, breastfeeding and childcare practices have been shaped by changing social, cultural and environmental contexts throughout history.

\footnotetext{
${ }^{124}$ See for example, Philippe Ariès, Centuries of Childhood : A Social History of Family Life (New York: Alfred A. Knopf), 1962; Barbara Welter, "The Cult of True Womanhood: 1820-1860," American Quarterly 18, no. 2 (1966), 151-74; Linda Kerber, "The Republican Mother: Women and the Enlightenment-An American Perspective," American Quarterly 28, no. 2 (1976), 187-205; Laurel Thatcher Ulrich, A Midwife's Tale: The Life of Martha Ballard, Based on Her Diary, 1785-1812 (New York: Vintage Books), 1991; Sara Blaffer Hrdy, Mother Nature : A History of Mothers, Infants, and Natural Selection (New York: Pantheon Books), 1999; David F. Lancy, The Anthropology of Childhood : Cherubs, Chattel, Changelings (Cambridge: Cambridge University Press), 2008.

${ }^{125}$ Lancy, The Anthropology of Childhood; Meredith F. Small, Our Babies, Ourselves : How Biology and Culture Shape the Way We Parent (New York: Anchor Books), 1999.
} 
Further, the emotional impact of these practices is difficult to assess even when studying contemporary women, and scholars who have studied the history of emotions caution against interpreting past behaviors and expressions of feeling through a presentist lens. ${ }^{126}$

Scholars have classified a range of models of motherhood and womanhood that have arisen at various times and various places and have identified the prevailing medical theories and economic, political and gender structures that shaped them. Thomas Laqueur's 1990 work Making Sex is a significant contribution to the study of historical gender relations. According to Laqueur, notions of the sexes as opposites date only as far back as the Enlightenment, and that from antiquity until that time medical science, philosophy and humoral science understood women as imperfect men. ${ }^{127}$ In the 1980 s and 1990s Linda Pollock wrote about the different ways parents in the early modern period understood their relationships with their children and the ways in which their expressions of their feelings toward their children have been shaped by religious and cultural ideologies. ${ }^{128}$ Pollock also analyzed childbirth in early modern England and called into question the notion of a harmonious "sisterhood" among the women who gathered to attend births. She suggested that women attended births for a variety of reasons, and offering moral support was not necessarily at the top of the list. ${ }^{129}$ Also in the 1980s, Valerie Files explored the practices of infant feeding from antiquity to the

${ }^{126}$ For a study that analyzes the emotions of living mothers see Newton, Maternal Emotions; For historical studies of parental emotions see Pollock, Forgotten Children and Linda A. Pollock, "Childbearing and Female Bonding in Early Modern England," Social History 22, no. 3 (1997), 286-306.

${ }^{127}$ Thomas Walter Laqueur, Making Sex: Body and Gender from the Greeks to Freud (Cambridge, Mass.: Harvard University Press), 1990.

${ }^{128}$ Pollock, Forgotten Children; Pollock, "Childbearing and Female Bonding in Early Modern England."

${ }^{129}$ Pollock, "Childbearing and Female Bonding in Early Modern England." 
nineteenth century and highlighted a wide range of recommendations and actual practices in infant feeding both at the breast and with various replacements and supplements. Significantly, she highlighted that, although mothers may not always have followed their advice, medical, legal, and religious authorities have sought to shape women's supposedly autonomous practices of infant feeding throughout recorded history. ${ }^{130}$

All of the above historical studies were conducted in recent decades, but even at the time the League was founded some of this information was available. Most relevant to the League's imagined history of female autonomy over breastfeeding would have been a series of historical articles by Ian G. Wickes, a British pediatrician, published in 1952 in Archives of Disease in Childhood. ${ }^{131}$ Although Wickes was not a historian, he wrote a fairly comprehensive survey of infant feeding from "primitive peoples" to the nineteenth century, citing many of the sources later used by Fildes. ${ }^{132}$ Like Fildes, Wickes demonstrated a long history of medical and religious intervention into infant feeding and shifting trends for and against maternal breastfeeding. It is possible that the League's founders never saw Wickes' articles, but they were published in the official journal of the British Royal College of Paediatrics and Child Health, one of the most prominent pediatric journals in the world. Given the founders' focus on of infant feeding, and their scouring of the relevant sources, it seems unlikely that the founders or one of their medical advisors would not have come across Wickes' research and noted its relevance to their endeavors.

\footnotetext{
${ }^{130}$ Fildes, Breasts, Bottles, Babies.

${ }^{131}$ Ian G. Wickes, "A History of Infant Feeding. I. Primitive Peoples; Ancient Works; Renaissance Writers," Archives of Disease in Childhood 28, no. 138 (1953), 151-8.

${ }^{132}$ Ibid., Fildes, Breasts, Bottles, Babies.
} 


\section{Delimiting Communities of Mothers}

By the late 1990s, the League was apparently aware of the history of various infant feeding methods. In 1998, in a lengthy unpublished history of the League's early years, Betty Wagner briefly delved into the history of breastfeeding prior to the League. ${ }^{133}$ She wrote that many babies throughout history have not been fed at their mothers' breast. She pointed to archeological evidence of artificial infant feeding apparatuses found in Egypt, Greece and the Roman Empire. She told of "early writings of physicians" which mention wet nurses. ${ }^{134}$ She also described the composition and administration of pap and panada, milk or broth mixtures used to feed infants who could or did not breastfeed. Wagner's account is fairly vague, but her facts are not inaccurate. Still, her overall account is highly morally inflected. She assumed that the only reasons babies were not breastfed were dire necessity: most commonly, the mother's death, or, more rarely, her physical inability to breastfeed - and selfishness - the mother actively chose not to breastfeed, despite awareness of the risks. She began her account by saying that "(d)own through the ages women for one reason or another decided not to breastfeed their own babies." She explained that wet nurses were employed when a mother was unable to breastfeed or "as a means of avoiding nursing one's own child."135 Surveying the unnamed sources, she asserted that "(w)e can speculate from historic writings that doctors and moralists have, over the ages, exhorted mothers to breastfeed their babies.

${ }^{133}$ Betty Wagner, “Betty Wagner's History of LLL from 1956-1967,” Box 4, Folder 15, La Leche League International Records, DePaul University Special Collections and Archives, DePaul University.

134 Ibid.

135 Ibid. 
Still it is plain that many women have been pleased to avoid breastfeeding if the possibility was open to them."136 This is not an entirely accurate reflection of the sources, even those available forty years before when the League was founded. According to Wickes, while many moralists have over the centuries have inveighed against mothers who did not breastfeed and saw wet nursing as "a cause or a symptom of the decline that was to follow," doctors did not necessarily subscribe to this point of view. ${ }^{137}$ Wickes cites numerous historical documents that contained guidelines for selecting a wet nurse, as well as a variety of temporary or permanent substitute foods for infants. For instance, Wickes cited the Indian Susruta from the second century BCE which advised feeding honey and clarified butter for several days before initiating breastfeeding, and Hippocrates who suggested infants be given "wine diluted with water." 138

Wagner's brief account of the history artificial infant feeding inaccurately suggested that medical and social elites in the past universally supported maternal breastfeeding and that women who historically did not breastfed did so for selfish reasons. She repeatedly constructed artificial feeding or employing a wet nurse as a choice on the part of individual mothers and that these mothers were "happy to leave the breastfeeding of their baby up to another."139 This ignored social pressures on women, cultural expectations, and deeply held beliefs about what is healthy for children and mothers. It makes artificial feeding or non-maternal breastfeeding into a question of

\footnotetext{
136 Ibid.

${ }^{137}$ Wickes, “A History of Infant Feeding I," 154.

${ }^{138}$ Ibid.

${ }^{139}$ Wagner, "Betty Wagner's History of LLL," 1.
} 
moral failure and places culpability squarely on the shoulders of mothers. Wagner's awareness that mothers throughout history fed their babies in a variety of ways and have therefore experienced breastfeeding and motherhood differently could have destabilized her, and LLL's, notion of breastfeeding as natural and their universalized construction of motherhood and a historical community of mothers. Instead, by accusing mothers who did not act according to her model of motherhood of moral failure, she placed these women outside the category of mother. For Wagner, these women were not different types of mothers, they were not mothers.

\section{Summary}

La Leche League is an international network of mothers that has linked thousands of small, local groups of pregnant and breastfeeding women. As a peer support group, LLL's success depended upon its participants recognizing one another as part of a coherent collectivity of women with similar values. The League therefore made concerted efforts to create a recognizable and appealing collective identity. Through the sharing of personal experiences and advice in person and the reading of League manuals, books and periodicals, League participants came to view themselves as part of a truly meaningful community. The organization further enhanced the cohesiveness of the contemporary communities of mothers within the organization by promoting a collective memory consciousness based on imagined semi-mystical connections between all women who have breastfed. League participants embraced this imagined past and shared their own visions of a sort of transhistorical sisterhood of mothers. Finally, in addition to encouraging breastfeeding women to identify with one another based on their shared 
embodied experiences of motherhood, the League constructed their imagined mothering community as the only true mothering community, thereby excluding women who did not share their collective identity from the entire institution of motherhood. 


\section{CREATING INSTITUTIONAL KNOWLEDGE}

\section{Introduction}

The founders of La Leche League did not all know one other before they gathered for the first meeting to plan what would become a global organization, but they did all travel in the same social circles among the white, middle-class, socially conscious Catholics of Chicago's western suburbs. This chapter explores the unique cultural context in which the LLL arose and how this environment influenced what sources of knowledge the founders tapped in forming the League's own institutional knowledge. Overall, the founders seem to have begun their organization with a definite view about what was wrong with modern American society and how to fix it. To achieve their aims, they sought out the support of like-minded men and women in positions of authorityprimarily doctors and other healthcare professionals - who could bolster their efforts to encourage women like themselves who had relatively less power-primarily white, middle-class housewives - to make a difference in the world through their efforts in the home. ${ }^{140}$ Although they discovered that more people shared their views than they had originally realized, this chapter shows that in their early years the League operated within a firmly delineated subculture of people who were critical of the "scientism" of mid-

\footnotetext{
${ }^{140}$ Of course, relative to other groups such as racial, ethnic, class and sexual minorities, these women held a great deal of power.
} 
twentieth century America, but who also, with few exceptions, took for granted what they viewed as traditional gendered divisions of labor. ${ }^{141}$

\section{Medical Knowledge}

When seven young mothers joined forces to create La Leche League in 1956, theirs was a small movement of volunteer middle-class housewives who pitted themselves against a well-established healthcare system dominated by highly-educated, respected male authorities. According to Edwina Froehlich, "The 1950s was an era when people went to the doctor all the time... Whenever the least little things was wrong you called the doctor and got an antibiotic. If the baby was sick, the hospital was the best place for him." ${ }^{, 142}$ Likewise, Tompson recalled that in the cultural environment of the 1950s, people tended to heed professionals' advice without questions, as "most people were pretty obedient in those days to authority figures, and few people were more authoritative than doctors and nurses."143 More than just authority figures, medical professionals in the twentieth century were heralded as miracle workers. Medical science had made remarkable strides in the last several decades and doctors seemed to be making discoveries daily, developing new antibiotics, vaccines and treatment innovations that allowed them to save lives that in earlier centuries would have been forfeit.

Psychologists and social scientists also seemed to hold the keys for understanding how to

\footnotetext{
${ }^{141}$ See “A La Leche League Dialogue," 198. The introduction, most likely written by Herbert Ratner, claims that La Leche League was necessary in the 1950s "because of an hostile, technologic culture, prone to scientism, and insensitive to, and rejective of, nature's obvious script."

${ }^{142}$ Lowman, LLLove Story, 47.

143 Tompson, Passionate Journey, 41.
} 
shape better, stronger, more secure children, and thereby improve society. Thus, the recommendations of scientific experts held a great deal of sway over individual's healthcare practices, and often, over how they lived their daily lives.

Nowhere was the influence of medical expertise and innovation more evident than in the fields of maternal and child health, as doctors and new medical innovations significantly lowered mortality rates, and also held the promise of decreasing the pain, frustration, and uncertainty associated with bearing and raising children. Male doctors had made significant inroads in the fields of obstetrics and pediatrics since the late nineteenth century, and although their ultimate goal was to save the lives of women and children, innovations in these fields significantly affected women's physical—and emotional — experience of early motherhood. By the 1950s, doctors wielded extensive control over how women used their reproductive bodies and how they mothered their children. In particular, midcentury doctors recommended three practices that, LLL's founders believed alienated women from their bodies and created physical and emotional distance between women and their children and other family members: 1) giving birth in hospitals, away from family, with a high level of medical intervention including sedation and the use of forceps; 2) feeding infants regulated quantities of complex, expensive cow's milk-based formulas from man-made bottles and nipples; and 3) strictly following detailed, scheduled childcare regimens found in medically and psychologically informed manuals.

Medical professionals had introduced most of these practices to save the lives of women and children. Forceps, which had been used in especially difficult births for more than three centuries, could facilitate deliveries that might otherwise have ended in the 
death of the mother and/or infant. Medications could help women to withstand the trauma and exhaustion of labor. Artificial formulas using pasteurized cow's milk and nutritional additives could save the lives of babies who could not breastfeed or would otherwise have been fed on less appropriate breastmilk substitutes such as broth or contaminated milk. Respected scientific authorities such as pediatrician Emmet Holt who wrote the extremely popular 1894 manual, The Care and Feeding of Children, recommended strict and detached childcare routines based at least in part on advances in hygiene that had helped to prevent the spread of many deadly infectious diseases of childhood. ${ }^{144}$ Psychologist John B. Watson wrote his own guidebook, Psychological Care of Infant and Child, in 1928, an approach inspired by cutting edge psychological theories regarding proper child development. ${ }^{145}$ Although Watson recommend practices that today seem cold and even cruel, such as not responding to cries and minimizing touching between parents and children, he believed this was for the best because coddling young children physically and emotionally was a poor preparation for the adult world. ${ }^{146}$

By the 1950s these three novel practices had become normative among America's white middle class. Historians and contemporary observers have attributed the rapid spread of these interventionist tendencies to several factors. Many people at the time believed that modern life had rendered middle class women unfit for childbirth and breastfeeding, either because their bodies were physically weakened by modern life and

\footnotetext{
${ }^{144}$ L. Emmett Holt, The Care and Feeding of Children: A Catechism for the Use of Mothers and Children's Nurses (New York and London: D. Appleton and Company), 1894.

${ }^{145}$ John B Watson and Rosalie Alberta (Rayner) Watson, Psychological Care of Infant and Child (New York: W.W. Norton \& Company), 1928.

${ }^{146}$ Ibid.
} 
contaminated urban environments or because modern stresses interfered with their tolerance of birth and with their milk production thereafter. Manufacturers of infant foods marketed them as healthful and convenient. The market for such foods grew both by a snowball effect, as women saw their peers using them and as people of lower classes aspired to class mobility through practices of consumption. ${ }^{147}$

Additionally, obstetricians and pediatricians sought to assert their authority in fields that had traditionally been dominated by women. In their efforts at professionalization and in line with a view of medicine as a rationalized science, doctors increasingly developed rigid standards for treating illness. Over time these standards expanded, so that doctors increasingly approached periods during which people were potentially vulnerable but not necessarily ill, such as pregnancy, birth and infancy, as they would approach pathologies. They therefore saw such conditions as in need of active management rather than more hands-off monitoring. ${ }^{148}$ Further, as medicine became more routinized, many doctors found performing an instrumental birth on a sedated patient or feeding a precisely formulated breastmilk substitute was much more

${ }^{147}$ Rima D. Apple, Mothers and Medicine : A Social History of Infant Feeding, 18901950, Wisconsin Publications in the History of Science and Medicine, No. 7 (Madison, WI.: University of Wisconsin Press), 1987; Valerie Fildes, "Infant Feeding Practices and Infant Mortality in England, 1900-1919," Continuity and Change 13 (1998), 251-80; Julia Grant, Raising Baby by the Book: The Education of American Mothers (New Haven: Yale University Press), 1998.

148 John A. Brett and Susan Niermeyer, "Neonatal Jaundice: The Cultural History of the Creation and Maintenance of a 'Disease' of Newborns,"in Nancy Scheper-Hughes, Carolyn F Sargent, and Carolyn Fishel Sargent, eds. Small Wars : The Cultural Politics of Childhood (Berkeley: University of California Press), 1998, 111-129. 
predictable than relying on the vagaries of the female body or dealing with highly emotional women. ${ }^{149}$

Scholars have traced the rise of medicalized hospital birth, artificial infant foods, and strict childcare schedules, revealing that a variety of interest groups interacted in promoting and resisting these practices, and that, at times, the same groups both promoted and resisted certain practices. ${ }^{150}$ According to a recent history by Mary Gibson, women drove the increase in anesthesia use in labor, especially of the controversial "twilight sleep" method in the early-twentieth century, because they wanted to give birth without pain. ${ }^{151}$ However, Gibson points out that in demanding control over pain in childbirth, they ultimately lost control of the process of birth, which was transferred to doctors and nurses, and the location which shifted from the home to the hospital. ${ }^{152}$ Rima Apple, Jacqueline Wolf and Valerie Fildes have shown that many late nineteenth- and early twentieth-century progressive reformers promoted a return to maternal breastfeeding while at the same time fighting for broader access to the pasteurized milk that enabled safer (if not entirely safe) artificial feeding. ${ }^{153}$ Apple and

\footnotetext{
${ }^{149}$ Apple, Mothers and Medicine; Mary E. Gibson, "An Early History of Anesthesia in Labor," Journal of Obstetric, Gynecologic \& Neonatal Nursing 46, no. 4 (2017), 619627.

${ }^{150}$ See Judith Walzer Leavitt, Brought to Bed : Childbearing in America, 1750 to 1950. 30th Anniversary ed. (New York, NY: Oxford University Press), 2016; Barbara Katz Rothman, In Labor : Women and Power in the Birthplace (New York: W.W. Norton), 1991; Richard W. Wertz, and Dorothy C Wertz, Lying-In : A History of Childbirth in America, expanded ed. (New Haven: Yale University Press), 1989.

${ }^{151}$ Gibson, "An Early History of Anesthesia in Labor," 623.

152 Ibid.

${ }^{153}$ Apple, Mothers and Medicine; Fildes, "Infant Feeding Practices and Infant Mortality in England;" Jacqueline H. Wolf, "Let Us Have More Mother-Fed Babies": Early Twentieth-Century Breastfeeding Campaigns in Chicago and Minneapolis." Journal of Human Lactation 15, no. 2 (2016), 101-05.
} 
Julia Grant have also shown that mothers have used childcare manuals in a variety of ways, seeking advice and information or support for their decisions while often ignoring what they saw as unnecessary or incorrect. ${ }^{154}$ However, these scholars' assessments are, of course, retrospective. Contemporary critics of the increasing medicalization of childbirth and motherhood, including LLL, often made more polemical statements, blaming an overweening male medical profession or modern women's increasing neuroses and status-seeking. ${ }^{155}$

The professionalization of the management of birth, breastfeeding and infant care in the 1950s transformed these into highly rationalized processes and left little room for emotional approaches. By the time Marian Tompson had her first child in 1950, an unmedicated hospital birth was a rarity among middle-class white women in the US. When Tompson went into the hospital in labor and refused sedation or other medications, she "became acutely aware of how unsuitable a place the hospital was to have a baby, and how clueless most birth attendants were to the needs of the woman in labor."156 According to Tompson, "( $\mathrm{t}$ )he human touch was totally missing" from the hospital birth process: "I remember wanting to ask someone in the delivery room to hold my hand just so I could be in touch with another person. But I knew my doctor would never understand why I wanted him to hold my hand, so I never said anything."157 Not only were the hospital staff insensitive, some of them were cruel. While she was in labor,

\footnotetext{
${ }^{154}$ Apple, Mothers and Medicine; Grant, Raising Baby by the Book.

${ }^{155}$ Herbert Ratner was critical of both the healthcare system and of women's vanity. See Herbert Ratner, "Comments on Breastfeeding," La Leche League News 4, no. 5 (1962), 1-2.

${ }^{156}$ Tompson, Passionate Journey, 40.

${ }^{157}$ Lowman, LLLove Story, 11.
} 
Tompson could hear what was happening in the delivery room next door. Drugged women were moaning and screaming and staff would tell them, "If you don't be quiet I'm going to walk out of this room and leave you." Tompson was appalled, "I had never heard one adult speak to another adult with such disdain before in my life." ${ }^{158}$ Ladies Home Journal published an exposé on the awful conditions under which American women gave birth. One woman wrote that women "receive such brutal inconsiderate treatment that the whole things is a horrible nightmare. They give you drugs, whether you want them or not, strap you down like an animal. ${ }^{, 159}$ In the face of these conditions, Tompson, along with the rest of the League's founders eventually decided not to deliver any more babies in a hospital, instead delivering at home with Gregory White attending. The League advocated natural childbirth as an important factor in establishing a strong breastfeeding relationship, and the organization frequently collaborated with natural birth advocacy group, the International Childbirth Education Association.

Women's experiences of infant feeding were not quite as traumatic, but they were in many ways, similarly impersonalized and dehumanized. The Womanly Art of Breastfeeding painted a picture, albeit a jaundiced one, of bottle feeding in 1957:

So many more new decisions had to be made - which formula to use, how to prepare it, how much, to hold the baby or not - a mother could easily begin to regard her baby as a most complex digestion system instead of a most dependent, but 'feeling' person. In the midst of scales and charts, mothers began to lose confidence in her own abilities, to miss the easy natural enjoyment of a new baby. ${ }^{160}$

\footnotetext{
${ }^{158}$ Tompson, Passionate Journey, 41.

${ }^{159}$ Cited in Leavitt, Brought to Bed, 190.

${ }^{160}$ La Leche League of Franklin Park, The Womanly Art of Breastfeeding, 1.
} 
Although this account is satirical, formula feeding had added a number of new considerations to the process of infant feeding such as selecting a formula, ensuring it and all of the materials necessary for preparing and feeding it were sterile, warming the bottle, feeding without overfeeding, etc. Further, since formula feeding was so widespread at this time, doctors managed breastfeeding based on standards that were drawn from bottle-fed babies. Since doctors could not easily measure how much a breastfed baby was eating, they were quick to blame inadequate quantities or qualities of breastmilk for slow weight gain. ${ }^{161}$ Many doctors and nurses also believed that the size or shape of a mother's breasts affected her milk production, and that if a mother had Rh negative blood she should not breastfeed.

Although most doctors believed that breastmilk was the best and safest source of nutrition for infants, many also believed that, in the developed conditions of the United States, artificial formulas could be just as healthful. ${ }^{162}$ In 1968, Northwestern pediatrician Herman F. Meyer wrote that "some" claimed breastfeeding was "a vestigial expediency dating from when this form of nurture stood between the attrition and perpetuation of the species." The practice of breastfeeding might "eventually disappear, albeit more slowly than swaddling or other outdated rituals of baby lore."163 Meyer seems to be playing devil's advocate to a certain extent here and presents the opposing argument that breastfeeding "is most essential in the neonate's feeling of security, as well as

\footnotetext{
${ }^{161}$ See Apple, Mothers and Medicine.

162 Ibid.

${ }^{163}$ Herman F. Meyer, "Clinical Review: Breast Feeding in the United States, Report of a 1966 National Survey with Comparable 1946 and 1956 Data," Clinical Pediatrics 7, no. 12 (1968), 708.
} 
granting the mother the fulfillment of her womanly destiny." "164 However, it does seem that Meyer operated from the assumption that, although breastfeeding was beneficial emotionally, formula was just as good, at least nutritionally, as breast milk. In a 1958 article he declared that "(m)ost of the serious nutritional and mechanical problems of infant feeding have now been solved" since formula developers now understood "the importance of curd tension in any given milk mixture, with special reference to evaporated milk and its soft flocculent curd." He conceded somewhat to the fitness of breastmilk by saying that formula was for "infants who are deprived of the natural nutrient, human milk," but glosses over this by saying that all these "deprived" babies "now can be fed successfully."165 By beginning with the sentiment that most infant feeding problems have been solved by advances in artificial formulas and only later mentioning (briefly) that formula is less natural than breastmilk, Meyer's account demonstrates that formula feeding, although not necessarily the ideal, was the norm of the day.

Midcentury critics of formula feeding, including La Leche League, suggested that women rejected breastfeeding not just because they had doubts about their abilities, but also because increasing consumerism and self-interest led mothers to deprioritize infant care in favor of activities they viewed as motivated by status-seeking. These activities might include overzealous housekeeping, social engagements and even paid work, which, from a white, middle class perspective, was typically viewed as a source of extra money

\footnotetext{
164 Ibid.

${ }^{165}$ Herman F. Meyer, “A Clinical Interpretation of the 'Colicky' Infant," Postgraduate Medicine 24, no. 6 (1958), 627.
} 
for luxuries. ${ }^{166}$ Using bottles filled with formula allowed mothers to place even young babies in the care of others or, for shorter periods, to leave an infant alone in a crib with a bottle propped in its mouth. Infants fed on formulas were often given cereals as early as a few weeks old, and since the combination took longer to digest than breastmilk, artificially fed infants ate less often and slept longer (because they did not need to wake up to eat) than exclusively breastfed babies. This allowed mothers even more time free from active childcare. According to Ratner, bottle feeding became popular for many reasons, "but one reason is the notion that breastfeeding ties the woman down...Women figured that with bottle feeding they'd be liberated. They became vulnerable to other persuasions. They ended up thinking of the baby as one who only needs diaper changing, feeding and sleeping." 167 Of course, Ratner's perception was based on observation of mothers' behaviors, which may not be a reliable indicator of their feelings about their children, especially given that many women behaved this way under the advice of doctors or childcare manuals.

Childcare manuals reinforced the hands-off approach of bottle-feeding by recommending that mothers avoid touching infants other than to clean or feed them, even if they cried, for fear of causing physical or psychological damage. It is hard to believe that parents could completely ignore infant cries to which they were evolutionarily wired and emotionally inclined to respond, and the testimonials of early League mothers provide evidence that many parents were very uncomfortable with the "Holt method" and

\footnotetext{
${ }^{166}$ See La Leche League of Franklin Park, The Womanly Art of Breastfeeding.

${ }^{167}$ Lowman, LLLove Story, 48.
} 
some of them chose, at least sometimes, to ignore the advice rather than the baby. ${ }^{168}$

Still, if parents believed, as the manuals suggested, that the potential risks of being overly solicitous to a child included serious illness, accidental injury and crippling psychological problems it is understandable that parents might seek to create a little distance between themselves and their offspring. Even if parents did not always follow professional advice to the letter, broadly speaking, childcare in middle class, mid-twentieth century America was decidedly more hands-off than at many other times and places. Contemporary accounts attest to this, and the layout and practices of maternity wards also substantiate this, as infants were kept in large nurseries and brought to their mothers for the first time 12 to 24 hours after birth and every four hours thereafter. Many women in this period had their first practical experience of infant care in the hospital after the birth of their first child, so the routines established there could be highly influential. La Leche League recognized this and one of their first pamphlets was addressed to maternity nurses, on the grounds that "(n)o single person has a greater influence on the new mother than the nurse with whom she comes in contact in the hospital." 169

The founders of La Leche League sought to overturn many of the interventionist practices associated with maternal and child healthcare. Helping mothers to succeed in breastfeeding was their primary stated goal, but their ideal of "mothering through breastfeeding" meant essentially the opposite of raising children according to Holt or

\footnotetext{
${ }^{168}$ Mary White said that Gregory White was interested in more sympathetic child care in part because his mother had been so unhappy with the "Holt method." See Cahill, Seven Voices, One Dream, 8-9. For more on mothers negotiated readings of medical and psychological advice see Grant, Raising Baby by the Book.

${ }^{169}$ La Leche League of Franklin Park, "How the Nurse Can Help the Breastfeeding Mother" (Franklin Park, IL: La Leche League of Franklin Park), n.d.
} 
Watson's manuals, and having a natural childbirth was a major contributor to eventual breastfeeding success. The founders and their advisors viewed doctors' interventions as intrusions on women's traditional terrain and sought to shift maternal authority away from medical practitioners and back towards the mothers themselves.

Although breastfeeding advocates often viewed mothers as largely victims in an unfortunate historical process, at times they placed a good deal of blame at the feet of women. Herbert Ratner wrote frequently about the "sick society" of the twentieth century with its high rates of "mental illness, psychosomatic disease, suicide, delinquency, alcoholism, drug addiction, illegitimacy, divorce, etc." ${ }^{" 170} \mathrm{He}$ was critical of the entire American healthcare system: "We can go all through medicine and find this steady conversion of normal states (as in breastfeeding) into abnormal states (as in bottle feeding) and the conversion of abnormal and unusual procedures into usual procedures. ${ }^{" 171}$ However, he often placed blame not on the doctors for developing and providing such care, but on the patients for demanding it. He wrote in his foreword to the second edition of the League's manual that although doctors knew that breastfeeding was best for infants, "most physicians have stood by—more or less as innocent bystanderswhile the vagaries of women, the styles of the time, and cultural pressures have converted the preferred and the customary into the exceptional." ${ }^{, 172}$ Ratner expressed his sympathy for these beleaguered doctors, and somewhat for their patients: "This insidious

\footnotetext{
${ }^{170}$ This quote comes from Ratner's foreword to the second edition of The Womanly Art of Breastfeeding, but he used similar expressions in his foreword to the third edition and a number of other critiques of the contemporary healthcare system.

${ }^{171}$ Ratner, "Comments on Breastfeeding," 2.

${ }^{172}$ Ratner, Foreword to La Leche League International The Womanly Art of Breastfeeding, $2^{\text {nd }}$ ed., v.
} 
progression is understandable. Physicians are human beings and patients their partners in the therapeutic decision. Physicians cannot be expected to stand up, day after day, to the pressures of women who, uncertain and misinformed about breastfeeding themselves, are confused by conflicting voices as to what they should do." ${ }^{, 173}$ Ratner constructed La Leche League's role in increasing breastfeeding rates not as helping women, but as helping doctors: "It is clear that physicians cannot fight this battle alone. That is why physicians are most grateful to La Leche League which has dedicated itself to the recovery of Nature's womanly art of breastfeeding." 174 Ratner's foreword seems to be aimed primarily at a medical audience, but since it is included in The Womanly Art whose largest readership was mothers, his denigration of women is somewhat less than tactful. However, the mothers reading the manual were likely to be women who were breastfeeding or were at least interested in doing so. Ratner's critique of "confused" women therefore served as validation for breastfeeding women who carry "the hope of rescuing us from a sick technological age by the restoration of certain basic human relations leading to a more wholesome culture. ${ }^{, 175}$ Ratner was almost always the most aggressive and rigid of any League writer, but the League's founders looked to him for advice and repeatedly cited his influence in shaping their values. ${ }^{176}$ Ratner was largely responsible for the League deciding to focus their mission on "mothering through breastfeeding" as opposed to simply breastfeeding. The founders had discussed their mission at an early meeting with Ratner, a few board members, and Gregory White. A

\footnotetext{
173 Ibid.

${ }^{174}$ Ibid.

175 Ibid.

${ }^{176}$ See the dedications to the various editions of The Womanly Art of Breastfeeding.
} 
transcription of this conversation was later published in its entirety in Child-Family Digest under the title, "A La Leche League Dialogue: An Historic Document." 177 This document describes Ratner as the "moderator" of the conversation, but he spoke far more than any other participant. ${ }^{178}$ The introduction to the "Dialogue" described Ratner as having "emulated to the extent his talents made possible, the Socratic midwife immortalized by Plato in the $4^{\text {th }}$ century B.C.: 'to thoroughly examine whether the thought which the mind [of the student] brings forth is... a noble and true birth [and that] the many fine discoveries to which they [the students] cling are to their own making."179 Ratner's Socratic midwife, however, seems to have taken on a role more similar to the domineering modern obstetricians he criticized. In the transcript following this introduction, although the women of the League ultimately decided to agree with Ratner, they repeatedly accused him of putting words into their mouths. He, meanwhile, told them that they agreed with him intellectually but that their emotions prevented them from recognizing their agreement. ${ }^{180}$

Despite their reliance on Ratner for guidance, the founders were generally more understanding than he was of the pressures women felt to conform to social pressures. They also generally felt that women were pressured by their doctors more than the other way around. As sharing struggles was a major part of the League's community building efforts, the founders shared numerous stories of times they had yielded to social and cultural influences. For instance, although Edwina Froehlich refused to deliver her

177 “A La Leche League Dialogue,” 198.

178 Ibid.

${ }^{179}$ Ibid. No author is listed for this introduction, but since Ratner was the editor of the journal in which it was published, it seems likely Ratner himself was the author.

180 “A La Leche League Dialogue," 217. 
babies in a hospital, she did have her physician, Gregory White, come to her home to attend the births. Froehlich explained this compromise, saying that, "Of course, women in the past, millions of them, have given birth to babies without physicians' assistance, but this was our culture and that was what we were used to. Most of us couldn't have done it (given birth naturally) if we hadn't known that there was a physician standing by if we needed him." 181 Viola Lennon similarly explained that she was "a victim of (her) era and (her) neighborhood" in that she had fed her first baby solids at three months simply because all her neighbors were doing so. ${ }^{182}$

In some of the League's accounts submitting to peer pressure is understandable, but the individual still has some moral culpability for giving in, and by contrast, earns moral praise for resisting. According to Gregory White,: "We're all social animals....We tend to move with the crowd. If the crowd were going in the right direction, that would be great. But ever since Adam bit the apple, there have been so many crowds going in wrong directions that following the crowd is usually not the thing to do." 183 The reference to Adam, who ate the apple despite God's explicit prohibition, here hints at people following their peers into doing things they know are wrong. Mary White described the situation for women who attempted to avoid "following the crowd" in bottle feeding, "By the time LLL came along, new mothers did not have the support of family or friends, let alone doctors, nurses, and hospitals. Mothers who tried to breastfeed on their own in the early 1950 s were almost destined to fail—it took a very unusual woman to succeed at breastfeeding with all the social pressures that were lined

${ }^{181}$ Cited in Cahill, Seven Voices, One Dream, 77.

182 Cited in Cahill, Seven Voices, One Dream, 54.

${ }^{183}$ Cited in Lowman, LLLove Story, 49. 
up against her at that time." ${ }^{184}$ Of course, in this construction, White paints herself and her co-founders as "unusual," exceptional women who were able to follow the dictates of nature despite negative social pressures.

Still, even when the founders were fairly confident that some of their unorthodox decisions were for the best, they expressed a certain reluctance to open themselves up to the censure of family and friends, and increasingly of a public audience. Mary Ann Kerwin described how "most friends and acquaintances thought I was crazy, just absolutely nuts, when we had our first baby at home." She said that eventually "I got to the point where I didn't even tell people what we were planning to do, because we were getting so much negative feedback." ${ }^{185}$ Marian Tompson recalled that the first time she wrote in the News about breastfeeding past infancy she "did it with much trepidation because at the time I wrote it I was thinking, 'Maybe some of my relatives will be reading this and they don't know that Brian is two years old and still nursing." Eventually, Tompson felt that writing about her experience was "a good thing because as a result of writing it I began hearing from other "closet nursers.",186 Tompson was thus far from alone in feeling slightly embarrassed, in the face of potential social scorn, about a decision she otherwise felt was right and healthy.

Yet, despite admitting their own struggles with social pressure, and acknowledging that psychological impediments are deep-seated and difficult to overcome, the founders sometimes hurled accusations of mental illness or selfishness at women who did not conform to the League's natural mothering ideals. In the first edition

${ }^{184}$ Cited in Cahill, Seven Voices, One Dream, 106.

${ }^{185}$ Cited in Cahill, Seven Voices One Dream, 56.

${ }^{186}$ Cited in Lowman, LLLove Story, 26. 
of The Womanly Art of Breastfeeding they say, somewhat sympathetically, that "(a) woman who finds the whole idea of nursing a baby repulsive can not, should not, be forced to breast-feed." This sentiment is immediately followed with the indictment that, "(s)he should realize, however, that this is an abnormal attitude, indicative of underlying maladjustment." ${ }^{187}$ Such an accusation is harsh and not necessarily accurate in the cultural environment of the time, in which an aversion to breastfeeding would have been a reasonable response to actual conditions. ${ }^{188}$ However, the League was fighting an uphill battle against a culture in which many biological norms of motherhood were rarities in practice. To disrupt the hegemony of science in motherhood, the League needed to demonstrate that it was contemporary conditions that were anomalous and that their ideas of natural mothering were therefore not radical, but rooted in nature and tradition.

\section{Domestic Knowledge}

In addition to the interventionist medical climate, the broader social and cultural environment of the 1950s shaped the League's view of motherhood. At the League's inception in 1956, the group's founders and allies were in many ways acutely aware of the uniqueness of the time and place in which they lived. They recognized that rapid social and technological changes had altered production and consumption patterns, especially in the industrialized West, and that these developments had led to novel work

${ }^{187}$ La Leche League of Franklin Park, The Womanly Art of Breastfeeding, 18. ${ }^{188}$ See Niles Newton, The Family Book of Childcare (New York: Harper and Row), 1957, 93 and Niles Newton, Maternal Emotions: A Study of Women's Feelings Toward Menstruation, Pregnancy, Childbirth, Breast Feeding, Infant Care, and Other Aspects of their Femininity (New York: Paul B. Hoeber), 1955. 
and domestic arrangements. They were deeply critical of a number of the innovations they saw. At the same time, they did not necessarily recognize or question some of the other unique facets that characterized their lives in the white, middle-class, suburban America of the 1950s.

One of the ways that LLL impacted maternal expectations was by downplaying the importance of housekeeping. The League's founders rejected the post-war explosion in consumer goods and materialism in favor of their motto of "people before things." The League emphasized that a mother and wife's primary job was to meet the physical and emotional needs of her family. Housework, therefore, falls low on the priority list, especially when a baby is in the home. The founders resisted a 1950s culture in which housewives were made to feel inferior if their homes were not sparkling clean. Marian Tompson frequently recounted that during her early years as a mother she felt like something was wrong with her because she spent so much time holding and nursing her babies and so little time cooking and cleaning: "My neighbors, most of whom were bottle-feeding and living by the four-hour feeding schedule, seemed to be so much better organized. Their houses always looked neat and tidy. I secretly suspected it was a weakness in me that led me to carry my baby around because I couldn't stand to let her cry." 189 With time, however, Tompson changed her perspective and "came to believe that it was probably the effect of my birth and breastfeeding experiences that helped mold me into the kind of mother my babies needed. ${ }^{190}$ Her babies needed to be held and to breastfeed; they did not need a sparkling home.

\footnotetext{
189 Tompson, Passionate Journey, 56.

${ }^{190}$ Ibid.
} 
In the first edition of The Womanly Art of Breastfeeding the founders wrote that a change in priorities and routines was a natural part of having a baby. They said that before having a baby, the reader may have placed high value on having a perfectly clean home, but "(w)ith parenthood that goal changes." They comforted mothers that this new arrangement was for the best: "Just remember the four walls of your house or apartment and its furnishings will no doubt be around long after you are gone. But you will never get back your child's babyhood. So, let the dust roll, and keep your baby happy no matter how much time this may demand."191 The League was responding here to certain elements of midcentury American culture that Betty Friedan later identified as the "problem that has no name," except that they saw women's salvation not in escaping home life, but in redefining motherhood as a worthy and fulfilling vocation in itself, and one entirely distinct from housekeeping. ${ }^{192}$ In the League's view, mothers should prioritize childcare because of their unique, biological bond with their children, "Anyone can come in and take over your housework, cooking, or laundry if they will, but no one can be as good a mother to your baby as you can." ${ }^{, 193}$ Cutting back on housekeeping was also important because mothers must avoid overstressing or exhausting themselves, especially in the first days and weeks after giving birth, so that they can recover from delivery and establish a strong milk supply. The League suggested that breastfeeding is in some way designed to keep mothers from overextending themselves, saying, "Nursing is Nature's way of helping you relax and rest... When your baby gets hungry you stop

\footnotetext{
${ }^{191}$ La Leche League of Franklin Park, The Womanly Art of Breastfeeding, 6. ${ }^{192}$ Betty Friedan, The Feminine Mystique (New York: W.W. Norton), 1997.

${ }^{193}$ La Leche League of Franklin Park, The Womanly Art of Breastfeeding, 6. Emphasis in original.
} 
right in the middle of some busy work and with a clear conscience rest comfortably with your baby and nurse him.",194

Ratner helped the founders to realize the significance of deprioritizing housekeeping in allowing mothers to focus on their children. He highlighted that sharing doubts and frustrations was an important element of providing mothers with support. Summarizing the "La Leche League Dialogue" with Ratner, Mary Ann Cahill wrote that when a mother expressed dismay over the state of her house, she could find comfort in hearing from a more experienced mother who "will smilingly admit to well-organized housewife's pangs at having dust on the living room tables after baby comes." Sharing this experience brought "the happy realization that shining table tops just don't compete with the joy and peacefulness of nursing one's baby." ${ }^{195}$ In the second edition of The Womanly Art of Breastfeeding, the League similarly suggested that lowering housekeeping standards could not only make life easier for an individual mother, but might allow her to set an example for her peers.

In general just resign yourself to living a more easy-going kind of life. Pretty soon you will find you like it that way. So will your friends. 'Keeping up with the Joneses' can be awfully wearing for everyone. Lots of mothers would be only too glad to know that you don't care if the breakfast dishes aren't done before lunch. They'll follow suit and we'll all relax. ${ }^{196}$

Here, the League offered a way for mothers to influence broader social values by their actions within their own homes.

${ }^{194}$ La Leche League of Franklin Park, The Womanly Art of Breastfeeding, 6-7.

${ }^{195}$ Mary Ann Cahill, "A Backward Glance and A Forward Look," La Leche League News 1 no. 2 (1958), 1.

${ }^{196}$ La Leche League International, The Womanly Art of Breastfeeding, $2^{\text {nd }}$ ed., 19. 
Ratner also encouraged fathers to expect more focus on mothering and less on housekeeping at the League's early "for father's only" meetings. Edwina Froehlich recalled overhearing Ratner lecturing a group of fathers, "Now, what is really important in life? It's not having a spotless house so your mother can come over and inspect. It's your kids that are important." 197 Betty Wagner explained that "fathers came away from the meeting with an understanding of a wife's new role as a mother and of her special attachment to the baby." 198 She emphasized that these values were not widespread at the time, and it was very important for a father to hear such things from Ratner because "he wasn't hearing them anyplace else." Many fathers responded positively to Ratner's sentiments, with one remarking on the cost savings of Ratner's session, "Think how much this would have cost us if we consulted privately with a doctor for three hours. We got it all for nothing!"199 Ratner's status as a professional and a medical authority reinforced views that husbands might otherwise have dismissed as laziness or radicalism on the part of their wives.

However, sometimes in their attempts to alter priorities and to help mothers and fathers feel better about dust bunnies on their floors, the League members and allies denigrated women who fell in line with the dominant cultural ethos of domesticity. Tompson recalled that Ratner endeared himself to her with the quip, "Show me a mother with a perfectly clean house and I'll show you a woman with serious psychological problems. ${ }^{200}$ This barb could make the woman with a messy house feel vindicated in

\footnotetext{
${ }^{197}$ Cited in Lowman, LLLove Story, 17.

${ }^{198}$ Ibid.

${ }^{199}$ Ibid.

${ }^{200}$ Tompson, Passionate Journey, 58.
} 
placing her priorities elsewhere, but what of the woman who feels compelled, for whatever reason, to keep an extremely tidy home or takes pride in doing so? With this sort of statement, Ratner elided what he considered suspect social standards into personal failings, and while the League's founders were generally not quite so strident, they did not disagree with him.

Additionally, the League's early views about prioritizing childcare over housework implied that these were the only two necessary tasks in which a woman was likely to engage. Her responsibilities and her world revolved around the home, the nuclear family and a few social engagements. According to the 1957 manual the only reasons a woman might want to use a pump to express milk are "to share your breast milk with another baby, or to send your milk to the hospital if your baby should be detained there for any reason."201 A mother could hand express milk into a bottle if she wanted to leave her child in the care of someone else. Of course, a mother should not leave her nursling very often, or for very long. The reasons the manual suggests a mother might leave her baby are to "do your bit of shopping, go to church or take the older children to school" or to have an occasional "big night out" or attend a wedding. Mothers should also make sure to have the proper attitude when leaving their children in the care of others: "don't rush—babies can sense it when you are in a hurry to 'get rid of them.",202 All of this reveals the writers' underlying assumption that their audience was made up of women of a similar economic status, social class, and racial or ethnic background who

${ }^{201}$ La Leche League of Franklin Park, The Womanly Art of Breastfeeding, 13. 202 Ibid. 
would not have had work or other obligations that would necessitate regularly leaving their babies in the care of others for more than a few hours at a time.

While La Leche League's founders and supporters questioned the increasing materialist focus of their era, they do not seem to have questioned increased fertility and growing families of the era. In retrospect, historians have described the mid-twentiethcentury baby boom and drop in marriage age as the result of unusually high prosperity and low mortality coupled with social-psychological reactions to a traumatizing, unrelenting sequence of global crises, from World War to Depression to World War to Cold War and "Atomic Age."203 In the 1950s, La Leche League's founders and allies saw young, large families as the resumption of an imagined historic constant that had been interrupted by these crises. Most of the founders' mothers had given birth to far fewer children than the founders themselves eventually would, but they chalked this difference up to the particularly burdensome economic situation of the Great Depression. The founders also saw having numerous children as part of a Catholic pattern. According to Tompson, "In those days, it never occurred to us to factor in the cost of a college education as part of the cost of having a baby. Being Catholic, we just expected that we'd have babies and trusted that God would provide."204 It certainly helped that Tompson's husband, like the husbands of all the founders, was gainfully and consistently employed in a job that paid a family wage.

Further, the League's founders and allies understood each childbirth and infancy as a maturing experience for the mother and the entire family, so having more children

${ }^{203}$ May, Homeward Bound; Stephanie Coontz, The Way We Never Were : American Families and the Nostalgia Trap (New York, NY: BasicBooks), 1992. ${ }^{204}$ Tompson, Passionate Journey, 52. 
was almost always desirable, regardless of economic conditions. ${ }^{205}$ Ratner summarized $^{2}$ the maturing, cumulative process of family formation and growth:

Going from the single state to the married state is one step....Going from being husband and wife to being father and mother is another step. We can no longer indulge in moments of selfishness as we can with another adult. The completely dependent baby necessitates total unselfishness. In the process one becomes a better person....Motherhood is another opportunity for growth. Three children nurture motherhood more than one. Each mothering experience enriches. ${ }^{206}$

The early League also accepted companionate marriage, a relatively recent

phenomenon in the West, as the ideal. They imagined that, although most couples would fall into roles divided roughly along gender lines, negotiation and mutual respect arising from a loving relationship would help to overcome any imbalance of power within the home. They suggested that although there were certain tasks that lent themselves to one gender or the other - childcare, cooking and cleaning for women, home repairs for mencouples should divide their chores "without worrying too much about losing our masculinity on the one hand or our women's rights on the other."207 Further, "(i)f one spouse is temporarily overburdened, love and reason impel the other to ease that burden." 208

${ }^{205}$ The League did support spacing births through natural means such as the Lactational Amenorrhea Method. However, the founders, as Catholics, did not support other forms of birth control or abortion. The League's views on the fertility of poor and minority families was thus less negative than those illuminated in the 1965 Moynihan Report, but they did join the Moynihan Report in warning of the dangers of childbearing outside of marriage. Additionally, the League has generally approached their work with poor and minority mothers differently from their work with middle-class white mothers, often constructing it more in terms of education and outreach than information and support. ${ }^{206}$ Lowman, LLLove Story, 48.

${ }^{207}$ La Leche League of Franklin Park, The Womanly Art of Breastfeeding, 19. 208 Ibid. 
Finally, although they recognized that the production model in which the father worked for pay some distance from home and the mother stayed in the home and did not work for pay had arisen relatively recently in the course of industrialization, the founders did not really propose any alternative to this arrangement. Women could economize or maybe find ways to make money from home if a family needed more income, but the League did not advise men to fundamentally rearrange their workplaces. Men should try to spend time with their families, of course, but in his spare time. The 1957 manual did recommend that husbands focus on providing their wives companionship when they return from work in the evening because a "woman who has been in the house with small children all day needs adult companionship, especially that of her husband. She likes to hear what is going on 'in the world,' and appreciates an occasional glimpse of it herself. Though woman's place may be in the home, so, outside of working hours, is man's."209 However, those working hours were a given, apparently based on biological and economic constants: "As long as women continue to bear babies (plural!) and to nurse them, there is not much danger that the roles of mothers and fathers will become badly confused. While the pregnant or nursing mother, of necessity, stays at home, the father of necessity, will go out and make a living." ${ }^{.210}$ While the League presented this family arrangement as a given, it was highly shaped by wage structures and urban planning characteristic of the mid-twentieth century. This pattern was widespread among families in suburban America at the time, but would not have held true for many rural, inner-city,

\footnotetext{
209 Ibid.

${ }^{210}$ Ibid.
} 
minority or poor families in the 1950s, much less for families before this time, and it did not continue into the end of the twentieth century.

\section{Catholic Knowledge}

Religion played a significant role in LLL's early development, and Catholic ideas about family and gender complementarity shaped the organization's structure and philosophy. The League's founders and most of their early allies were Catholic and moved in the same social circles in suburban Chicago, and the League spread nationally through a network of Catholic individuals and publications. Although the founders insisted from the beginning that La Leche League was a "non-sectarian" organization, their philosophy, their early writings, and even their name are shot through with explicit and implicit Catholic references. When first forming their breastfeeding support group, the founders had struggled to come up with a suitable name. Newspapers refused to print meeting notices with the word "breast" in them, as it was considered lewd. Edwina Froehlich later joked that “(i)n those days you didn't mention 'breast' in print unless you were talking about Jean Harlow." ${ }^{211}$ The women were afraid that using the more culturally acceptable term "nursing" in their name would give the impression they were a group for nurses. Their husbands made unhelpful name suggestions such as the "Milk Maids" and the "Busty Broads," until finally, Mary White's husband, Gregory White, suggested the name La Leche League. He had heard from one of his breastfeeding patients about a shrine built by early Spanish settlers in St. Augustine dedicated to Nuestra Senora de la Leche y Buen Parto (which translates Our Lady of the Milk and

${ }^{211}$ Cited in Lowman, LLLove Story, 18. 
Good Delivery). The founders liked the name not only because it was cryptic and inoffensive, but because the breastfeeding Mother of God was an apt role model and patroness for their organization and its members. ${ }^{212}$

Although the oblique reference to Mary in their name was not obvious to the uninitiated, the League's writings demonstrate much more unambiguous Catholic ties. In their earliest pamphlets and newsletters and the first two editions of their manual, the League made frequent reference to Mary, Eve, God and other Christian figures or symbols. Mary White wrote articles for the Catholic magazines Grail and Marriage, and some of the earliest references to LLL in national media were in articles submitted to these magazines by League supporters. Even the journal from which the League drew much of their early medical information, Child-Family Digest, was strongly Catholicleaning. League gatherings could be sites of religious expression as well. The luncheon of the first La Leche League International Convention in 1964 was opened with an invocation by Reverend James O'Donnell which stated that the goal of those assembled was to "help mothers to achieve their purpose and to perform their function more in keeping with your Divine Design and thus raise in Your honor a family that is dedicated to Your honor and glory. ${ }^{, 213}$ While the founders recognized that not all of their members and allies were Catholic or even Christian, they apparently expected that they would share a basic belief in an overarching plan for humanity with mothers assigned a specific role.

212 Cahill, Seven Voices One Dream 37; Tompson, Passionate Journey, 66.

213 James O'Donnell, Invocation Delivered at La Leche League International Convention, cited in La Leche League News 6, no. 4 (1964): 1. 
The League's founders and allies found in their Catholic faith a strong ground on which to base their resistance to the social and medical ills of their day. They frequently referenced God's plan for humanity or more specifically for mothers and children. Mary was not only the namesake of La Leche League, she was an important symbol of ideal motherhood that the League referenced in their writings. Catholics had a long tradition of revering Christ's mother, and particularly of appealing to her for safe delivery and a healthy mother and child. The Virgo lactans, Mary nursing the infant Christ, was a common devotional image, particularly in medieval iconography. The League referenced Mary's breastfeeding of Christ in early editions of The Womanly Art of Breastfeeding as well as in its newsletters. For instance, a 1962 winter edition of the News featured the heading "Christmas Old and New" under two images, a painting of the Virgin nursing Christ and a photograph of founder Betty Wagner nursing her daughter Helen. ${ }^{214}$

The League drew other models of motherhood from the Bible. Early League texts often cited Eve as a symbol of the continuity of natural mothering practices across time. Both The Womanly Art of Breastfeeding and early League pamphlets describe how "Mothers have happily nursed their babies since the time of Eve."215 The League assumes that breastfeeding must have been a straightforward, natural process for Eve:

How did Eve manage? Certainly she didn't join a League. Eve had it easy. The baby came. Her milk came. She nursed the baby.... Eve, of course, did not have well-meaning but not too well-informed friends and relatives questioning her ability to breast feed her baby. Eve - and you — nourished this baby completely for nine months in the womb, why any sudden doubts now? Her ability to nurse

214 “Christmas Old and New," La Leche League News 4, no. 6 (1962), n.p.

${ }^{215}$ La Leche League International, The Womanly Art of Breastfeeding, $2^{\text {nd }}$ ed., n.p.; La Leche League International, Why Nurse Your Baby? (Franklin Park, Ill.: La Leche League International), 1966. 
was taken for granted....Also, Eve had no choice. There just weren't bottles and formulae. $^{216}$

Although the Bible does not specifically reference Eve's breastfeeding, the founders assumed she must have breastfed because she had no other options. As the first woman, Eve's actions took on the increased significance of a precedent and of God's plan for all women.

The League likely invoked Mary and Eve in a symbolic sense, as widely recognized cultural figures rather than as part of any missionizing objective or an attempt at a coherent woman-centered scriptural exegesis. However, their use of Mary and Eve as symbols of motherhood was complicated by existing associations with these figures. First, in Catholic doctrine, Mary was the Virgin Mother of God, born free of Original Sin. Other Christian sects held different beliefs regarding Mary's continued virginity and her sinless states, but according to Biblical sources, Mary was a virgin when God asked her to bear his son. Thus, although Catholics revered her in a special way, for all Christians Mary was simultaneously a virgin and a mother, and therefore a role model no real woman could ever live up to. Eve, by contrast, had a long history of being blamed for the Fall of Man. She was a symbol of woman's sensuality and deceit. Although the League intended to invoke Eve as a symbol of nature, her image could not be separated from her corrupting legacy. Further, the Eve metaphor did not fully bear out, even in the League's account. In the above quoted segment, the founders say that Eve was able to breastfeed because she had no friends or relatives around to dissuade her or otherwise influence her actions. Yet, a few paragraphs later, the manual asserts that all women "except for Eve"

${ }^{216}$ La Leche League of Franklin Park, The Womanly Art of Breastfeeding, 1. Bold text in original. 
need the support of other mothers to successfully breastfeed. ${ }^{217}$ For the founders, breastfeeding was thus paradoxically an instinctual activity, but one that required communal support.

Other early League publications made free use of a variety of Christian metaphors, at times blurring the line between understandings of religion, nature and science. The title of a 1964 News article "A Doctor Pays Tribute to Mothering" gives the impression that the piece will include some sort of medical support for the act of breastfeeding. Instead, this article is a lengthy allegory in which the writer compares breastfeeding to Christian faith. Written by an anonymous doctor from Pennsylvania, the piece begins with a hypothetical speech from one doctor to his professional peers: "Gentlemen, we once believed in the woman and we believed that breastfeeding was best. When we failed to persuade her to breastfeed, and failed worse in teaching those who tried, rather than blaming ourselves, we withdrew our faith, and decided that breastfeeding was not so important after all.” The physician-writer continues:

And there is something about (La Leche League's) teaching which the first Christians had before Christianity became fashionable, a truth which words cannot convey....And there is something about your teaching which is quite as basic as that of the early Christian. You teach earthly means of joining the body with an inspired mind to discover a saving grace in a new sort of life experience. Although the experience is as old as Eden or older, now it becomes new again, unique, personal, and relevant to today....It is relevant to today because it counteracts the creeping threat confronting people, in this country especially - of being dehumanized and being made into little more than things at times. ${ }^{218}$

This physician constructed as a physical and metaphorical bridge between the natural past, over the unnatural present, into a natural future. The article could have been written

${ }^{217}$ La Leche League of Franklin Park, The Womanly Art of Breastfeeding, 2.

218 “A Doctor Pays Tribute to Mothering," La Leche League News 6, no. 3 (1964): 1-3. 
by anyone with strong feelings about breastfeeding, nature and Christianity, but emphasizing in the title that the author was a doctor lent it a further weight and gave the impression that it was based in scientific fact rather than philosophy or theology.

\section{Expert Knowledge: Masculine and Feminine}

The above article is a somewhat bizarre example of invoking medical authority, as medicine was largely irrelevant to the argument at hand. However, the League frequently publicized the support they received from doctors because it helped them to establish a reputation as more than just a group of mothers. According to Edwina Froehlich, "in those days nobody took you seriously when it came to giving child care advice unless you had medical authorities backing you up."219 The first two medical authorities the League sought out to support them were Ratner and Gregory White. The founders went to Ratner and White not only because of their close personal relationships with them, but also because Ratner and White had been instrumental in shaping most of the women's embrace of natural childbirth and breastfeeding in the first place.

Although the League frequently constructed their movement as one of mothers for mothers and they spoke of breastfeeding as a womanly art to be passed down among female communities, Ratner and White, male doctors, were highly influential in shaping the founders' mothering ideology and had been since long before the League began. That male medical professionals played such a significant role in initiating and guiding the League as an organization calls into question the founders' assertions that breastfeeding — except in unusual cases—should be managed within lay, female

${ }^{219}$ Cited in Cahill, Seven Voices One Dream, 36. 
communities and that their organization was a continuation of historical, autonomous female communities. White and Ratner's influence is perhaps most evident on Gregory White's wife, Mary White. By the time the League was founded and subsequently throughout her life, Mary White was perhaps the most ardent supporter of breastfeeding, natural childbirth and mother-infant togetherness among the League's founders. Yet, apparently none of these issues had been of particular concern to her until her husband, Gregory White, brought them up. She explained, 'I'm really thankful that I married the guy I did, because I know for certain that if it had been left up to me, our children would have been raised quite differently. Greg was the one who picked up on the idea of doing things 'nature's way,' and he passed that philosophy along to me." ${ }^{220}$ Gregory White's interest in these subjects had, in turn, been shaped by his mentor, Ratner. According to Mary White, "Herb Ratner played a significant role in the development of Greg's thinking about breastfeeding, natural childbirth, the care of infants and babies, child care, and family life in general."221 Certainly, Mary White was not forced into this way of thinking and she expressed that she would be "forever grateful" to her husband for introducing her to a way of life that brought her much joy and satisfaction, but it is significant to note that he, and Ratner somewhat more indirectly, were at the root of her conversion, and that two men therefore inspired her embrace of womanly arts. ${ }^{222}$ Mary White underplayed the ways in which her commitment to at-home motherhood, natural birth and breastfeeding facilitated her husband's medical career, both by freeing him from the burden of providing or paying for childcare and by serving as a living

${ }^{220}$ Cited in Cahill, Seven Voices, One Dream 9.

221 Ibid.

222 Ibid. 
advertisement of his model of medicine. ${ }^{223}$ And Mary White was a very effective postermother for Dr. White's services: many of her friends, relatives, and fellow church members became Gregory White's patients.

In their capacity as family doctors, Ratner and White had also influenced the other founders views on birth, mothering, and breastfeeding since before the League was founded. Gregory White delivered all three of Edwina Froehlich's children, and supported her desire to have a home birth and to breastfeed even though others warned that a first time mother at the advanced age of 36 would be incapable. According to Froehlich, "He made you feel so good about becoming a mother....He started during pregnancy to give you confidence that you would be able to handle your future role as a mother. He made you feel that babies were a very special blessing and that it was terribly exciting and wonderful that you were going to have a baby, whether it was your first or your tenth." ${ }^{224}$ Ratner had served as Edwina Froehlich's doctor before White, when she was pregnant with her first child. Froehlich said she had learned a great deal from Ratner, "He made me feel that I, as a mother, had a tremendously important contribution to make to my own family and to society....He said that good mothers were the basis for a good society. He felt that to shortchange a baby was to do a tremendous disservice to yourself, the baby and society." ${ }^{225}$ Thus Ratner taught Froehlich not just about medicine but about a philosophy of motherhood.

\footnotetext{
${ }^{223}$ Here, Mary White's perspective and actions reflect those explored in Bobel, "Bounded Liberation" and Bobel, The Paradox of Natural Mothering.

${ }^{224}$ Cited in Lowman, LLLove Story, 47, 49.

${ }^{225}$ Cited in Lowman, LLLove Story, 46.
} 
However, both Ratner and White were quick to say that although they promoted breastfeeding and other natural practices among their female patients, that to be successful most women needed to learn about them from other mothers. Ratner asserted that "( $(\mathrm{t}) \mathrm{he}$ art of mothering cannot be taught by physicians, ministers, or child experts. It is not a learned art; it is a practical art." ${ }^{, 226}$ According to White, "A person who is in a situation has more feeling for it than someone who never has been and never can be, so I had nursing mothers helping each other on an informal basis." He said that La Leche League became popular and other similar organization di not because other fledgling breastfeeding support groups "were a product of doctors and nurses rather than mothers themselves. They were professionals teaching, rather than mothers helping mothers, and these groups stayed small." ${ }^{227}$ Given the League's success, it is possible that Ratner and White were correct in their belief that breastfeeding women would respond best to the support of women, but at times it seems as if the two doctors, particularly Ratner, sought to use the League as instruments to serve their own ends. ${ }^{228}$

Still, although Ratner and White credited women for supporting one another, the League credited Ratner and White with giving them the idea and the tools to do so. In League writer Kaye Lowman's assessment, “It was Dr. White's positive, encouraging approach to helping mothers that provided the model for the founding mothers as they began helping other women." 229 Edwina Froehlich recalled that White had a wonderful manner when answering mothers phone calls, "I was always floating when I hung up the

226 Ibid.

${ }^{227}$ Cited in Lowman, LLLove Story, 49.

${ }^{228}$ See "A La Leche League Dialogue: An Historic Document." Ratner comes across as steamrolling the founders until they became too confused or tired to disagree with him. ${ }^{229}$ Lowman, LLLove Story, 49. 
phone after talking to him." ${ }^{230}$ She used his positive style as an inspiration when she began taking calls from nursing mothers. Mary Ann Cahill said that the League's founders "looked to him for the answers we needed. He had long ago recognized the importance of mother-to-mother help in breastfeeding and had had it going informally in his practice for quite a while...He recognized that one woman needed another."231 If not for Gregory White, Cahill suggested, the League would never have come to fruition: "Seven mothers would only have been seven mothers without his professional guidance." 232 The third edition of The Womanly Art of Breastfeeding is dedicated to the League's participants, the founders' husbands and children, and "in a very special way" to "Doctors Herbert Ratner and Gregory White, all of whom helped the seven of us learn the womanly art of breastfeeding., ${ }^{, 233}$ To this dedication, the authors append a further paragraph thanking Ratner and White, without whose "unfailing counsel" the manual "would not have been written and the basic principles underlying the work of La Leche League would not have withstood the test of time as they have."234 Much of the League's philosophy derived from the founders themselves and developed over the years as they interacted with countless mothers from across the globe. However, Ratner and White's influence clearly helped to shape a construction of motherhood that, while it upheld women's moral authority and their power within their own homes, it also, in Bobel's words, led women to "police themselves as good mothers and good wives who protect

230 Ibid.

${ }^{231}$ Cited in Lowman, LLLove Story, 14.

232 Ibid.

${ }^{233}$ La Leche League International, The Womanly Art of Breastfeeding, $3^{\text {rd }}$ ed., v. ${ }^{234}$ Ibid. 
the socially constructed boundary between women and men."235 The founders might have been more amenable to mainstream feminism without the influence of these two men, but they may never have embraced natural mothering practices so strongly without Ratner and White's influence either.

Ratner and White were not the founders' only source of scientific information and support in their early days, however. The League cultivated relationships with other professionals, including several women. In fact, one of the ways the League demonstrated their medical backing in their earliest public meetings was by having Herbert Ratner's wife, Dorothy Ratner, attend. Although Dorothy Ratner shared with her husband, and the League, the view that children required full-time mothering, and was not practicing medicine professionally in 1956, she was a trained physician who kept up with current medical science. Froehlich said of Dorothy Ratner, "having her there gave our group a certain credibility, a certain legitimacy that we wouldn't have had otherwise." Having Dorothy Ratner at the meetings, was preferable to having her husband, or Mary White's physician husband, Gregory White, attend because if a male doctor sat in on a meeting, it was likely to devolve into a question and answer session with the doctor. Dorothy Ratner, by contrast, participated in the group primarily as a mother and, therefore, a peer. Her status as a doctor was significant, though, as was her silence on medical subjects. According to Froehlich, if Dorothy Ratner did not speak up, it meant that the League was correct because "(w)e knew she would let us know if we were giving mothers the wrong information., 236

${ }^{235}$ Bobel, The Paradox of Natural Mothering, 99.

${ }^{236}$ Cited in Cahill, Seven Voices, One Dream, 36. 
Dorothy Ratner's presence served mainly as a quality-check on the founders' medical information, but they tracked down most of this material on their own, making use of their existing relationships with people in the working in healthcare. Tompson recalled that "there was so little in print at the time that validated breastfeeding," that even after scouring Gregory White's personal medical library Mary White had only found one relevant book, which "was written by a male physician who, while wellintentioned, had some strange suggestions. For example, if the baby wasn't taking in enough milk, he recommended the mother give the baby an enema before a feeding!" 237 The founders finally found the information they were seeking when one of their early supporters, nutritionist Mildred Hatch, told them they should reach out to "this woman in New Orleans who is right up your alley" because she shared their "belief about doing things the natural way, especially when it comes to children."238

That woman was Charolotte Aiken, who, along with her husband, Gayle, published Child-Family Digest. The Aikens launched their journal in 1949 in memory of their son who had been killed in World War II. The Digest reprinted and commented upon articles about "child, parent and family relationships" culled from a variety of healthcare publications. In the first issue, the Aikens had avowed a mission to "oppose degenerative trends in our culture; to promote research; and to promote public understanding of the requirements for development of the mature, stable, well adjusted personalities which would constitute a socially cooperative, wholesome race. ${ }^{, 239}$ Like the League, the Aikens and their contributors believed that science could be put to use to

${ }^{237}$ Tompson, Passionate Journey, 62.

${ }^{238}$ Edwina Froehlich, cited in Cahill, Seven Voices, One Dream 38.

239 The Editors, Child-Family Digest 1, no. 1 (1949), n.p. 
create a more harmonious society. An epigraph in the same issue by Duke anthropologist and Digest advisory editor, Weston La Barre, summarizes this view:

Whether he knows it or not, man has the key to his own future evolution in his unwitting and unready hands, for through anthropological and psychiatric knowledge and control of the bringing up of our children, we are potentially able to shape almost any kind of human personality which an increasingly integrated world would seem to require. ${ }^{240}$

Although the Aikens asserted their efforts to "gather this dynamic knowledge impartially from authoritative sources in related fields," their journal promoted a particular worldview, influenced by a profound faith in the order of the natural world as well as mid-twentieth century American Catholicism, and therefore tends to endorse biologically determined behaviors and gender roles. ${ }^{241}$ Child-Family Digest remained influential to the League founders for decades. After the Aikens ceased publication in the late 1960s, the journal was acquired by the Catholic-leaning National Commission on Human Life, Reproduction and Rhythm, and Herbert Ratner took over as editor. In his first issue as editor, Ratner promised to publish articles "which illuminate traditional concepts of family, life and sex."242 Assembling articles with a slant toward nature, tradition and Catholic values culled from a variety of publications, the Digest could create the

${ }^{240}$ Weston La Barre, Child-Family Digest 1, no. 1 (1949), n.p. La Barre's anthropology was highly shaped by psychoanalytic theory and he tended to develop universal theories based on his observations of distinctive cultural practices.

${ }^{241}$ Child-Family Digest 1, no. 1 (949), n.p. The journal also reflected a faith in the perfectibility of humanity that harkened back to the eugenics movement of the early $20^{\text {th }}$ century. La Leche League's relationship with eugenicist thought would be an interesting avenue for future research but is beyond the scope of this project. For more on relations between religious groups and the eugenics movement see Christine Rosen, Preaching Eugenics : Religious Leaders and the American Eugenics Movement (Oxford: Oxford University Press), 2004.

${ }^{242}$ Herbert Ratner, "National Commission on Human Life Reproduction and Rhythm," The Linacre Quarterly 36, no. 1 (1969), 77. 
impression that the views expressed within it were more mainstream than they actually were.

The founders have described finding Child-Family Digest as a sort of epiphany. Marian Tompson remembered how "(w)e used to read and reread those copies of the Child-Family Digest" and how it "supported the way we were inclined and was a good education for us." ${ }^{243}$ According to Mary White, the Digest was a "goldmine" and Charlotte Aiken was the founders" "guiding light." ${ }^{\text {"24 }}$ Both of the Aikens "supplied the seven of us with large doses of support, and we soaked up everything in the Digest like sponges. ${ }^{245}$ Edwina Froehlich recalled how Charlotte Aiken helped the League expand their network by introducing the founders to others "who were interested in the same things" and describing the League to "people all over the country who were interested in an organization like ours." ${ }^{246}$ These recollections reveal that, from the beginning, the League turned to science for endorsement of beliefs they already held, and their sources skewed in the philosophical directions they were already leaning. Although this does not necessarily mean that the science the League embraced was inaccurate, it does mean that the League's selection of sources was not at all impartial. Further, their relationships with Dorothy Ratner — mother/physician — and Charlotte Aiken — mother/science publisher-highlight the League's internal conflict over whether scientific expertise or mothering experience lends greater credibility. Although the League almost always played up the scientific authority of male advisors, at times they downplayed the

${ }^{243}$ Cited in Lowman, LLLove Story, 23.

${ }^{244}$ Ibid.

${ }^{245}$ Ibid.

${ }^{246}$ Ibid. 
scholarly credentials of the female professionals who advised them in order to privilege the natural, embodied nature of women's breastfeeding knowledge.

The League's relationship with another female scientific advisor further underscores the uneasy balance between scientific expertise and maternal insight as sources of authoritative knowledge in the eyes of the League, breastfeeding mothers and the medical community. The League recommended behavioral psychologist Niles Newton's book The Family Book of Child Care in their earliest publications, and even sold copies of the book to raise funds for the organization. Newton was a highly qualified scientist and an expert on the psychology of pregnancy, childbirth, breastfeeding and childcare practices. She had earned her doctorate from Columbia in 1952, where she had written her dissertation on "Attitudes of Mothers of Newborn Babies Toward Their Biological Feminine Functions.” Newton's academic interest in breastfeeding had been sparked by the lack of support she had received for nursing at the hospital when her first daughter was born in 1944. Soon after giving birth, Newton, then an undergraduate student, searched medical libraries for information on breastfeeding, but found that "(a)lmost no well controlled studies on the management of breast feeding were available." Newton was "horrified" by what little information and misinformation she did find, much of which was "on the level of old wives' tales." 247 To counter this dearth of evidence, she and her husband, obstetrician Michael Newton later conducted several of their own studies on breastfeeding, including important analyses of the letdown reflex and the effects of the hormones prolactin and oxytocin. The Newtons also

${ }^{247}$ Niles Newton, "Breastfeeding Today," Speech at the National Convention for Childbirth Education, Milwaukee, WI, May 21, 1960. 
assembled and wrote reviews of what little credible breastfeeding research they could find. Niles Newton later studied cross-cultural analysis with Margaret Mead and, in 1967, the two jointly published an article (over eighty pages in length) on "Cultural Patterning in Perinatal Behavior.",248

Despite Newton's spectacular credentials, one of the major selling points of Newton's childcare manual, according to La Leche League News was that “Dr. Newton's approach, while based on her scientific knowledge, is essentially that of a mother who has nursed her babies."249 Although this assessment minimizes Newton's academic achievements, Newton herself asserted that, as evidenced by her own life and academic history, experience with breastfeeding was often the trigger for scientists to become interested in studying the issue, "Researchers now documenting the many unique qualities of human milk are very often parents of breastfed babies. ${ }^{\text {250 }}$ The best doctors for breastfeeding women were likewise those with personal experience according to Newton: "A woman doctor who has had an abundance of milk for her own babies is ideal. A male doctor who has a wife who has successfully breast fed his children is likely to be very helpful, since he knows from his own experience the intimacies of successful breast feeding." ${ }^{, 251}$ Even before she had corresponded with LLL, Newton suggested that a breastfeeding mother would find especially helpful advice from a friend or acquaintance who had breastfed. Presaging the League's community building, she wrote

\footnotetext{
${ }^{248}$ Margaret Mead and Niles Newton, "Cultural Pattering in Perinatal Behavior," Newton on Birth and Women: Selected Works of Niles Newton, Both Classic and Current (Seattle: Birth and Life Bookstore), 1990.

${ }^{249}$ Review of The Family Book of Childcare, by Niles Newton, La Leche League News 1 , no. 1, n.p.

${ }^{250}$ Niles Newton, Foreword to The Womanly Art of Breastfeeding, $3^{\text {rd }}$ ed., xiii.

${ }^{251}$ Niles Newton, Family Book of Childcare, 91.
} 
that not only would the new mother be helped but her friend would "almost certainly be pleased, since our society usually affords very little real recognition to mothers who breast feed successfully. ${ }^{, 252}$ Newton believed that recognition for achievements was important for a woman's psychological well-being. Over the years, however, although Newton remained an ardent supporter of the League, her views about what women needed departed from those of the League. Newton recognized that she had been unusually fortunate in having the financial and emotional support of her husband and the childcare support of her mother to enable her to pursue her academic career on a parttime basis while her four children were young. Based on her own experience, and an awareness that other women did not have the same opportunities, Newton became concerned not only with how women could shape a better society by raising emotionally and physically healthy children, but how society needed to be restructured to allow women more options for fulfillment through empowered birth and mothering experiences, fertility control and meaningful paid work. ${ }^{253}$ Thus, unlike LLL, Newton was able to reconcile her embrace of embodied maternity with mainstream second-wave feminist thought.

\section{Summary}

During the earliest years of their existence, La Leche League began to build a body of institutional knowledge about breastfeeding and mutual support to fulfill their mission to "(h)elp mothers successfully breastfeed their babies, and so successfully

\footnotetext{
${ }^{252}$ Niles Newton, Family Book of Childcare, 92.

${ }^{253}$ See Niles Newton, Newton on Birth and Women Selected Works of Niles Newton, Both Classic and Current (Seattle: Birth and Life Bookstore), 1990.
} 
mother them." ${ }^{254}$ They drew from a few existing bodies of knowledge: medical knowledge, which they (like most midcentury Americans) typically construed as masculine; domestic knowledge, which they saw as largely feminine but relatively unimportant in mother's lives; Catholic knowledge, to which they turned for moral and natural archetypes of motherhood; and embodied mothering knowledge, an exclusively feminine way of knowing that endowed breastfeeding mothers with insights not available to men or even to other women. The League amassed this knowledge in large part to counter the authority of oppressive, male medical experts and the consumerist cultural values that they felt interfered with women's experiences of mothering. Yet, along the way, LLL seems to have at times co-opted the authority associated with expert knowledge only to confuse and constrain new generations of women in service of their own institutional agenda of maternal breastfeeding.

The League advocated breastfeeding as a natural, instinctive biological process, governed by hormones and physiologic mechanisms, and they cited recent medical research to back up this model. They referenced Eve, who had apparently had no choice but to breastfeed in the Garden of Eden, as an exemplar of the time-honored, natural practice of breastfeeding. Yet in their manual, they also insisted, contradictorily, that women (except for Eve) needed the support and advice of a community of mothers to succeed in breastfeeding. ${ }^{255}$ The founders believed that their culture placed too much pressure on women to maintain unrealistic standards of tidiness in their homes, and they

${ }^{254}$ Cahill, "A Backward Glance and a Forward Look," 1. Emphasis in original. This mission was distilled following the conversation between the founders and Ratner transcribed in "A La Leche League Dialogue."

${ }^{255}$ La Leche League of Franklin Park, The Womanly Art of Breastfeeding, 1-2. 
argued in their manual that men should not hesitate to help their wives with housekeeping if necessary. However, men could only do this in their spare time, since the League still maintained the existence of a natural, gendered division of labor within nuclear families that entailed men working outside the home and women doing most of the childcare and upkeep within the home. Finally, in their efforts to valorize embodied female knowledge, the League often privileged mothering experience over the scientific training of the professional women who advised them. Beyond this, they also, rather strangely, asserted the importance of women's embodied knowledge by citing the opinions of their male medical advisors. In sum, the League's founders built a body of institutional knowledge that endorsed their vision of motherhood, but this knowledge was not always internally consistent and it was infused with unacknowledged values - patriarchal, classed, religious - that limited its appeal or applicability for women outside their own demographic milieu. 


\section{SHAPING AND RESHAPING INSTITUTIONAL KNOWLEDGE}

\section{Introduction}

Over the years La Leche League engaged with scholarly research on motherhood to add to their institutional knowledge, but they have incorporated elements of this research selectively. In some respects, the League broadened their recognition of different experiences of motherhood for women of different backgrounds, particularly working women. The League increasingly recognized that these women faced particular constraints on their abilities to mother in line with the League's ideal, which was based on particular white, middle-class, midcentury American values. However, the League's philosophy and their writings continued to suggest that these women should do their best to achieve LLL's mothering ideal regardless of their ability, or their desire, to achieve it. I begin this chapter by tracing LLL's selective engagement with anthropological studies of breastfeeding and their relationships with certain controversial scientists. I then explore the League's relationship with mainstream feminism in the late $20^{\text {th }}$ century. Finally, I analyze LLL's embrace of the psychological theories of John Bowlby and their continued ambivalence regarding mothers of young children working for pay outside the home. 


\section{Anthropological Knowledge}

Anthropological studies in recent decades have called into question the notion of a single maternal ideal of exclusive breastfeeding and constant physical and emotional availability. Evolutionary anthropologist Sara Hrdy has theorized that rather than extensive maternal investment, human childhood is characterized by the care of a variety of alloparents — particularly maternal grandmothers and elder sisters — whose assistance with tending and feeding nutritious supplementary foods allows mothers to return to productive work sooner. This decreased burden for mothers helped them to thrive and procreate sooner, while the care of kin or other community members, whose productive work was less valuable, helped to ensure the survival of toddlers who otherwise might have suffered from malnourishment or deadly gastrointestinal infections during the weaning process. ${ }^{256}$ Meanwhile a broad range of social and cultural anthropology studies have shown wide variation in birth, feeding and childcare practices in more recent history and the contemporary world. As Heather Montgomery summarized, “Anthropologists who have looked at childhood have consistently shown that there is no one universal form of nurturing or correct path to adulthood and that nurturance is as dependent on cultural and environmental considerations as it is on biological ones. ${ }^{257}$

Of course most of this anthropological research has been conducted in recent decades. However, Ian Wickes had written about anthropological evidence regarding infant feeding in his 1952 surveys, and even if the League's founders had been unaware

\footnotetext{
${ }^{256}$ Hrdy, Mother Nature.

${ }^{257}$ Heather Montgomery, An Introduction to Childhood : Anthropological Perspectives on Children's Lives (Malden, MA: Blackwell Pub), 2009.

106. See also Lancy, Anthropology of Childhood.
} 
of Wickes' research, they formed relationships with anthropologists and others who conducted cross-cultural studies early in their history. They just tended to cite their studies selectively. Wickes cited anthropological research in the first installment of his 1952 history of infant feeding, stating that "(a)nthropological studies show that there is a remarkable tendency to obscure the natural method of infant feeding." ${ }^{, 258}$ He cited prevalent taboos against feeding colostrum (the sticky, yellowish substance a new mother's breasts secrete before she begins producing milk), and a wide range of ages at weaning. He also stated that frequent bodily and skin-to-skin contact between mother and infant, even while actively breastfeeding, is not necessarily universal, illustrating this with a photograph of an Armenian woman leaning over an infant in a cradle to nurse, so that only the mother's breast and the child's mouth are in contact. ${ }^{259}$

The League turned to anthropological evidence primarily to support their argument for breastfeeding past one year of age. For information on this subject they turned to famous anthropologist Ashley Montagu, who joined LLL's Professional Advisory Board within the first few years of the League's existence. ${ }^{260}$ Montagu wrote to Marian Tompson in 1960 in response to her question about weaning in "more natural societies," saying that he did not know of any comprehensive studies on the subject but that "Australian aborigines often suckled the children for three years" and that "a good many Indonesian peoples often nurse their children for as many as six years." He said there was "a great deal of variability" in weaning age, but estimated the average age

\footnotetext{
${ }^{258}$ Wickes, "A History of Infant Feeding I," 151.

${ }^{259}$ Wickes, "A History of Infant Feeding I," 152.

${ }^{260}$ Cahill, Seven Voices One Dream, 79.
} 
among "non-literate peoples" as 2.25 years. ${ }^{261}$ He pointed Tompson to The Cross Cultural Survey Center at Yale as a fund of anthropological information that would include breastfeeding duration. Montagu believed that obstetricians were not well informed about weaning and that "it is far better to follow motherly instinct than any rule of thumb. ${ }^{262}$ What motherly instinct means here is unclear and could be usefully interpreted to mean anything the League wanted.

Interestingly, just three years before asking Montagu for information from "natural societies" to bolster their extended weaning philosophy, the League had rejected evidence from such societies as examples of natural behaviors. In an early issue of the News a question and answer segment included the question "Why do the Polynesians breast feed two, three and four years?"263 The League's response was "Some Polynesian groups do and some don't. Many groups of people all over the world nurse until two or three years because the baby wants to. If nursed past that age, it's probably because starvation would be the only alternative. Why must we incorrectly equate good natural practices with 'natives on a little island?' They are just as apt to be misled as anyone, anywhere." ${ }^{264}$ This answer is somewhat confusing, but it gives the impression that breastfeeding until two because a child wants to is natural, but breastfeeding longer because a child might starve is not. Perhaps this second option is not natural because it is a response to particularly exigent circumstances.

\footnotetext{
${ }^{261}$ Ashley Montagu to Marian Tompson, 26 April 1960, Box 87, Folder 1, La Leche League International Records, DePaul University Special Collections and Archives, DePaul University.

${ }^{262}$ Ibid.

263 "Some Questions Fathers Ask," La Leche League News 2, no. 4 (1959), 3.

${ }^{264}$ Ibid.
} 
Several anecdotes in early League publications tried to find inspiration for human breastfeeding from even more natural sources in the animal kingdom. Rather than primate studies by anthropologists, League writers cited the example of their pets, cats in particular, as inspiration for true, natural motherhood. In her column "Memos from Marian" in the News, Marian Tompson joked that mothers looking for a new source of moral support (in addition to The Womanly Art of Breastfeeding, of course) should obtain a mother cat. The Tompson family cat, Domino, had recently given birth to two kittens and proved to be a remarkable mother who "didn't seem to mind (the kittens') continuous nursing," and was with her offspring nearly nonstop, responding to the "tiniest mee-ow." Tompson remarked sardonically that not nursing the kittens never occurred to the cat or any of the Tompson family, and "(n)o one suggested that the milk of Cindy Lou, the Cocker Spaniel next door, might be more nourishing for newborn kittens or at least would help them to sleep all night." ${ }^{265}$ While Tompson's account was lighthearted and satirical, the cat allegory crossed into more dubious territory when it was employed by a doctor. In a 1959 magazine article, Dr. Lloyd Smith wrote about his breastfeeding cat, Mitzie. ${ }^{266}$ He recommended La Leche League as a source to help human mothers do what Mitzie was able to do purely by instinct. While Smith's story was intended to be cute, the fact that it was published with a doctor's name appended suggests that there is some sort of scientific authority to the article, rather than an inappropriate comparison

\footnotetext{
${ }^{265}$ Marian Tompson, "Memos from Marian," La Leche League News 4, no. 3, n.p. ${ }^{266}$ Lloyd Smith, "I wish you could meet Mitzie," Let's Live Magazine (1959), Box 4, Folder 1, La Leche League International Records, DePaul University Special Collections and Archives, DePaul University.
} 
between animals with highly different evolutionary patterns of infant maturity and infant care.

The League did have other sources of legitimate anthropological insights, however. Although she was a psychologist by training, Niles Newton trained with renowned anthropologist Margaret Mead. In 1967, the two collaborated on an expansive article on "Cultural Patterning in Perinatal Behavior."267 Broadly speaking, Newton and Mead's study supported the League's overarching belief that childbirth was primarily managed by women and that most mothers breastfed their infants. However, the study revealed a wide variability in exactly how these processes were managed, even within relatively undeveloped societies. ${ }^{268}$ The League does not seem to have taken much notice of these differences. The founders were not interested in shades of gray or different ways of being a mother; they looked at the general trends and were satisfied that these supported their beliefs.

More recently, the League has promoted the research of one of their current professional advisors, anthropologist James J. McKenna, and writings by anthropologist Meredith Small on the subject of mother-baby co-sleeping. ${ }^{269}$ They have done so to counter widely held taboos in American and other cultures against adults sleeping with children. These taboos derive from concerns about inappropriate sexual contact between

${ }^{267}$ Mead and Newton, "Cultural Patterning in Perinatal Behavior." ${ }^{268}$ Ibid.

${ }^{269}$ James J. McKenna, Helen L Ball, and Lee T Gettler, "Mother-Infant Cosleeping, Breastfeeding and Sudden Infant Death Syndrome: What Biological Anthropology Has Discovered About Normal Infant Sleep and Pediatric Sleep Medicine," American Journal of Physical Anthropology 134, no. S45 (2007), 133-61; James J. McKenna, Sleeping with Your Baby: A Parent's Guide to Cosleeping, 3rd ed. (Washington, DC: Platypus Media, LLC), 2012; Small, Our Babies, Ourselves. 
adults and children or children witnessing sex between their parents, as well as fears of overlaying (rolling over and smothering the child) and Sudden Infant Death Syndrome (SIDS). McKenna's research, based on insights from primate behavior and extensive data from his mother-baby sleep lab, shows that such fears are mostly exaggerated and that in most cases — and following certain safety precautions—-mothers sharing sleep with their children can be beneficial to the physical and emotional health of both mother and child. $^{270}$ This anthropological evidence provides validation for the many League participants who engaged in this practice, which ran counter to the recommendations of public health agencies and the American Academy of Pediatrics. The League asserts that families should make their own choices about sleeping arrangements and that " $(t) h e$ only right choice is what works to give the whole family as much rest as possible." However, they cite a passage from Small's Our Babies, Ourselves that strongly suggests that not co-sleeping is misguided and likely damaging to children:

For millions of years, the normal sleeping position of human infants has been on their backs nestled next to mother. Only in western cultures do we force babies to sleep alone, thinking they are more safe and independent placed in a crib with no contact. But history, and how most babies sleep in other cultures, suggests that the West is out of step with what is best physically and emotionally for our children. ${ }^{271}$

Despite the emphasis on choice, it is evident that from the League's perspective, not cosleeping is a choice made for the parents' benefit rather than the children's, and the overarching narrative of League literature and philosophy has established that children's

${ }^{270}$ Cited in La Leche League International, “Should I Sleep With My Baby?” 9 January 2016, accessed, November 6, 2017, http://www.1lli.org/faq/cosleep.html.

271 Ibid. 
needs should be placed ahead of parents.' Parents can make other choices, but these choices are not neutral in their implications.

\section{Controversial Knowledge}

The League has been accustomed to a certain amount of controversy surrounding their professional advisors since their earliest days. The League's advocacy of natural childbirth and maternal breastfeeding were countercultural views in 1956, so any doctor proposing these practices was already somewhat anti-establishment. While White may have had his detractors and Ratner was often intentionally incendiary in his critiques of modern medicine, the most provocative early medical advisor of the League was Grantly Dick-Read. Arranging a talk by this internationally known British obstetrician, the author of Childbirth Without Fear, was the League's first major public relations coup. ${ }^{272}$ All of the founders had read Dick-Read's book to prepare them for their natural labors and they appreciated his method as well as his description of the spiritual, almost mystical experience of giving birth without sedation. In 1957 the founders heard that Dick-Read was doing a speaking tour in the United States, so they took the risk of paying his steep \$700 speaking fee and brought him to speak in Franklin Park. The event turned out to be a blockbuster, attracting an audience of hundreds of physicians and natural childbirth enthusiasts from three states. Ticket sales left the League with a profit of $\$ 350$, enough to print the first edition of their manual, The Womanly Art of Breastfeeding. The League was blown away with the success of the event, especially since newspapers,

${ }^{272}$ Grantly Dick Read, Childbirth Without Fear, $2^{\text {nd }}$ ed. (London: William Heinemann), 1954. 
including the Chicago Tribune, had refused to print notices, believing that Dick-Read was a quack. $^{273}$

Mary Ann Cahill recalled that although Dick-Read was a world-famous physician, she did not feel intimidated by him at the reception after his talk, "We were all part of a subculture and we took to each other on that basis. It was more a case of our all being cohorts together rather than his being a celebrity whom we were privileged to meet." ${ }^{274}$ Mary Ann Kerwin remembered that meeting Dick-Read was a truly validating experience:

His talk was wonderful. He wasn't an entertainer, but it was the content and the reassurance of what we believed about childbirth and breastfeeding. He just underlined everything we were doing. And, of course we had all read his book. It was just wonderful to hear him say all those things in person. It was a reaffirmation of what we were saying, which we badly needed. I mean, we were looking so much for acceptance. And respect. We wanted to be respected. We knew we were right but we weren't getting widespread support. But that night we got plenty of support! $!^{275}$

This lengthy passage clearly demonstrates that the founders looked to scientific authorities, like Dick-Read, to support feelings they already held. As Kerwin states, the founders had all read Dick-Read's book years before, and they had all utilized his natural childbirth technique. The doctor's philosophy was thus already imbricated with their own, having contributed to their views of mothering since the time they had given birth to their oldest children. Hearing Dick-Read speak was then a circular confirmation of a belief system that he had largely shaped in the first place.

${ }^{273}$ Lowman, LLlove Story, 21.

274 Ibid.

${ }^{275}$ Cahill, Seven Voices, One Dream, 81-82. 
The League's current association with celebrity pediatrician William Sears and has led to several controversies, most notably when Time magazine published an article on William Sears called "The Man Who Remade Motherhood." 276 The Time issue created a media uproar, particularly due to the provocative cover depicting a young, attractive woman nursing a standing three-year old boy, while her breast is partly exposed and both look directly at the camera. This image is paired with the incendiary headline "Are You Mom Enough?" Although LLL is not mentioned in the Time article, Sears and his family have a long history with the group. His wife and sometime co-author, Martha, is a former LLL Leader and Sears is a longtime member of LLL's Medical Advisory Board/Health Advisory Council. Many of his books and a Dr. Sears branded baby sling have been available for purchase through LLL, with a percentage of profits going to the League. Many members of LLL embrace Sears style of parenting, finding that Sears' "attachment parenting" philosophy fits well with the ten principles of the La Leche League Philosophy. ${ }^{277}$ Although the controversy surrounding Sears and the Time issue may have turned off some mothers who were not already familiar with the organization or the celebrity doctor, ultimately it probably mainly served to provide the League with press coverage and reaffirm the values of those who already embraced Sears and the League. $^{278}$

${ }^{276}$ Kate Pickert, "The Man Who Remade Motherhood," Time, May 21, 2012. 277 Ibid.

${ }^{278}$ At least one LLL subsidiary group criticized the Time cover as incendiary while praising Sears. See La Leche League of Washington, "Time Magazine Response," c. May 2012, accessed November 6, 2017, http:/www.lllofwa.org/2012/05/time-magazineresponse. 
While they may not have reached quite the same level of celebrity or notoriety as Dick-Read and Sears, Gregory White and Herbert Ratner did have controversial viewpoints. Beyond simply advocating all things natural, both men came to highly moralistic conclusions about the meaning of breastfeeding. According to White, the physical process of breastfeeding fundamentally and uniquely shaped the mother-child relationship to the point that a mother who did not breastfeed could never reach her full potential as a mother:

The mother is enormously influenced and developed by the breastfeeding relationship, even on a physical basis. The mother who bottlefeeds doesn't have high prolactin levels, and doesn't have the same physical feelings toward her baby. She's handicapped. If she had a good mother and a good grandmother and was brought up with her motherly feelings encouraged, she may turn out to be a pretty good mother. But she could have been a lot better mother if she had breastfed. ${ }^{279}$

For Ratner, the significance of breastfeeding was not just that the experience of breastfeeding made women better mothers, but that the choice to breastfeed in itself demonstrated a certain level of fitness for motherhood, and choosing not to breastfeed demonstrated the opposite. Breastfeeding, per Ratner, "is the first occasion where the mother's desires to retain the advantages of the childless state are being tested. If she doesn't win this battle, let us recognize that she is not as yet psychologically ready for the road ahead, and the joys ahead."280 Thus, for the League's two most important medical advisors, breastfeeding was both a cause and a symptom of good mothering.

${ }^{279}$ Cited in LLLove Story, 49.

280 Ratner, "Comments on Breastfeeding," 1. 


\section{Feminist Knowledge}

In contrast to White and Ratner, Niles Newton felt that negative social pressures against breastfeeding were powerful and that cultural perceptions of the breast as sexual could be significant deterrents to breastfeeding: "The idea of putting the baby to the breast may seem a little disgusting to you. Quite a number of women feel that way nowadays. It a natural feeling to have in a society like ours." ${ }^{281}$ Although she was a strong proponent of breastfeeding and had done a number of studies that highlighted that hormones released during breastfeeding gave women physical and emotional pleasure and increased maternal behaviors, she did not have nearly so negative an opinion of women who did not breastfeed or of the prospects for their children's emotional and physical health. In her childcare manual, she consoled bottle-feeding mothers, "If you try to breast feed your baby but can't go on, don't feel inadequate or that you are depriving your baby of a good start in life. The really important thing is your basic relationship with the baby - regardless of breast feeding or bottle feeding."282 The League as an organization disagreed with Newton's acceptance of bottle feeding and qualified its endorsement of her books saying, "Certain sections seem geared more to the bottle-fed baby, and the section on weaning is not in accord with LLL recommendations." 283

Related to her acceptance of bottle feeding, Newton also disagreed with general League philosophy that employment was an impediment to motherhood, especially for breastfeeding mothers. As early as 1957 she wrote:

Jobs are quite compatible with breast feeding after the first few months. One woman doctor I know nursed all five of her children for six months yet worked

${ }^{281}$ Niles Newton, Family Book of Childcare, 93.

282 Ibid.

${ }^{283}$ La Leche League International, The Womanly Art of Breastfeeding $2^{\text {nd }}$ ed., 144. 
forty hours a week. She went back to work when the children were two months old, and fed them two breast feedings before she left in the morning and two more after she came home at night. The babies needed only one bottle to see them through the day. ${ }^{284}$

As mentioned above, Newton recommended a female doctor who had breastfed as the best physician for a nursing mother.

Newton never ceased her support of the League's breastfeeding advocacy efforts, but over time her feminism demonstrated a much more radical tendency than the League's maternalist strand. Despite the growing social influence of the Second Wave of feminism from the early 1960s, La Leche League's basic positions on womanhood and motherhood had not really changed since 1956. By 1971, despite her continued relationship with LLL, Newton seemed to have more in common with the Boston Women's Book Collective and other feminists at the core of the women's health movement. She strongly rejected universal constructions of women and mothers, and instead of suggesting a return to imagined historical modes of life or that individual families make compromises between work and full-time motherhood (as LLL suggested), Newton advocated a more fundamental restructuring of society which would adapt to new demographic realities of work and fertility:

To sum it up, this world which we are creating in the seventies - with its increasingly effective techniques for fertility control—is a world which could be unfortunate in its emotional impact on women-unless women are given more opportunities for meaningful work outside the home - unless more effort is made to make each of the fewer child-bearing experiences truly satisfying ones andunless we individualize between women, letting each find a fertility pattern which maximizes her gifts and potential service to the world. ${ }^{285}$

${ }^{284}$ Newton, Family Book of Childcare, 88.

${ }^{285}$ Niles Newton, "What Women Need Most," Baby Talk, (May 1971), emphasis in original. 
Newton's strand of feminism, like that of La Leche League, sought to valorize women's reproductive and domestic roles as important contributions to society, but she did not believe motherhood was or should be the primary occupation of all women, or even of all women with small children. She saw successful breastfeeding and full-time childcare as beneficial to the emotional and physical health of both mothers and children, but she did not see the alternatives as inherently inferior, especially in the changing world of the 1970s when women were raising fewer children than they had in the previous generation. She believed that a desire to raise healthy, competent children was the foundation of good motherhood and that a variety of routes could be followed to achieve this end.

Over time, as the League accumulated more stories from more women, and popular early stories were repeated and reinterpreted, the League's collective memory evolved in response to changing social conditions and priorities of its participants. In recent years, the League has reconsidered their early history and recast the founders as precursors of both Consciousness-Raising and the women's health movement. The League's 2003 history, The Revolutionaries Wore Pearls, encapsulates the League's current construction of their organization as a simultaneously progressive and traditional organization. ${ }^{286}$ Writer Kaye Lowman said that although "it is unlikely that any of La Leche League's Founders had even heard the word 'feminist' in 1956, they were clearly on the leading edge of the feminist revolution, creating a revolution of their own with

${ }^{286}$ Lowman, The Revolutionaries Wore Pearls. 
worldwide repercussions. ${ }^{, 287}$ She compared the traditions they embraced to pearls:

harmless, charming, decorative aspects of the femininity of a bygone era:

They cooked and cleaned, ironed their husbands shirts, and hung the bed sheets on a clothesline to dry, prepared meals from scratch, wore pearl necklaces and white gloves, volunteered in their churches, schools, and communities, and among them raised a total of 56 children... Not a typical description of revolutionaries. But they were anything but a typical group of women. ${ }^{288}$

These relatively innocuous domestic tasks defined the women as typical of their era, in Lowman's assessment. What defined them as atypical was that, "They thought for themselves. They rose above the stereotypical role models of their culture. They refused to be defined by other people's ideals or expectations. They dared to do what they believed was right, regardless of what neighbors, relatives, or even doctors said they should do." 289 Yet, this praise of the founders inadvertently, or perhaps intentionally, insults the other women of their era, implying that they were all conformist flunkies who did not think for themselves.

Lowman distinguished the League's feminism from other branches of feminism to a certain extent, by emphasizing their traditional domesticity. She implied that the League's feminism went down a somewhat conservative, maternalist path largely because of the organization's emphasis on motherhood. For example, Lowman wrote that Gregory White "believed that nature intended women to enjoy giving birth." ${ }^{290}$ She cited Edwina Froehlich's reflection on the disconnect between male doctors and the underlying meaning of breastfeeding:

${ }^{287}$ Lowman, The Revolutionaries Wore Pearls, 5.

${ }^{288}$ Lowman, The Revolutionaries Wore Pearls, 3.

${ }^{289}$ Lowman, The Revolutionaries Wore Pearls, 5.

${ }^{290}$ Lowman, The Revolutionaries Wore Pearls, 8. 
'I felt strongly that the medical community was doing a terrible disservice to women,' Edwina said. 'For the most part, doctors at that time were men. I didn't have a problem with that, I just thought, "Come one-what do they know about this natural, womanly art?" In my mind, it had nothing to do with medicine. Nourishing her baby with the milk from her body was a gift only a woman could give to her baby. I really wanted women to understand this and to be proud of being a woman. 291

Thus for Froehlich, not just female, but maternal embodiment was central to her understanding of empowerment, with birth and breastfeeding providing women with deep satisfaction. This in many ways echoes the sentiments of the introduction, likely written by Herbert Ratner, to “A La Leche League Dialogue," that formative conversation between Ratner and the founders in which they had defined the League's mission and ideology. However in 1974, when that introduction was written, Ratner (or whoever the author was) asserted that the League, while "a woman's movement," was clearly distinct from "the feminist movement."

...La Leche League's strength was that it was truly a woman's movement, grounded on the realities of nature and responsive to nature's vested and unimpeachable goal, namely that woman, the nurturant, be her womanly self (and man, his manly self). In this sense, it was distinguished from the feminist movement, a movement it is bound to outlast, since nature is on its side. ${ }^{292}$

That Ratner saw it necessary to mention the feminist movement signals an underlying concern about its influence. In Ratner's view, feminism went against nature, and the feminist movement was therefore misguided and its aims suspect.

One might argue that an emphasis on motherhood, birth and breastfeeding would necessarily lead one into the sort of maternalist, semi-traditionalist feminism the League embraced. However, Niles Newton also felt strongly about the possible impact of

${ }^{291}$ Cited in Lowman, The Revolutionaries Wore Pearls, 8. 292 “A La Leche League Dialogue," 198. 
motherhood on women and advocated for natural birth and breastfeeding, but she came to different conclusions than the League. Newton believed, based on experience as well as her scientific and cross-cultural studies, that birth, breastfeeding and mothering could be deeply satisfying. Where Newton diverged was that she did not feel that these were essential components of female embodiment or necessary for a woman's sense of fulfillment. Since Newton's studies formed the scientific underpinnings of much of the League's philosophy, Newton's style of feminism represents a path not taken by the League. For Newton, her studies of women impelled her to seek new rights and opportunities for them in the public sphere, but the League did not follow this lead. The League could have followed Newton into a more radical form of feminism and a less universalized vision of motherhood. Instead they chose to embrace only the elements of Newton's science that supported the views they already held, rejecting those that upset their existing thought.

\section{Psychological Knowledge}

The portion of the League's ideology that Newton's support of employment upset was the "third concept" of the League's ten-concept philosophy. The third concept states "In the early years the baby has an intense need to be with his mother which is as basic as his need for food." This concept was based on the belief that mothers and infants should not be separated except in cases of dire necessity such as extreme poverty or hospitalization. It was highly influenced by the research of British psychologist John Bowlby, the father of attachment theory, who wrote of the dramatic psychological 
damage arising in children as a result of "maternal deprivation." 293 Bowlby's attachment theory has been taken by many, including La Leche League, to mean that a very young child requires a one-on-one, intensive, highly physical and emotional relationship with its mother (or an individual, permanent mother substitute). According to Bowlby, long-term separations can lead to delinquency and psychopathy, but even short separations cause significant distress. However, Bowlby's research was based largely on observations of delinquents, criminals and homeless children following World War II. His work has been criticized for its small sample sizes, methodological flaws, and a failure to distinguish between privation and deprivation, that is, the lack of a strong mother-child relationship versus the sudden loss of a strong mother-child relationship. ${ }^{294}$ Although she was not directly critiquing Bowlby, Newton wrote in her 1955 book, Maternal Emotions, of the dangers of extrapolating from data based on "disturbed" subjects in clinical or institutional settings: "(T)here is no proof that emotional phenomena in disturbed persons are only quantitatively different from those who seek no aid in handling their emotions." A person who is deemed in need of professional psychological help "may have a somewhat different kind of emotion... as well as a different degree of emotion." 295

Nevertheless, the League has continued to use Bowlby's attachment theory to argue against mothers of young children working outside the home, citing Bowlby's

${ }^{293}$ John Bowlby and Edwin Powers, "Forty-Four Juvenile Thieves: Their Characters and Home-Life," Journal of Abnormal and Social Psychology 43, no. 4 (1948), 561-63; John Bowlby, Maternal Care and Mental Health, World Health Organization Monograph Series No. 2 (Geneva: World Health Organization), 1951.

${ }^{294}$ Michael Rutter, Maternal Deprivation Reassessed 2nd ed. Penguin Modern Psychology (Harmondsworth, Middlesex: Penguin Books), 1981.

${ }^{295}$ Newton, Maternal Emotions, 7. Emphasis in original. 
research as recently as 2013 to support the unchanged language of the third concept. ${ }^{296}$ Many women and feminist organizations have interpreted the League's deployment of science such as Bowlby's, along with related assertions—-such as White's and Ratner's that breastfeeding mothers are more maternal and more mature - as moralizing and guiltinducing. ${ }^{297}$ The League has denied that their use of science is moralistic or that they have ever intended to make anyone feel guilty. Mary White emphatically rejected the notion that the League's science or philosophies could be coercive: "It seems as though some folks would have us believe that, simply by presenting the facts, we have made these mothers feel 'guilty.' Well, I am sorry, I just don't buy that. You cannot force a woman to breastfeed her baby." ${ }^{298}$ Women attended LLL meetings "of their own free will" and decided for themselves whether and how to breastfeed. "The decisions are all theirs. We just want to make sure that they are making informed decisions." ${ }^{299}$ The League's science was, in White's view, disinterested fact of which women needed to be informed.

Not only was the League's science disinterested, according to White, it has always been unassailable. "Incidentally, none of our references has ever been disproved...Nobody has said, 'Oops, La Leche League told me that that drug was okay and now it's been proven that it isn't okay.' That hasn't happened." ${ }^{300}$ Mary Ann Cahill likewise sweepingly asserted that the League has "never been proven wrong on any of the

296 Betty Crase, "A History of the Mother-Baby Togetherness Concept," Leaven 48, no. 1 (2013), 10.

${ }^{297}$ See Martucci, Back to the Breast for discussion of women's resentment of the League's moralizing language.

${ }^{298}$ Cited in Cahill, Seven Voices, One Dream, 65.

299 Ibid.

${ }^{300}$ Cited in Cahill, Seven Voices, One Dream, 97. 
medical or breastfeeding information that we presented. This was certainly true of the first manual. ${ }^{301}$ It is, of course, hard to counter that anyone has ever truly proven the League wrong as the argument would likely devolve into an ontological debate about what can be proven or disproven by science, but the League itself has changed its position on certain medical recommendations. Most glaringly, the first manual suggested that it was not necessary for mothers to quit smoking while breastfeeding, and that doing so might actually be a poor decision because it would heighten a mother's stress level and inhibit the let-down reflex necessary for milk release. ${ }^{302}$ It is particularly interesting, therefore to consider the League's position in a recent, 2015, press release in response to a New York Times column that had been critical of the League and breastfeeding advocacy more broadly. In this press release, the author, presumably Diana West, LLL's Director of Media Relations, compared the low rate of breastfeeding in the mid $20^{\text {th }}$ century to the high rates of smoking in the same era. Both were due, according to the author, to dis- or misinformation that has subsequently been corrected by later medical research which was ostensibly more accurate and impartial than earlier research supporting the earlier view. Further, the press release dismissed evidence from recent studies that disputed some of the positive impacts of breastfeeding. However the wording is at times contradictory and its logic is circular.

This deepening understanding of the importance and value of human milk for human babies from an immunological, physiological, and psychological standpoint is a result of an ever-increasing, vast, and incontrovertible body of research. Even though occasional studies refute or question certain qualities, the world's scientists and health organizations have conclusively concluded that

\footnotetext{
301 Ibid.

${ }^{302}$ La Leche League of Franklin Park, The Womanly Art of Breastfeeding, 25.
} 
breastfeeding is essential for infant and maternal health because the overall research has definitively proven its worth and importance. ${ }^{303}$

If the evidence is incontrovertible it may be possible to question it, but it should not be possible to refute it. While the use of the phrase "conclusively concluded" may be a typo, this redundancy may also be an effort to shore up an assertion that is not nearly as certain as the author would like it to seem. Moreover, the entire sentence is a circular argument that essentially states that scientists have proven that breastfeeding is important by proving that breastfeeding is important. The author further denies that arguing from a scientific basis could ever possibly be construed as moralizing, anyway. She also insists that mothers could not behave against their own desires or interests. She asserts that “There isn’t any pressure in our society that could force intelligent women to do something that doesn't make sense. Mothers simply want to breastfeed because they want the best health for their children and themselves." ${ }^{304}$ Yet this sentiment directly contradicts the League founders' frequent acknowledgment that, in the 1950s, intelligent women, including themselves, were pressured into bottle feeding, largely influenced by doctors who claimed they had science on their side.

\section{Working Knowledge}

Laying aside the objectivity of the science that the League has used to support their arguments against mother-child separation, they have absolutely used other forms of

\footnotetext{
${ }^{303}$ La Leche League International, "La Leche League International Refutes New York Times Editorial,” [Press Release] 3 November 2015, accessed 6 November 2017, http://www.1lli.org/lllinews2015/11li_refutes_newyork_times_editorial. ${ }^{304}$ Ibid.
} 
moral and emotional argument to persuade mothers not to work. By the $1980 \mathrm{~s}$, the League recognized that more and more mothers of young children were working outside the home and leaving their children in the care of others. As described above, the League was facing a financial crisis at this time and its growth had dropped off steeply. The Board had to decide if they wanted to provide breastfeeding advice and support to working women, who might not have anywhere else to turn, or to continue to argue for their deeply held belief that women should remain home while their children were small. Ultimately, the League hedged their bets and did both.

The 1983 edition of The Womanly Art of Breastfeeding was the first to feature a chapter on breastfeeding while working, but a significant portion of this new section was devoted dissuading mothers from working in the first place. It contained dire warnings to women about the unreliability of day care centers and nannies and the psychological risks to children tended by inadequate caregivers. The text is deeply manipulative, and seems almost designed to make an already conflicted mother cry: "A baby's first steps can never be as meaningful to a sitter as they are to mother. Sharing the excitement and wonder of such everyday triumphs is payday for a mother with a little one, and there is a sense of sadness when it's missed."305 The chapter also suggested a number of ways to cut back on costs so that families can survive without a mother's income (assuming that a father exists to earn for the whole family) and strategies for bringing a baby into the mother's workplace. Images of a contented Kaye Lowman sitting at a computer with a quiet baby in her lap and a smiling preschool teacher wrangling children with a baby strapped to her back grace the pages of the section of bringing baby to work, suggesting

${ }^{305}$ La Leche League International, The Womanly Art of Breastfeeding $3^{\text {rd }}$ ed., 62. 
that if a mother could not do her job and care for a baby at the same time, she was not trying hard enough. ${ }^{306}$

Two years later, in 1985, the League published an entire book, The Heart Has Its Own Reasons, penned by founder Mary Ann Cahill, whose aim was to "show you how to economize, spend money wisely, grow your own food, conserve energy, discover hidden assets, increase your income, and enjoy life while focusing on the importance to the family of having a mother-at-home while her children are small." ${ }^{\text {307 }}$ Cahill and the League deemed the physical, psychological and economic burdens these practices place on mothers worth the sacrifice for the sake of the child.

Marian Tompson's account of when she first began to work in the League office is revealing here. Despite having dedicated countless hours to her League duties and having travelled internationally to speak on behalf of the League, Tompson did not begin working from the La Leche League office until roughly seven years after it had been opened, when her youngest son was in second grade. Even then she only went to work there one afternoon a week. For Tompson, simply being at home held deep symbolic significance regardless of what she was doing there, whether League work or domestic duties. "I really didn't want to go into the office because it wasn't my image of myself," she said, "I was a mother, not a career person." 308 For Tompson, the fact of working is not nearly as problematic as the location of work, "I always say that a woman who can work at home is really the most liberated woman because she can decide what she is

\footnotetext{
${ }^{306}$ La Leche League International, The Womanly Art of Breastfeeding $3^{\text {rd }}$ ed., 65, 67. ${ }^{307}$ Mary Ann Cahill, The Heart Has Its Own Reasons: Mothering Wisdom for the 1980s (Franklin Park, IL: La Leche League International), 1983, back cover.

${ }^{308}$ Cited in, Cahill, Seven Voices One Dream, 107
} 
going to do and when she is going to do it." ${ }^{309}$ This perspective falls in line with LLL's general emphasis on keeping League administrative positions mother-sized, a term they understood to mean that League work should always take a backseat to the more important daily work of mothering.

Tompson butted heads on the subject of women's work with no less a figure than Betty Friedan. In 1964, Tompson had attended a meeting of the Maternal and Child Health Association in Springfield, Illinois where Friedan was the keynote speaker. During a breakout session when Friedan was talking about "why it was important for a woman to have a paycheck as a confirmation her worth" Tompson stood up, holding her three month-old son, and said that "just seeing Philip breastfeeding, happy, and healthy, and knowing how I contributed to this was all the justification I needed to feel important as a woman." 310 Friedan replied to Tompson that "you are building up your self esteem at the expense of your baby." ${ }^{311}$ Tompson said this encounter demonstrated to her that she and Friedan "were the product of two very different life experiences, and she might never understand why I enjoyed being a mother."312 However, Tompson did not recognize that she, in turn, had failed to fully understand Friedan's message. In Tompson's emphasis on a "paycheck" she believed that Friedan saw work as meaningful only for monetary gain and financial independence. Certainly, this was important to Friedan. But, again, focusing on the notion of pay, Tompson overlooks the reality that, other than the fact that she was not paid wages for her League work, and that she tried to

\footnotetext{
${ }^{309}$ Cited in Cahill, Seven Voices, One Dream, 89.

310 Tompson, Passionate Journey, 58.

311 Ibid.

312 Tompson, Passionate Journey, 59.
} 
work from home whenever possible, she was a working mother. She engaged in work beyond meeting the needs of her family, work that was intellectually stimulating and allowed her to contribute to a cause she believed in - the welfare of mothers and children. Even though she travelled internationally and spent many hours on League activities, Tompson was able to maintain avoid cognitive dissonance between her constructions of "mother" and "career woman" by classifying her LLL tasks in her mind as something other than work.

Tompson's views on work were not necessarily shared by all of the League founders, as several of them worked nearly full time in the League office. However, as mentioned above, they still largely shaped their work schedules around their children's school schedules, in an effort to keep even paid League jobs mother-sized. In subsequent editions of The Womanly Art of Breastfeeding, the sections about working and breastfeeding were less focused on persuading women not to work at all costs, but the League did continue to suggest that women go above and beyond to integrate work with breastfeeding and family life. ${ }^{313}$ While developing workplace structures and childcare arrangements that enable women to satisfactorily combine motherhood and productive work is a worthy goal, and the League actively structures its own operations to allow mothers to balance work, volunteer and family responsibilities, the League's distaste for

${ }^{313}$ La Leche League International, The Womanly Art of Breastfeeding $4^{\text {th }}$ ed.; La Leche League International, The Womanly Art of Breastfeeding, 40th Anniversary $\left(5^{\text {th }}\right)$ ed. (New York: Penguin Books), 1997; Judy Torgus, Gwen Gotsch, and La Leche League International, The Womanly Art of Breastfeeding 6th revised ed. (Schaumburg, Ill.: La Leche League International), 1999; La Leche League International. The Womanly Art of Breastfeeding 7th revised ed. (New York: Plume), 2004; La Leche League International, Diane Wiessinger, Diana West, and Teresa Pitman, The Womanly Art of Breastfeeding 8th revised ed. (New York: Ballantine), 2010. 
political engagement and their lingering reservations about mother-baby separation prevented them from actively lobbying for mother-friendly workplaces. This has left most of the burden for securing such arrangements on individual women rather than on government or industry. Just as the League once praised women for economizing and clipping coupons to stay home, they now lionize women who make enormous sacrifices to work and breastfeed. The 2005 book, Hirkani's Daughters published by the League was inspired by a four-hundred-year-old legend about a mother who climbs down a one thousand foot sheer cliff-face to breastfeed her child. It contains stories of contemporary women who work and breastfeed. ${ }^{314}$ The subtitle is highly telling: Women Who Scale Modern Mountains to Combine Breastfeeding and Working. Although the book is meant to inspire women that they can overcome contemporary social and economic obstacles to breastfeeding, many women do not have much flexibility in shaping their work environments or schedules. Sensitive new mothers could easily interpret the message of this book as if you do not "scale modern mountains," you are just giving up. ${ }^{315}$

Additionally, even into the twenty-first century, Mary White continued to question the wisdom of allowing working mothers to serve as Leaders. She said that a working mother was already busy and that Leadership would likely be a burden that would push her over the edge so that she "end(s) up getting burned out as a Leader, at her job, as a mother." 316 This would be "a terrible price to pay" not only for the mother, but for her children. White suggested that this burn-out was common among mothers in

\footnotetext{
314 Jennifer Bowen Hicks, Hirkani's Daughters : Women Who Scale Modern Mountains to Combine Breastfeeding and Working (Schaumburg, Ill.: La Leche League International), 2006.

315 Ibid.

${ }^{316}$ Cited in Cahill, Seven Voices, One Dream, 160.
} 
general and "the consequences of inadequate mothering are showing up in some very unhappy children and young people." ${ }^{317}$ White still viewed a mother's employment as nearly always selfish and an unnecessary supplement to a husband's income. She lamented that "One of the great tragedies now taking place in America is a kind of selfcenteredness that has us putting ourselves and our careers ahead of our responsibilities as parents....To think that consumerism takes precedence over your responsibilities as a parent is to abdicate your moral obligations as a parent." ${ }^{\text {318 }}$ Just as Betty Wagner had in the 1990s placed women in the past who did not breastfeed outside the category of mother, in 2001, Mary White continued to view most working mothers as not actually mothering their children.

\section{Summary}

In their efforts to support a consistent worldview, LLL has generally overlooked evidence that undercut their claims to the universality of their mothering ideal. Further, as new generations of mothers have joined the ranks of the League and questioned some of the values that were taken for granted by the League's founders and earliest members, LLL has rewritten the narrative of their early history, focusing on those values that younger mothers would appreciate, namely feminism and women's health. However, despite the new spin, the League's underlying construction of motherhood has not actually changed substantially, if at all. They tell mothers that they can work for pay

${ }^{317}$ Ibid. This stands in contrast to Kathleen Gerson's study of the children of working, divorced and single parents: Kathleen Gerson, The Unfinished Revolution : Coming of Age in a New Era of Gender, Work, and Family (Oxford: Oxford University Press), 2011. ${ }^{318}$ Cited in Cahill, Seven Voices, One Dream, 160. 
while breastfeeding and that they should make every sacrifice necessary to do so, but their published philosophy, to which all Leaders must adhere, maintains the original perspective they first articulated in The Womanly Art of Breastfeeding in 1956. The League has always recognized that women are not perfect and that every mother falls short of their ideal in a variety of ways, but by constructing particular shortcomings as moral failures, the League has placed women who do not meet these standards not only as imperfect, but beyond the pale of motherhood. 


\section{CONCLUSION}

This thesis charts how La Leche League navigated different ways of knowingscientific, gendered, spiritual — in building their own institutional knowledge. The value the League placed upon these different types of knowledge was shaped by their particular collective memory consciousness and their overall emphasis on precedent as authoritative. That is, the League tended to privilege knowledge they believed to have historical, natural roots over that they viewed as novel or shaped by human society. More importantly, the League looked to various sources of knowledge with the specific goal of justifying their existing beliefs. They challenged the knowledge of dominant

groups such as male medical professionals and (sometimes) male household heads, but, when it served their interests, they co-opted such knowledge to enhance their own arguments in the public sphere. At other times they acquiesced to particular male authority figures or unquestioningly accepted certain types of knowledge - primarily economic and political — as the province of men, without recognizing the power differential this perpetuated in gender relations. Additionally, in the organization's efforts to ennoble the embodied and communal knowledge of mothers, they idealized the natural experiences they assumed to be universal among women in the premodern world and in poor or less developed areas of the modern world, and failed to recognize that 
these women also faced constraints on their mothering behaviors. Overall, in selectively deeming certain types of knowledge valid and decrying others as biased or ill-founded, the League was able to create and sustain a universal ideal of motherhood in the face of counterarguments that others viewed as credible.

La Leche League's organizational discourse has blended history, contemporary experiences, and medical data since their earliest days. The 1966 version of the pamphlet "Why Nurse Your Baby?" includes a page with the heading "Did you know that recent medical research confirms traditional experience that..." followed by thirteen bullet pointed statements. ${ }^{319}$ Three of these statements are enclosed in quotes and followed by physicians' names in parentheses. The others provide no citation, but a reader familiar with contemporary medical research could affirm that each of these statements does derive from peer-reviewed, if not yet widely accepted published studies. ${ }^{320}$ However, it is more difficult to discern what exactly "traditional experience" means here and therefore whether any of these statements can rightly be attributed to it. It would be impossible to make such broad statements about historic and cross-cultural beliefs, since, as established above, cultural beliefs and taboos associated with breastfeeding have varied widely. Statements like "You can nurse a baby through a breast infection;" "Menstruation is no obstacle to successful nursing," "Breastfeeding affords natural spacing of children;" "The size of a mother's breast has nothing to do with her ability to nurse her baby;" "Twins can almost always be completely breastfed right from the start;"

${ }^{319}$ La Leche Leage International, Why Nurse Your Baby?

${ }^{320}$ For example, Niles Newton's research supports many of the claims, including that menstruation does not negatively impact breastfeeding. See Niles Newton and Michael Newton, Newton on Breastfeeding : Reproductions of Early Classic Works (Seattle, Wash.: Birth \& Life Bookstore), 1990. 
and "There is no nutritious food a nursing mother should avoid" would not have been universally accepted in the past or across the globe. ${ }^{321}$ Further, the fact that the League felt the need to refute these statements underscored that these views persisted in the US at the time the pamphlet was published. ${ }^{322}$

The writers' use of "traditional experience" rather than "belief" or "knowledge" may have been intentional here to stress that women who have breastfed through an infection or while menstruating, or women who have eaten taboo foods - whether or not their culture believed the practices to be harmful—experienced no actual ill-effects. ${ }^{323}$ However, it is difficult to say how widespread such experiences would have been in the face of cultural proscriptions. If the predominant view held that such practices were dangerous, most women would likely have been afraid to defy them. It is likely that some women, for a variety of reasons, acted in ways that defied their culture's recommended practices, and distinct bodies of knowledge and belief within a single community, such as medicine versus midwifery, or practices across different religions may have contradicted one another. ${ }^{324}$ However, the records of divergent personal experiences as contained within diaries, letters, or biographies are much more limited than the records of a culture's norms and recommendations as one might find in advice manuals, medical and

${ }^{321}$ La Leche Leage International, Why Nurse Your Baby? For evidence of contrary beliefs and practices in history and in contemporary societies, see Wickes, "A History of Infant Feeding I;" Mead and Newton, "Cultural Patterning in Perinatal Behavior;" Maher, Anthropology of Breastfeeding; Montgomery, An Introduction to Childhood; Lancy, Anthropology of Childhood.

${ }^{322}$ Many persist today. LLL's "Frequently Asked Questions" address a number of these issues. See La Leche League International, “Alphabetical FAQ Subject Index," January 9, 2016, accessed November 7, 2017, http://www.1lli.org/faq/faqsubject.html.

${ }^{323}$ La Leche Leage International, Why Nurse Your Baby?

${ }^{324}$ For examples of women's resistance to authority in relatively recent history, see Grant, Raising Baby by the Book. 
midwifery books, laws, religious texts, and literature. So while personal accounts certainly serve as evidence of resistance to prescriptions, it is hard to establish concretely that a large number of women's experiences were different from what their culture recommended. Thus, although individual women who ate taboo foods might have experienced no negative consequence to their infants' health, there is little record of this. It is therefore difficult to assert that "traditional experience" varied to a significant degree from "traditional beliefs." 325 Further, as shown above, the League themselves tend to embrace the most common experiences as authoritative, and aberrations as representative not of variations, but of a completely different kind of experience. Thus, while perhaps the reader could take on faith that some known, but unnamed medical scientists confirmed the statements listed in the pamphlet, it would be a far greater leap of faith to accept that all the statements represent traditional experiences of any known peoples, much less a broad swath of peoples who could reasonably be lumped together to comprise a universal shared "traditional experience.",326

To highlight this tendency to imagine historical experiences without substantiation, the most recent edition of The Womanly Art of Breastfeeding bears a brief examination. Despite all that has been published on the subject of the history and anthropology of motherhood, in 2010, Mary Ann Cahill wrote in her "Welcome" to the new manual of a mystical continuity of embodied female experience across millennia and across continents.

Before there was The Womanly Art of Breastfeeding, there was what I've always thought of as 'The Story of Breastfeeding.' That story wasn't written down; it was the breastfeeding wisdom passed down from one generation to the next,

${ }^{325}$ La Leche Leage International, Why Nurse Your Baby?

${ }^{326}$ Ibid. 
mother to mother. Unexpectedly, beginning in the first part of the twentieth century in the most developed parts of the world, the transfer of 'The Story' practically ceased. But not entirely. The remembrance of 'The Story of Breastfeeding' nourished the writing of the first edition of The Womanly Art, published in 1958, cradling it and sustaining its promise. ${ }^{327}$

Cahill further stated that although the current version of the manual was composed by three authors, "in the background, arrayed like a Greek chorus, stand the many mothers who have come before us." ${ }^{328}$ She explicitly offered the reader the opportunity, through breastfeeding, to be part of a timeless community of women, bridging the past and the future: "Dear Reader, turn the pages, begin the story, and discover the beauty and power of breastfeeding. Step into history. There is a place for you in what will always be your own highly personal experience and enduring memories but also an act of great consequence to you, your child, and your family. To all of society. To the world. Thank you!" ${ }^{329}$ Cahill here affirms the experiences of breastfeeding mothers and seeks to draw them into a community of nursing mothers, but this community necessarily excludes women who do or did not breastfeed and minimizes the variety of experiences that breastfeeding has entailed throughout history.

Since 1956, La Leche League has had to defend their organization from criticisms that it was both old-fashioned and radical. The League has argued that the dominant midtwentieth century model of scientifically driven motherhood against which they were reacting was more radical and historically anomalous than their own model of natural

${ }^{327}$ Mary Ann Cahill, "Welcome!" in La Leche League International, Diane Wiessinger, Diana West, and Teresa Pitman, The Womanly Art of Breastfeeding $8^{\text {th }}$ ed. (New York: Ballantine), 2010, xv.

${ }^{328}$ Cahill, "Welcome!" xvii.

${ }^{329}$ Ibid. 
motherhood. They supported this conclusion with personal testimonies of mother's feelings and experiences and the work of researchers (doctors, psychologists, behavioral scientists) who that suggested the old-fashioned practices and values the League advocates were rooted in biological constants rather than the products of any historical period or social context, and thus more timeless or natural than old-fashioned.

Although La Leche League proposed a change in the dominant model of motherhood, they always argued that their model was not actually new, calling it "the original plan for care and feeding. ${ }^{, 330}$ I argue that their model was not truly old either, but rooted in a shared, cultural construction of the past as a literal or figurative Eden, before modern, human values had corrupted Nature. The founders and early League members held an abiding belief in the order and intentionality of Nature. They understood Nature's plan as an ideal state of existence, ordained by God, evolution, or some combination of the two. In line with this view, League publications found role models for breastfeeding mothers in figures such as Eve, the Virgin Mary, and cave women. Belief in an ordered natural world also entailed the conviction that generally, the closer any item or practice was to its natural, prehistoric state, the healthier-and the more morally superior - it was. Early League members therefore believed that an ideal pattern of human relations, including mother-child relations, must have existed until man and society tainted "Nature" or "God's plan." The League saw the rapid spread of artificial formula and the rise in male-dominated, interventional maternity and pediatric care as the first and only large-scale, sustained threat to mothers' natural functioning. Bottle feeding, rigid schedules and lack of physical and emotional intimacy between

${ }^{330}$ La Leche League of Franklin Park, The Womanly Art of Breastfeeding, 2. 
mother and child marked the abhorred contemporary, scientific motherhood of the midtwentieth century, so the opposite practices of maternal breastfeeding, lack of fixed timetables, and intense closeness between mother and child must have been central to natural, pre-modern mothering. The League acknowledged historical exceptions to their ideal maternal model, such as wet nursing and the feeding of animal milk or pap, but dismissed these as largely limited to wealthy elites, orphans, or rare cases in which mothers were unable to breastfeed. Since twentieth century innovations were the only truly significant, sustained cause of decay in family relations, the League concluded that natural mother-child relations had, in fact, predominated until quite recently. In the vast and ill-defined past prior to modernity, mothers from Eve to grandma are collapsed into the same, all-encompassing category, forming an imagined historical community of mothers. In a circular fashion, the League constructed a vision of motherhood in opposition to modern, unnatural practices, assumed that most mothers in the pre-modern past must have lived in accordance with this vision of nature, and then referenced the imagined experiences of these women as evidence in support of their vision of natural motherhood.

The limitation of relying on medical and psychological science for understanding historical human behavior is that these disciplines look for standards and repeatable patterns and therefore can be interpreted in ways that are universalizing and uncompromising. Researchers attempt to control for confounding factors, but they are impossible to eliminate in life outside the laboratory. There is and never has been in human history a naturally existing control group of standard human bodies outside social and environmental influence. Likewise, seeking to identify with people from the past 
leads to ignoring significant differences in life experiences and belief systems. Eliding these differences can create unity among identity groups, but it paints an inaccurate picture of the diversity of human experience. While La Leche League validly criticized the exception becoming the rule when medical interventions in childbirth and artificial infant feeding became normative, they countered these practices with a counter-model in which the rule of supposed natural motherhood leaves little room for exceptions.

Although the League's founders recognized in 1956 that it was difficult for women in the modern world to achieve the physically and emotionally intensive motherchild relationships to which the League said they should aspire, the organization continues in the twenty-first century to imagine that these relationships were prevalent in the pre-modern world. Their persistent belief that their ideal of totally natural, biologically shaped relationships between mothers and children were the norm throughout human history until the modern era and can and should be the norm today prevents them from fully recognizing the various psychological, ethnocultural, economic and environmental challenges that prevent women from achieving this ideal. Further, they fail to comprehend that some (or many) women may be striving for other ideals. For Margaret Mead, even the rarest of mothering practices was worthy of consideration because, as she wrote in the study she co-authored with Niles Newton, "any behavior characteristic of one group of human beings, in terms of which they have been able to reproduce and survive as a group, throws light on the potentialities and limitations of human beings everywhere." 331 If, as they phrased it in their manual, "La Leche League is a neighbor with something in her hand and heart to share with you," she seems to be

${ }^{331}$ Mead and Newton, "Cultural Patterning of Perinatal Behavior," 82. 
offering mothers a Sisyphean task, urging them to strive towards a single model of ideal motherhood, all the while knowing that this ideal is incompatible with their life circumstances. ${ }^{332}$

${ }^{332}$ La Leche League of Franklin Park, The Womanly Art of Breastfeeding, 1. 


\section{REFERENCES}

Acker, Joan. "Hierarchies, Jobs, Bodies: A Theory of Gendered Organizations," in Judith Lorber and Susan A. Farrell, eds. The Social Construction of Gender. Newbury Park, Calif.: Sage Publications, 1991.

Ariès, Philippe. Centuries of Childhood : A Social History of Family Life. New York: Alfred A. Knopf, 1962.

Arnold, Meredith. "Dear Mothers of La Leche League.” La Leche League News 2, vol. 4 (1959): 1.

“A Doctor Pays Tribute to Mothering.” La Leche League News 6, no. 3 (1964): 1-3.

“Advice When Speaking to Doctors.” Leaven 1, no.2 (1965): n.p.

“A La Leche League Dialogue: An Historic Document." Child and Family 13, no. 3 (1974): 199-223.

Anderson, Benedict Richard O'Gorman. Imagined Communities : Reflections on the Origin and Spread of Nationalism, Rev. ed. London: Verso, 2006.

Apple, Rima D. Mothers and Medicine : A Social History of Infant Feeding, 1890-1950. Wisconsin Publications in the History of Science and Medicine, No. 7. Madison, WI.: University of Wisconsin Press, 1987.

Apple, Rima D. Perfect Motherhood: Science and Childrearing in America. New Brunswick, N.J.: Rutgers University Press, 2006.

Badinter, Elisabeth. The conflict: How modern motherhood undermines the status of women. New York: Metropolitan Books/Henry Holt and Co., 2011.

Bartky, Sandra L. "Toward a Phenomenology of Feminist Consciousness." Social Theory and Practice 3, no. 4 (1975): 425-439.

Blum, Linda M. "Mothers, Babies, and Breastfeeding in Late Capitalist America: The Shifting Contexts of Feminist Theory." Feminist Studies 19, no. 2 (1993): 291311. 
Blum, Linda M. and Elizabeth A. Vandewater. "Mother to Mother": A Maternalist Organization in Late Capitalist America." Social Problems 40, no. 3 (1993): 285300.

Bobel, Chris. The Paradox of Natural Mothering. Philadelphia, PA: Temple University Press, 2002.

Bobel, Christina G. "Bounded Liberation." Gender \& Society 15, no. 1 (2001): 130-51.

Boston Women's Health Book Collective. Our Bodies Ourselves. New York: Simon and Schuster, 1973.

Bowlby, John. Maternal Care and Mental Health, World Health Organization Monograph Series No. 2. Geneva: World Health Organization, 1951.

Bowlby, John and Edwin Powers, "Forty-Four Juvenile Thieves: Their Characters and Home-Life." Journal of Abnormal and Social Psychology 43, no. 4 (1948): 56163.

Brett, John A. and Susan Niermeyer. "Neonatal Jaundice: The Cultural History of the Creation and Maintenance of a 'Disease' of Newborns," in Nancy ScheperHughes, Carolyn F Sargent, and Carolyn Fishel Sargent, eds. Small Wars: The Cultural Politics of Childhood, 111-129. Berkeley: University of California Press, 1998.

Cahill, Mary Ann. “A Backward Glance and a Forward Look," La Leche League News 1 no. 2 (1958): 1.

Cahill, Mary Ann. Seven Voices One Dream. Schaumburg, IL: La Leche League, 2001.

Cahill, Mary Ann. The Heart Has Its Own Reasons: Mothering Wisdom for the 1980s. Franklin Park, IL: La Leche League International, 1983.

Cahill, Mary Ann. "Welcome!" in La Leche League International, Diane Wiessinger, Diana West, and Teresa Pitman, The Womanly Art of Breastfeeding $8^{\text {th }}$ ed., xvxvii. New York: Ballantine, 2010.

Centers for Disease Control, National Center for Chronic Disease Prevention and Health Promotion, Division of Nutrition, Physical Activity, and Obesity, "Breastfeeding Report Card, Progressing Toward National Breastfeeding Goals, United States, 2016." Atlanta: Centers for Disease Control, 2016.

“Christmas Old and New.” La Leche League News 4, no. 6 (1962): n.p. 
Collins, Patricia Hill. "Shifting the Center: Race, Class and Feminist Theorizing About Motherhood," in Maternal Theory: Essential Readings, ed. Andrea O'Reilly, 311-330. Toronto: Demeter Press, 2007.

Coontz, Stephanie. The Way We Never Were : American Families and the Nostalgia Trap. New York, NY: BasicBooks, 1992.

Crase, Betty. "A History of the Mother-Baby Togetherness Concept." Leaven 48, no. 1 (2013): 10-11.

Crenshaw, Kimberle. "Mapping the Margins: Intersectionality, Identity Politics, and Violence against Women of Color." Stanford Law Review 43, no. 6 (1991): 1241299.

Dick Read, Grantly. Childbirth Without Fear, $2^{\text {nd }}$ ed. London: William Heinemann, 1954.

Fildes, Valerie. Breasts, Bottles, and Babies : A History of Infant Feeding. Edinburgh: Edinburgh University Press, 1986.

Fildes, Valerie. "Infant Feeding Practices and Infant Mortality in England, 19001919." Continuity and Change 13 (1998): 251-80.

"Find Facilities." Baby Friendly USA. November 2, 2017, accessed November 6, 2017, https://www.babyfriendlyusa.org/.

Frisbie, Margery. An Alley in Chicago : The Ministry of a City Priest. Kansas City, MO: Sheed \& Ward, 1991.

Gerson, Kathleen. The Unfinished Revolution : Coming of Age in a New Era of Gender, Work, and Family. Oxford: Oxford University Press, 2011.

Gibson, Mary E. "An Early History of Anesthesia in Labor." Journal of Obstetric, Gynecologic \& Neonatal Nursing 46, no. 4 (2017): 619-627.

Grant, Julia. Raising Baby by the Book: The Education of American Mothers. New Haven: Yale University Press, 1998.

Friedan, Betty. The Feminine Mystique. New York: W.W. Norton, 1997.

Hays, Sharon. The Cultural Contradictions of Motherhood. New Haven: Yale University Press, 1996.

Halbwachs, Maurice. On Collective Memory. Lewis A Coser, ed. Chicago: University of Chicago Press, 1992. 
Halonen, Virginia Sutton, Nancy Mohrbacher, and La Leche League International. Learning a Loving Way of Life. Franklin Park, Ill.: La Leche League International, 1987.

Hausman, Bernice L. Mother's Milk: Breastfeeding Controversies in American Culture. Hoboken: Taylor and Francis, 2014.

Holt, L. Emmett. The Care and Feeding of Children: A Catechism for the Use of Mothers and Children's Nurses. New York and London: D. Appleton and Company, 1894.

Hrdy, Sara Blaffer. Mother Nature: A History of Mothers, Infants, and Natural Selection. New York: Pantheon Books, 1999.

Kammen, Michael. Mystic Chords of Memory, The Transformation of Tradition in American Culture. New York: Vintage Books, 1993.

Kerber, Linda. "The Republican Mother: Women and the Enlightenment-An American Perspective." American Quarterly 28, no. 2 (1976): 187-205.

Kukla, Rebecca. "Ethics and Ideology in Breastfeeding Advocacy Campaigns." Hypatia 21, no. 1 (2006), 177.

La Barre, Weston. Child-Family Digest 1, no. 1 (1949): n.p.

Ladd-Taylor, Molly. "Toward Defining Maternalism in U.S. History." Journal of Women's History 5, no. 2 (1993): 110-113.

La Leche League International. “Alphabetical FAQ Subject Index.” January 9, 2016, accessed November 7, 2017, http://www.1lli.org/faq/faqsubject.html.

La Leche League International. "La Leche League International Refutes New York Times Editorial," [Press Release]. November 3, 2015, accessed 6 November 2017, http://www.1lli.org/1llinews2015/11li_refutes_newyork_times_editorial.

La Leche League International. "Should I Sleep With My Baby?" January 9, 2016, accessed, November 6, 2017, http://www.1lli.org/faq/cosleep.html.

La Leche League International. The Womanly Art of Breastfeeding, $2^{\text {nd }}$ ed. Franklin Park, IL: La Leche League International, 1963.

La Leche League International. The Womanly Art of Breastfeeding, $3^{\text {rd }}$ ed. Franklin Park, IL: La Leche League International, 1981.

La Leche League International. The Womanly Art of Breastfeeding, $4^{\text {th }}$ ed. Franklin Park, IL: La Leche League International, 1990. 
La Leche League International. The Womanly Art of Breastfeeding, 40th Anniversary $\left(5^{\text {th }}\right)$ ed. New York: Penguin Books, 1997.

La Leche League International. The Womanly Art of Breastfeeding, 7th revised ed. New York: Plume, 2004.

La Leche League International. Why Nurse Your Baby? Franklin Park, IL: La Leche League International, 1966.

La Leche League International, Diane Wiessinger, Diana West, and Teresa Pitman. The Womanly Art of Breastfeeding, 8th revised ed. New York: Ballantine, 2010.

La Leche League of Franklin Park, "How the Nurse Can Help the Breastfeeding Mother." Franklin Park, IL: La Leche League of Franklin Park, n.d.

La Leche League of Franklin Park, The Womanly Art of Breastfeeding. Franklin Park, IL: La Leche League of Franklin Park, 1957.

La Leche League of Washington. "Time Magazine Response.” c. May 2012, accessed November 6, 2017, http://www.1llofwa.org/2012/05/time-magazine-response.

"La Leche League Philosophy," La Leche League International, February 19, 2017, accessed November 3, 2017, http://www.1lli.org/philosophy.html.

Lancy, David F. The Anthropology of Childhood: Cherubs, Chattel, Changelings. Cambridge: Cambridge University Press, 2008.

Laqueur, Thomas Walter. Making Sex: Body and Gender from the Greeks to Freud. Cambridge, MA: Harvard University Press, 1990.

Leaven 1, no. 1 (1965): 1.

Leaven 1, no.3 (1966), n.p.

Leavitt, Judith Walzer. Brought to Bed: Childbearing in America, 1750 to 1950, 30th Anniversary ed. New York, NY: Oxford University Press, 2016.

LINKAGES Project. "Facts for Feeding: Recommended Practices to Improve Infant Nutrition during the First Six Months." Washington, DC: LINKAGES, Academy for Educational Development, 1999.

Lowman, Kaye. LLLove Story. Franklin Park, IL: La Leche League International, 1978.

Lowman, Kaye. The Revolutionaries Wore Pearls. Schaumburg, IL: La Leche League, 2007. 
“LLL Purpose,” La Leche League International, November 2004, accessed November 4, 2017, http://www.1lli.org/lad/talll/philosophy.html.

Maher, Vanessa. The Anthropology of Breast-Feeding : Natural Law or Social Construct. Oxford: Berg, 1992.

Martucci, Jessica L. Back to the Breast: Natural Motherhood and Breastfeeding in America. Chicago: University of Chicago Press, 2015.

Matria, C. and Patricia Mullen, "Reclaiming Menstruation." Women \& Health 3, no. 3 (1978): 23-30.

May, Elaine Tyler. Homeward Bound: American Families in the Cold War Era. Fully Rev. and Updated 20th Anniversary ed. New York: Basic Books, 2008.

McKenna, James J. Sleeping with Your Baby: A Parent's Guide to Cosleeping, 3rd ed. Washington, DC: Platypus Media, LLC, 2012.

McKenna, James J., Helen L Ball, and Lee T Gettler, "Mother-Infant Cosleeping, Breastfeeding and Sudden Infant Death Syndrome: What Biological Anthropology Has Discovered About Normal Infant Sleep and Pediatric Sleep Medicine." American Journal of Physical Anthropology 134, no. S45 (2007): 13361.

McNulty, M.J. La Leche League News, Illinois Sparks and Prisms. (1975): 1.

Mead, Margaret and Niles Newton, "Cultural Pattering in Perinatal Behavior." Newton on Birth and Women: Selected Works of Niles Newton, Both Classic and Current.Seattle: Birth and Life Bookstore, 1990.

Merrill, Elizabeth Bryant. "Learning How to Mother: An Ethnographic Investigation of an Urban Breastfeeding Group." Anthropology \& Education Quarterly 18, no. 3 (1987): 222-240.

Meyer, Herman F. "A Clinical Interpretation of the 'Colicky' Infant." Postgraduate Medicine 24, no. 6 (1958): 627-632.

Meyer, Herman F. "Breastfeeding in the United States: Extent and Possible Trend." Pediatrics 22, no. 1 (1958): 116-121.

Meyer, Herman F. "Clinical Review: Breast Feeding in the United States, Report of a 1966 National Survey with Comparable 1946 and 1956 Data." Clinical Pediatrics 7, no. 12 (1968): 708-715. 
Montagu, Ashley. Letter to Marian Tompson, April 26, 1960. Box 87, Folder 1, La Leche League International Records, DePaul University Special Collections and Archives, DePaul University.

Montgomery, Heather. An Introduction to Childhood: Anthropological Perspectives on Children's Lives. Malden, MA: Blackwell Pub, 2009.

Muller, Mike. "Nestlé Baby Milk Scandal Has Grown Up But Not Gone Away," The Guardian, 13 February 2013, accessed 6 November 2017, https://www.theguardian.com/sustainable-business/nestle-baby-milk-scandalfood-industry-standards.

Muller, Mike. The Baby Killer: A War on Want Investigation into the Promotion and Sale of Powdered Baby Milks in the Third World. London: War on Want, 1974.

Newton, Niles. "Breastfeeding Today." Speech at the National Convention for Childbirth Education, Milwaukee, WI, May 21, 1960.

Newton, Niles. The Family Book of Childcare. New York: Harper and Row, 1957.

Newton, Niles. Maternal Emotions: A Study of Women's Feelings Toward Menstruation, Pregnancy, Childbirth, Breast Feeding, Infant Care, and Other Aspects of their Femininity. New York: Paul B. Hoeber, 1955.

Newton, Niles. "What Women Need Most.” Baby Talk, (May 1971).

Newton, Niles and Michael Newton. Newton on Breastfeeding : Reproductions of Early Classic Works. Seattle, Wash.: Birth \& Life Bookstore, 1990.

O'Donnell, James. Invocation Delivered at La Leche League International Convention, cited in La Leche League News 6, no. 4 (1964): 1.

O'Reilly, Andrea, ed., Maternal Theor : Essential Readings. Toronto: Demeter Press, 2007.

Pickert, Kate. “The Man Who Remade Motherhood.” Time, May 21, 2012.

Pollock, Linda. Forgotten Children: Parent-Child Relations from 1500 to 1900. Cambridge: Cambridge University Press, 1983.

Pollock, Linda A. "Childbearing and Female Bonding in Early Modern England." Social History 22, no. 3 (1997): 286-306.

Ratner, Herbert. “Comments on Breastfeeding." La Leche League News 4, no. 5 (1962): $1-2$. 
Ratner, Herbert. Foreword to The Womanly Art of Breastfeeding $2^{\text {nd }}$ ed., by La Leche League International, v-vii. Franklin Park, IL: La Leche League International, 1963.

Ratner, Herbert. Foreword to The Womanly Art of Breastfeeding $3^{\text {rd }}$ ed., by La Leche League International, ix-xii. Franklin Park, IL: La Leche League International, 1981.

Ratner, Herbert. "National Commission on Human Life Reproduction and Rhythm." The Linacre Quarterly 36, no. 1 (1969): 77.

Review of The Family Book of Childcare, by Niles Newton. La Leche League News 1, no. 1, n.p.

Reynoldson, Fiona, Eileen Harrison and Monique Kitts. "The History of LLL Philosophy." Leaven 39, no. 5 (2003): 102-103.

Roberts, Dorothy. Killing the Black Body: Race, Reproduction, and the Meaning of Liberty. New York: Pantheon Books, 1997.

Rosen, Christine. Preaching Eugenics: Religious Leaders and the American Eugenics Movement. Oxford: Oxford University Press, 2004.

Rosenzweig, Roy and David P. Thelen. The Presence of the Past : Popular Uses of History in American Life. New York: Columbia University Press, 1998.

Rothman, Barbara Katz. In Labor: Women and Power in the Birthplace. New York: W.W. Norton, 1991.

Ruddick, Sara. Maternal Thinking: Toward a Politics of Peace. Boston, Massachusetts: Beacon Press, 1995

Ruddick, Sara. "On Maternal Thinking." Wsq: Women's Studies Quarterly 37, no. 2 (2010): 305-308.

Rutter, Michael. Maternal Deprivation Reassessed 2nd ed. Penguin Modern Psychology. Harmondsworth, Middlesex: Penguin Books, 1981.

Sachetti, Dor. ed. La Leche League International Leader's Handbook, $3^{\text {rd }}$ ed. Schaumburg, IL: La Leche League International, 1998.

Sarachild, Kathie. "A Program for Feminist 'Consciousness Raising," in Notes from the Second Year: Major Writings of the Radical Feminists. New York: Radical Feminism, 1970. 
“Some Questions Fathers Ask.” La Leche League News 2, no. 4 (1959):3.

Small, Meredith F. Our Babies, Ourselves: How Biology and Culture Shape the Way We Parent. New York: Anchor Books, 1999.

Smith, Lloyd. "I wish you could meet Mitzie." Let's Live Magazine (1959). Box 4, Folder 1, La Leche League International Records, DePaul University Special Collections and Archives, DePaul University.

Smith, Paige Hall. "Is It Just so My Right?" Women Repossessing Breastfeeding." International Breastfeeding Journal 3, no. 1 (2008), n.p.

The Editors. Child-Family Digest 1, no. 1 (1949): n.p.

“The Modern Nursing Mother.” La Leche League News 4, no. 4, 1962.

Tompson, Marian. "La Leche League: The Story of Our life or 'The First Eighteen Months Are the Hardest." La Leche League Newsletter 1, no. 1 (1957): 1.

Tompson, Marian. "Memos from Marian," La Leche League News 4, no. 3, n.p.

Tompson, Marian Leonard. Passionate Journey: My Unexpected Life. Amarillo, TX: Hale Pub, 2011.

Torgus, Judy, Gwen Gotsch, and La Leche League International. The Womanly Art of Breastfeeding, 6th revised ed. Schaumburg, Ill.: La Leche League International, 1999.

Ulrich, Laurel Thatcher. A Midwife's Tale: The Life of Martha Ballard, Based on Her Diary, 1785-1812. New York: Vintage Books, 1991.

Umanski, Lauri. "Breastfeeding in the 1990s: The Karen Carter Case and the Politics of Maternal Sexuality," in Molly Ladd-Taylor and Lauri Umansky, eds. "bad" Mothers : The Politics of Blame in Twentieth-Century America. New York: New York University Press, 1998.

UNICEF. Letter to Ronald Reagan, June 24, 1985. Box 4, Folder 10, La Leche League International Records, DePaul University Special Collections and Archives, DePaul University.

Uno, Kathleen S. “Maternalism in Modern Japan.” Journal of Women's History 5, no. 2 (1993): 126-130.

Wagner, Betty. “Betty Wagner's History of LLL from 1956-1967.” Box 4, Folder 15, La Leche League International Records, DePaul University Special Collections and Archives, DePaul University. 
Ward, Jule DeJager. La Leche League: At the Crossroads of Medicine, Feminism, and Religion. Chapel Hill: University of North Carolina Press, 2000.

Watson, John B. and Rosalie Alberta (Rayner) Watson. Psychological Care of Infant and Child. New York: W.W. Norton \& Company, 1928.

Weiner, Lynn, ed., "Maternalism as a Paradigm," Journal of Women's History 5, no. 2 (1993): 95-130.

Weiner, Lynn. "Maternalism as a Paradigm: Defining the Issues." Journal of Women's History 5, no. 2 (1993): 96-98.

Weiner, Lynn Y. Letter to La Leche League, May 5, 1992. Box 4, Folder 14. La Leche League International Records, DePaul University Special Collections and Archives, DePaul University.

Weiner, Lynn Y. "Reconstructing Motherhood: The La Leche League in Postwar America." The Journal of American History 80, no. 4 (1994): 1357-381.

Welter, Barbara. "The Cult of True Womanhood: 1820-1860." American Quarterly 18, no. 2 (1966): 151-174.

Wertz, Richard W, and Dorothy C Wertz. Lying-In : A History of Childbirth in America. Expanded Ed. ed. New Haven: Yale University Press, 1989.

White, Mary. "Mary White Reviews." La Leche League News 1, no.3, n.p.

Wickes, Ian G. "A History of Infant Feeding. I. Primitive Peoples; Ancient Works; Renaissance Writers." Archives of Disease in Childhood 28, no. 138 (1953): 1518 .

Williams Christine L. Still a Man's World: Men Who Do "Women's Work." Berkeley: University of California Press, 1995.

Wolf, Jacqueline H. "'Let Us Have More Mother-Fed Babies': Early Twentieth-Century Breastfeeding Campaigns in Chicago and Minneapolis." Journal of Human Lactation 15, no. 2 (2016): 101-05. 


\section{CURRICULUM VITA}

NAME: Joanna Paxton Federico

ADDRESS: 4330 Pines Rd.

Paducah, KY 42001

DOB: $\quad$ Evanston, Illinois - April 30, 1984.

EDUCATION: $\quad$ B.A., English; Film, Television and Theatre University of Notre Dame

2002-2006

M.A., History

University of Louisville

2015-2017

AWARDS: Graduate Network in Arts and Sciences Graduate Research Grant, University of Louisville (October 2017)

Carolyn Krause Maddox Award for Best Paper in Women's and Gender Studies, University of Louisville (March 2017)

PRESENTATIONS: “'Since the Time of Eve': La Leche League and the Silencing of Historical Experiences of Breastfeeding and Motherhood." Loyola History Graduate Student Conference at Loyola University of Chicago (November 2017).

"Our Lady of the Milk: 'Non-Sectarianism' in La Leche League's Breastfeeding Advocacy." McGill Center for Research on Religion Graduate Conference at McGill University (September 2017).

“"In Between Sources': The Meaning of Replica Objects in Museum Education.” Brian Bertoti Innovative Perspectives in Graduate Research Conference at Virginia Polytechnic Institute and State University (March 2017). 
“Judging Judgmental Language: Putting the 'Dark Ages' on Trial." Kentucky History Education Conference at the Kentucky

Historical Society (July 2016). 